\title{
Living with Fukushima
}

Imagining a future for the people of Namie

By Ruby Somerville

A 120-point thesis submitted to the Victoria University of Wellington in partial fulfilment of the requirements of the degree of Master of Architecture (Professional).

Victoria University of Wellington School of Architecture 2018 


$$
\square
$$




\section{Dedication}

I would like to begin by thanking...

- My supervisor Daniele for believing in this thesis more than I did,

- My family for being so sure I would make it to the finish line,

- And mostly my amazing group of girls for seeing me through these crazy, stressful years. Could not have done it without you all. 


\section{Preface}

This thesis is the result of years of curiosity and concern for what was going on behind closed doors in my birth country.

I remember watching the news coverage of the Tohoku Earthquake, the live aerial footage of the tsunami hitting the coast. I was at home with my whole family because we, in Christchurch, had just been hit with the devastating 2011 earthquake only a week before.

It kind of felt like the world was ending...

Of course, it wasn't. I finished high school and went on to university.

In the years that followed, the occasional news article would catch my attention, talking about the shutdown of the plants, radioactive fish and nuclear refugee camps - little reminders of the harsh reality that people around the world had been quick to forget.

I remember in 2012 I went with my Mum to Japan and she mentioned that we would only be in Tokyo for three days because she didn't want to risk exposing us to radiation for too long. Until then, I hadn't really thought about what the prolonged radiation exposure meant.

In Christchurch our rebuild seemed painfully slow. Japan appeared to have cleared their earthquake damage in weeks. On the exterior was their typical, ultra-efficient image, but if you looked a little closer you would see the damage that remained.

In late 2016, when I was planning my thesis year, there was a surge of news articles about the state of Fukushima, five years on. Robots were being sent down into the reactor buildings and melting down from the intense radiation, and people were returning home.

This brings me to the start of my thesis. 


\section{Abstract}

Nuclear power is a highly disputed and powerful industry that continues to grow worldwide alongside safer renewable resources. No country seemed to have as much unwavering faith in the nuclear industry as Japan, until the catastrophic events of Fukushima in 2011. Although large-scale disasters caused by nuclear power facilities are few and far between, the devastation to the environment is, in most cases, irreparable. Fukushima remains to this day a painful reminder of this fact.

In 2011 Japan suffered an unprecedented three-strike disaster. First a 9.0 magnitude earthquake struck the country. This was followed by a subsequent tsunami which tore apart Japan's East Coast and resulted in the loss of more than 20,000 lives. However, it was the triple meltdown at the Fukushima Daichi Nuclear Power Plant that was the final devastating blow. 160,000 people were forced to evacuate. These nuclear refugees, as they have come to be known, have paid the ultimate price. Their home lands have been permanently scarred by the radiation, with only small sections able to be decontaminated. Even in these areas, land that has been cultivated for centuries will likely never again be able to produce safe crops in the traditional way. In a region highly valued for its agriculture and fishing industries, they have lost everything that they spent generations working and caring for.

The Architecture and Dystopia Stream challenges architectural projects to call attention to the dystopian realities that our generation will face in the future. This is a project for a small broken town, Namie, and how we might propose a future where the people can live alongside the damage left by nuclear contamination. The project attempts to capture intimate day-today moments for the people within a much larger scheme that sheds light on the potentially damaging consequences of the nuclear industry. In this sense, the true challenge of the project is to simultaneously explore both the megascale and the human-scale.
Earlier this year Namie was one of the first towns in the Fukushima exclusion zone to be partially reopened. Since then thousands of residents have made the tough decision between the familiarity of and love for their home town and the invisible threat of radiation. It is heard continually in surveys, interviews, and political rallies that these evacuees simply want their old lives back, and those who are returning to Namie have seized this chance. It is clear, however, that the 'cleanup' of these towns that are reopening cannot repair the lasting damage of the nuclear radiation on the natural environment. Fishing in the river, picking mushrooms in the foothills, these sorts of activities were part of daily life in this rural town that can no longer be enjoyed without great risk. Not only have they lost many of the joys that come with living so closely amongst the environment, they also can no longer make a living off their land. It is feared that their lives here will be a shadow of what they were before. Although the reality sounds bleak and dystopian, the architectural intervention designed for Namie will be Utopian, focussing on the future that these returning residents are daring to hope for.

Lastly, it has been openly speculated that the heavy influence of the nuclear industry on Japanese government is responsible for Japan's lack of exploration into safer, sustainable energy sources. Japan is usually on the forefront of new technologies. Following the Fukushima meltdown, for the first time since it was introduced to the country, Japanese are questioning and openly challenging the use of nuclear energy in their country. The uncertainty of the future has spurred opportunities for a change in direction, in what many consider is a pivotal moment in Japan's history. This project aims to be bold and push past what might be an expected solution, capitalising on this rare openness towards new beginnings, to propose a highly unconventional project that optimistically envisions a better future for the people of Namie. 


\section{Contents}

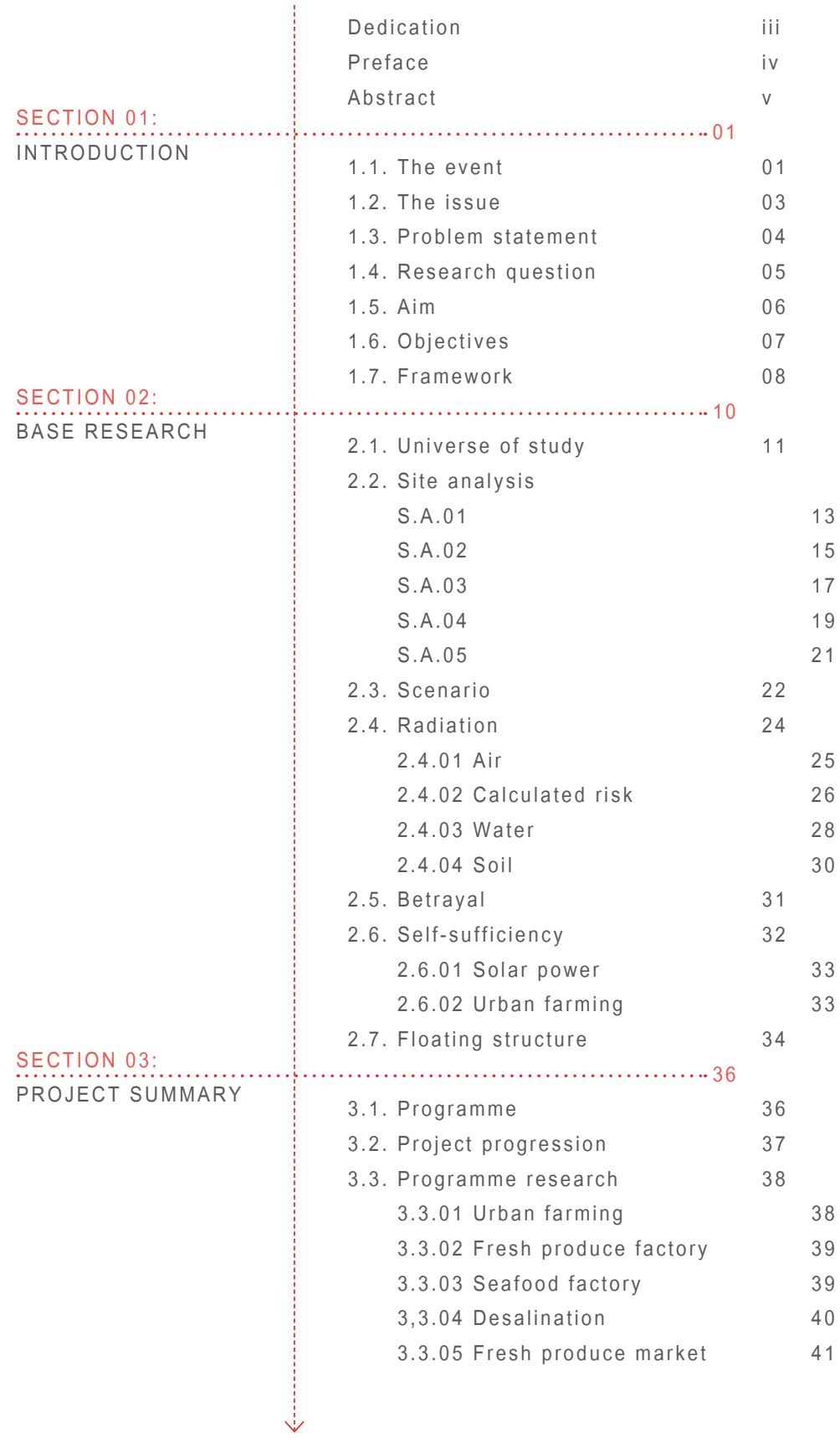




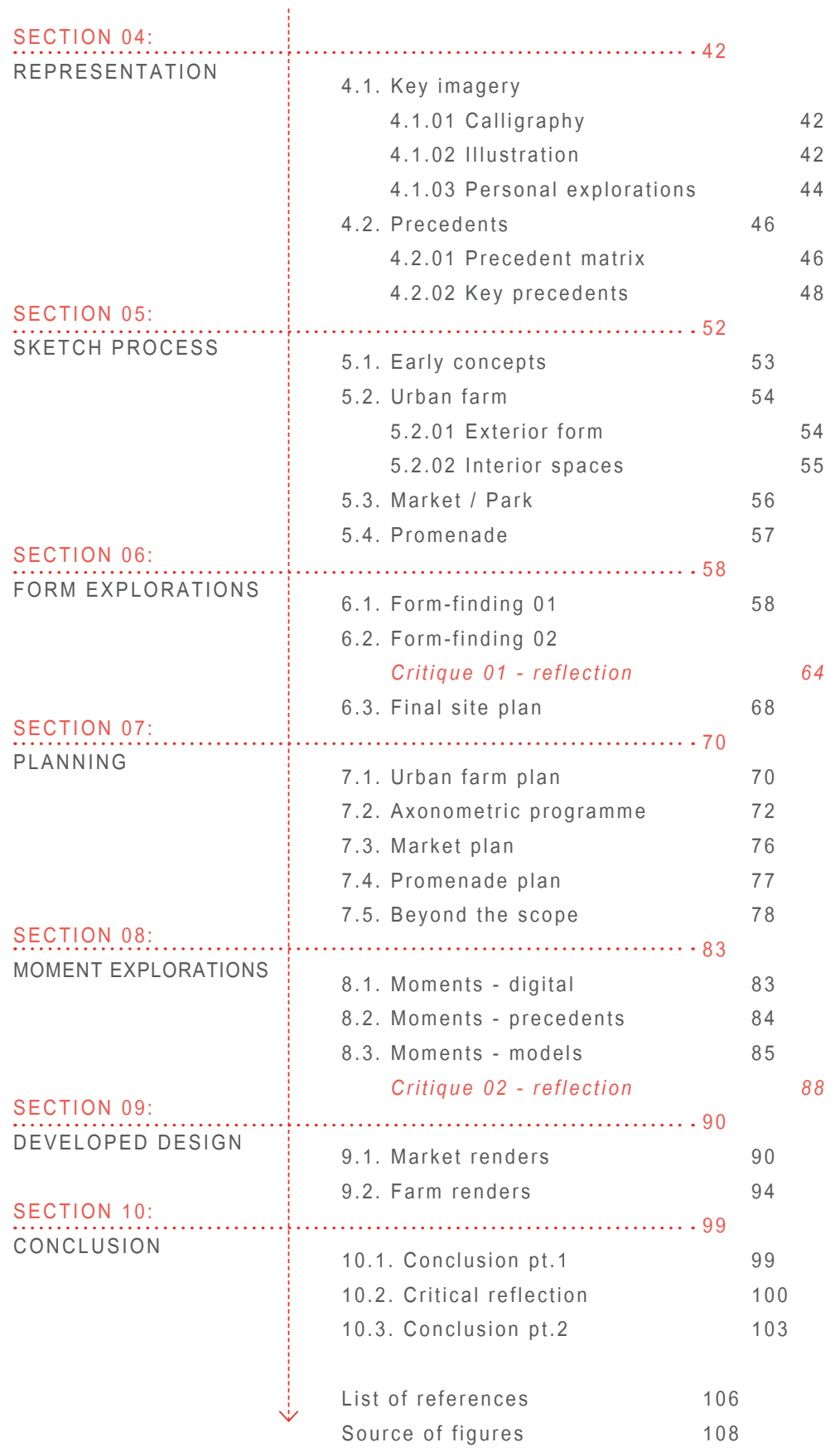




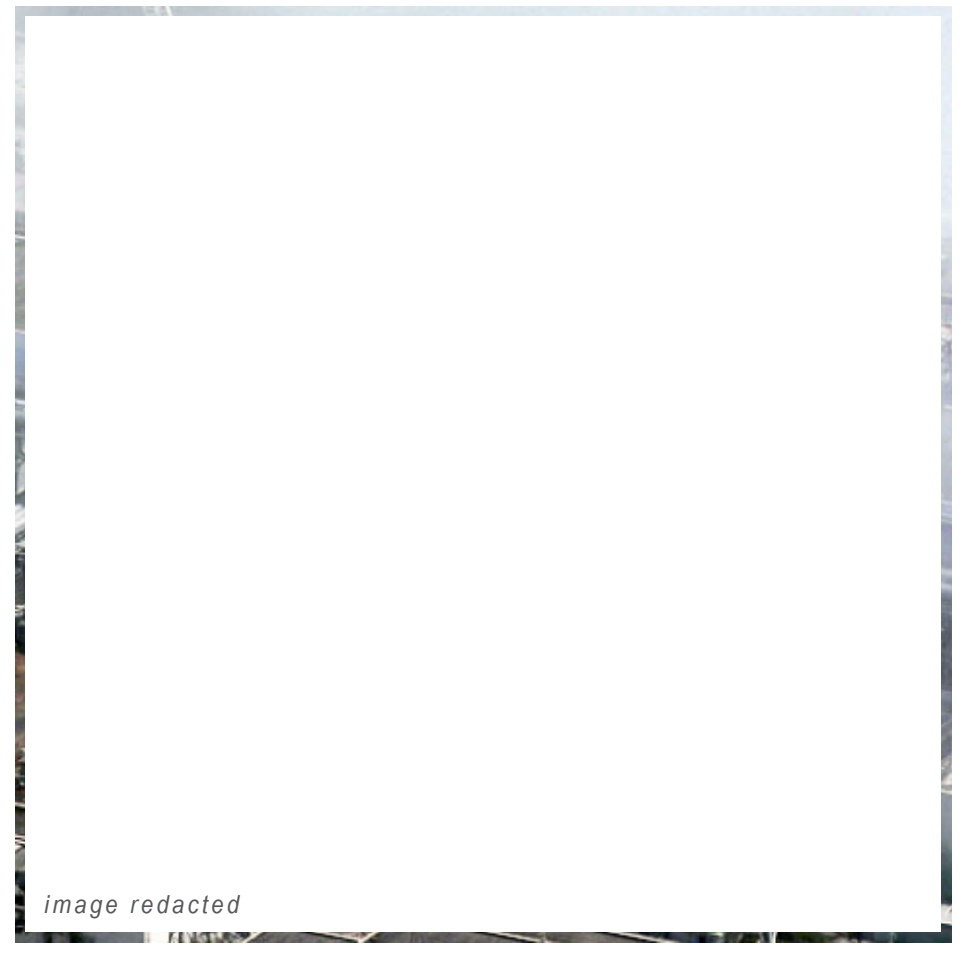




\subsection{The event}

11.03.2011: Japan's East Coast suffered a horrendous three-stage disaster. It was struck by a 9.0 magnitude earthquake and subsequent tsunami which resulted in the loss of more than 20,000 lives (Broinowski, 2013). However, it was the third strike, an unprecedented triple meltdown at the TepCo. Fukushima Daiichi Nuclear Power Plant, that caused the most destruction. At least 60,000 people were evacuated from their homes under the invisible threat of radiation (Kadota, 2014).

Hundreds of square kilometres of land have been left contaminated; much of this was highly valuable and productive farmlands that had been cultivated by families for generations (Broinowski, 2013). Six years on, the plant continues to be in a state of instability. Although 'cold shutdown' was achieved in late 2011 the location of the melted radioactive fuel remains unknown (Funahashi, 2013). With the rods exposed no one can say for certain that there is zero radiation, although scientific studies show that as time passes levels continue to decrease in the region (Gale \& Lax, 2013).

'Safe' habitation levels were announced by the government and portions of the region have reopened earlier this year

(Pearce, 2017). 


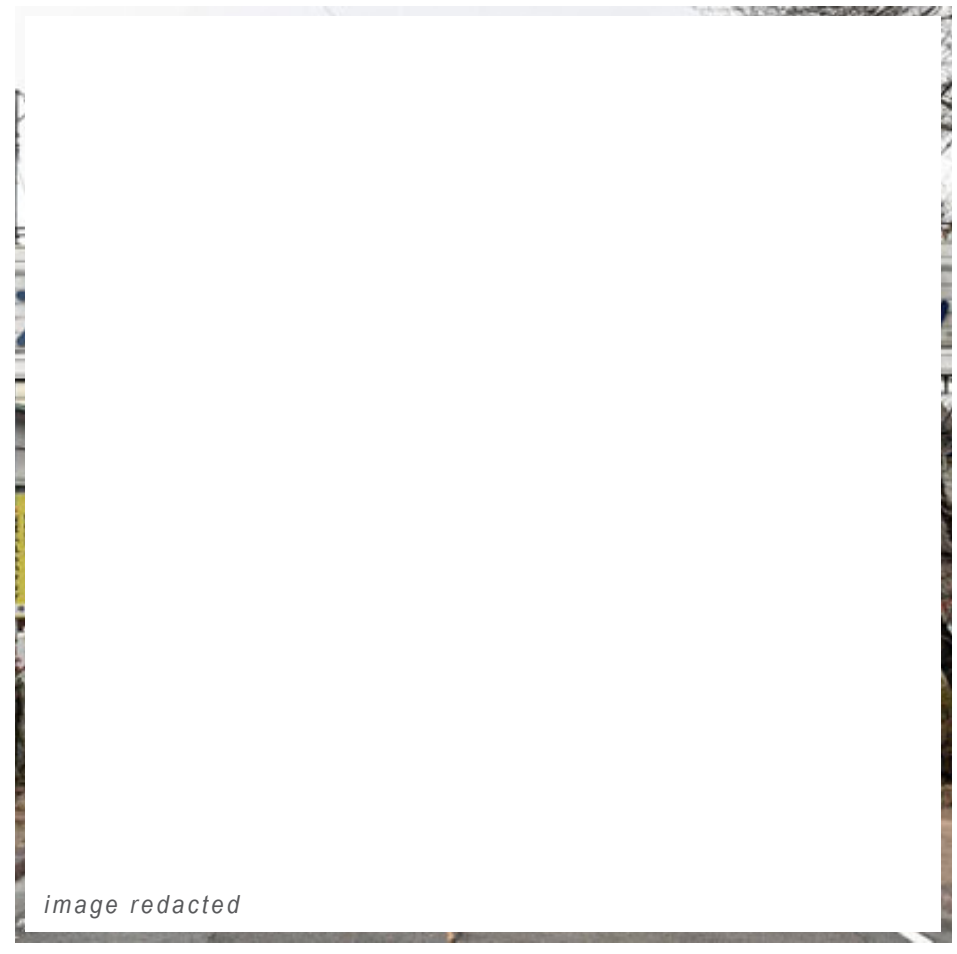

"Nuclear power, energy for a brighter future." 


\subsection{The issue}

Stream:

Architecture and Dystopia

This research stream focuses on architectural projects that address the 'dystopian realities' that our generation will face in the future.

Dystopian realities are global issues that are inherently bad and which do not appear to have easy solutions, for example: sea level rise, refugee camps.

Project:

\section{Living with Fukushima}

How to live with environments that have been irreparably damaged by nuclear contamination.

Nuclear power is a highly disputed, powerful industry that, despite the known devastating risks, continues to expand worldwide despite the availability of safer renewable resources such as solar and wind energy (NEI, 2017). 


\subsection{Problem statement}

Earlier this year the Japanese Government lifted the evacuation order on various decontaminated 'Zone A' sections of the Fukushima Daiichi Exclusion Zone. With this order came the impending reality that the financial compensation being provided to these nuclear refugees for the last six years, that many rely on to survive, will come to an end as their homes are now deemed 'safe' to return to (Hirano \& Yuichi, 2017). Despite the risks of radiation exposure, and the reality that the natural environment surrounding these rural townships will remain contaminated for centuries, many of the tens of thousands who were evacuated are expected to simply 'pick up where they left off' and attempt to rebuild the lives they had before the disaster. Many citizens will be willing to risk ongoing exposure to low level, lingering radiation in order to return to the places they know and love, where they have strong community and family ties, and where they have cared for the land for generations (Broinowski, 2013). However, the heart of these agricultural and fishing towns has been irreparably damaged by nuclear radiation and very few job prospects remain, leaving these citizens with a heavy reliance on a government that many feel has betrayed them (Grossman, 2017). 


\subsection{Research question}

How can a non-conventional architectural project be developed to tackle the larger issues surrounding the nuclear industry while also addressing the needs of the nuclear refugees at an intimate scale, allowing them to thrive in their radiationtorn regions?
A non-conventional design solution
is required because the problem is unprecedented. 


\subsection{Aim}

To design an architectural intervention that will challenge the larger issues of the corrupt and fraught nuclear industry while simultaneously addressing the needs of the people of Namie at an intimate human scale. The design will allow the Fukushima nuclear refugees to not only return, but thrive in their devastated regions. It will provide residents with the self-sufficiency and future prospects that were lost in the disaster, and enable them to live alongside the damaged natural environment for which they have cared for generations. 


\subsection{Objectives}

To provide a non-conventional solution that aids those who choose (or are pressured) to return to their homes within the Exclusion Zone l must:

- Understand the extent of damage from radiation contamination and the lasting consequences of this damage.

- Research the site and make realistic conclusions about the livability and safety of the area.

- Study Japanese culture in order to understand the people who live here, their needs, and why they wish to return.

- Study Japanese culture in order to understand the lifestyles of the people in these rural townships, and what they love about this lifestyle.

- Identify key programmes that will truly benefit the people who are returning long-term.

- Study Japanese visionary architecture to understand a Japanese design approach suited to Japanese lifestyles.

- Explore architectural precedents that create intimate moments within a larger design.
To design an intervention that highlights the risks surrounding the nuclear power industry I must:

- Understand the nature of radiation and the long-term effects of radiation contamination.

- Understand the controversial nature of the nuclear industry and make informed decisions on what information sources are reliable.

- Identify key programmes that directly respond to and highlight the lasting damage inflicted by nuclear contamination. 


\subsection{Framework}

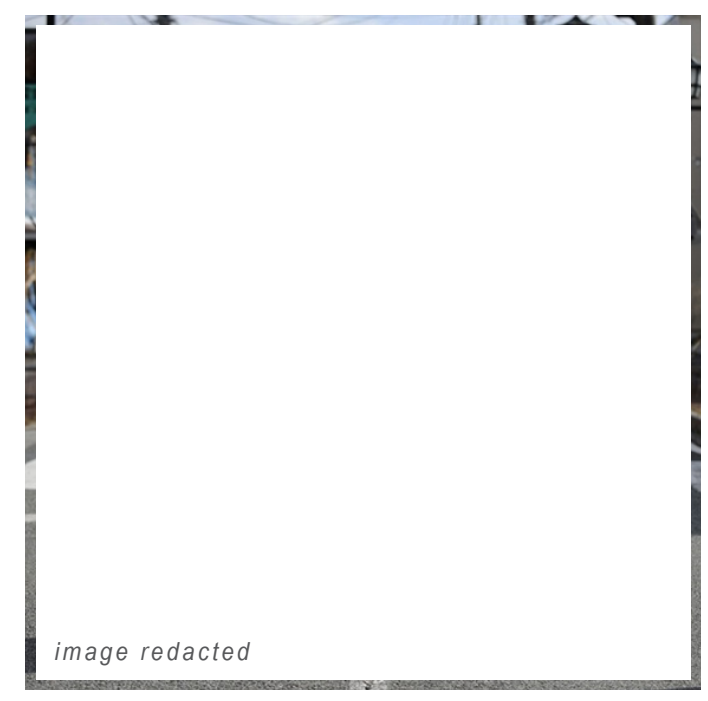

The framework that I have constructed to guide my thesis focuses on two strong and pure streams of thinking that converge together to form a concept for the people of Namie. I was very aware that the scenario I was responding to is a day-to-day reality for thousands of Japanese people. With the nature of the nuclear industry being so highly controversial and disputed I knew I would need a very strong base research from which to form my own educated assumptions on these topics. I was also incredibly aware that this topic could quickly spiral beyond simply being an architectural thesis. Within the first few weeks of intensive research into the topic I was yet to pick up any architectural texts or precedents. For this reason I decided my project would have a stream of pure design exploration that intuitively stemmed from precedents and visual representation studies fully separate from my research and justification. This framework (refer to dia.01, right) shows how these two lines of exploration merge to form a justified, rounded architectural project.

This framework means that this thesis has not developed in a traditional sense, where multiple preliminary designs are tested and a final design is selected to be developed into a detailed design. Instead the extensive research culminated in a project scope of six programmes, any one significant enough to be its own nine-month thesis project. This project has been like a mountain that I have been chipping away at trying to uncover as much as I can in the seven-month design timespan. Rather than creating many preliminary designs, each design experiment has instead focused on exploring a new fragment of the larger design, with each providing a new layer of information. The final design attempts to piece together these fragments, capturing an overall vision for this project. 


\section{Research}

The event

- Earthquake

- Tsunami

- Meltdown

- Evacuation

- Decontamination

\section{The people}

- Culture

- The town - Namie (site analysis)

- Lifestyles

- Jobs

- Identity

\section{Lasting effects}

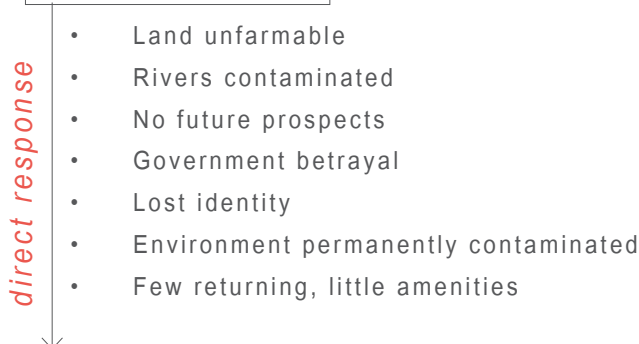

\section{Programme}

- Urban farm

- Bridge

- Fishing docks

- Desalination

- Recreation green space

- Fresh produce market
Representation

\section{Key imagery \\ - Japanese illustration \\ - Japanese calligraphy \\ Precedents \\ - Teshima Art Museum \\ - Chichu Art Museum \\ - Shima Kitchen \\ - Brazilian Congress}

\section{Form-finding}

- Sketch

- Model

- Photograph

\section{Formal relationship}

- Precedents

- Model

- Photograph

\section{Development}

- Programme layout

- Relationship to site

- Moments

\section{Final Design}

- Plans \& sections

- Moment models

- Human experience (renders) 
I dedicated approximately the first two months of my thesis to becoming an expert on the events and resulting conditions of the nuclear meltdown at Fukushima. The 'Universe of Study' (dia.02, right) summarises the key aspects and relationships of this research. For example, research into lasting effects of radiation links to the ocean which links to research into desalination which links back to issues surrounding freshwater quality. This also had a side connection to the concept of a floating structure which stemmed from the Japanese metabolists who link back to research into visionary architectural approaches and Japanese cultural influences. In this way, the key points of research build upon one another to justify my scenario and resulting project.

Due to my specific project method and framework (refer to pages $9 \& 10$ ) the research headings focus on key concepts and findings rather than key literature reviews and theorists as is typical for an architectural thesis.
This section will present the research by answering the following key questions that justify my scenario and resulting project.

Site analysis:

- Who are the people of Namie?

- What is significant to them? Why?

- What are their lives like?

- How many have been affected?

- Do they want to return? Why?

- What have they lost permanently?

Scientific research:

- What are the current conditions?

- Can we live with radiation in the air?

- Is the information provided true?

- What do the readings really mean?

- Is the soil safe to farm?

- Is the water safe (ocean and river)?

- Can the town be 'decontaminated'?

- Will the landscape recover? 
T. Must Utopia be an Island?

Ryue Nishizawa

C. Teshima Art Museum

$10 \%$ of land within 'safe' zone pre-disaster population: 21,400 post-disaster prediction: 10,000
Namie-mach
Site analysis
soil free space saving

aeroponic and hydroponic systems

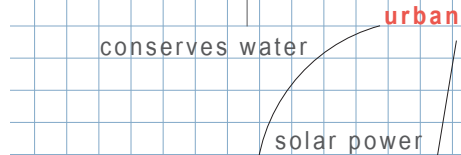

solar power farming

C. ReGen village

Eco village

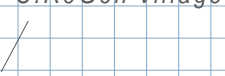

T. Healing in a Japanese

Ecovillage

\section{Self sufficiency}

C.Mirai urban plant factory

$2,500 \mathrm{sq} / \mathrm{m}$

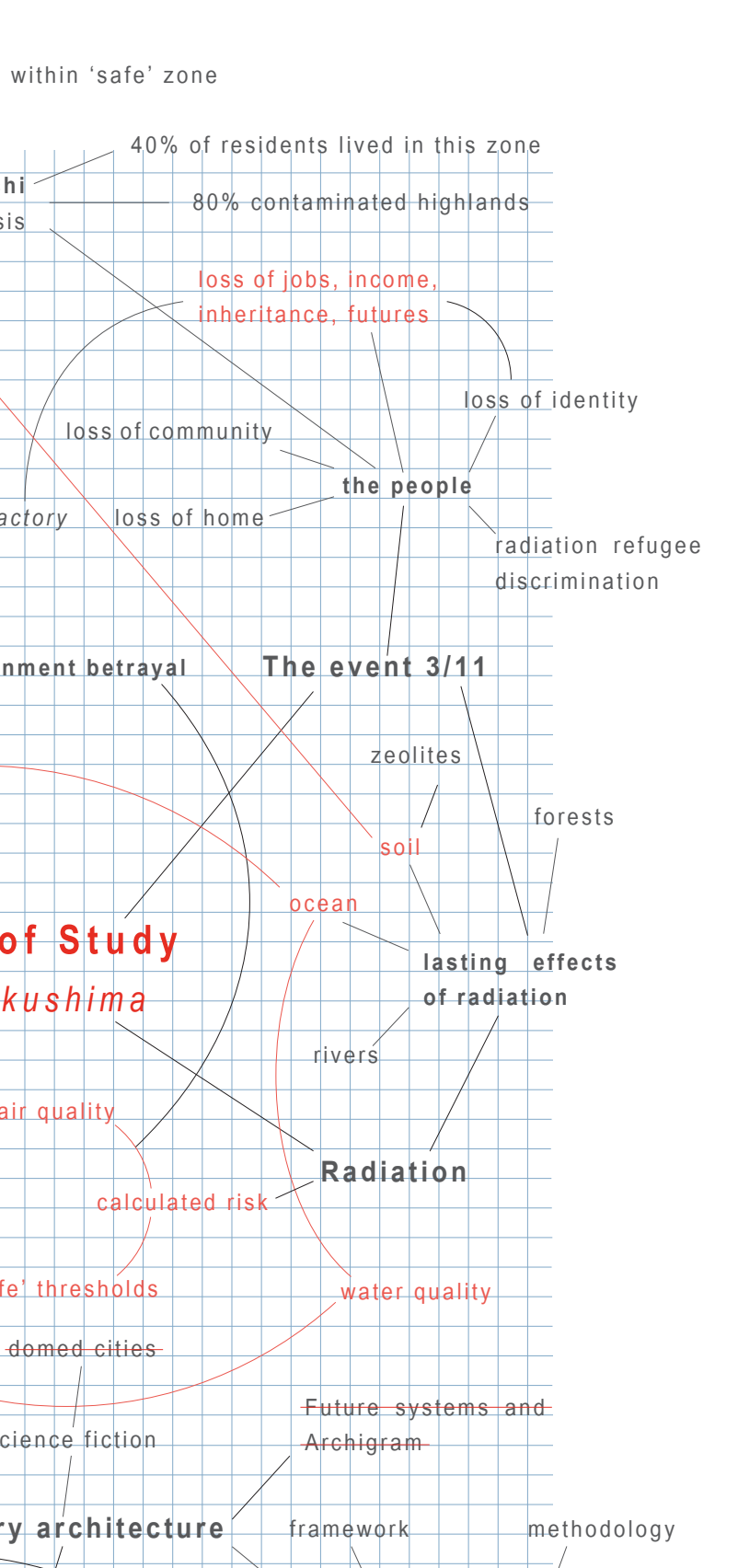

$40 \%$ of residents lived in this zone $80 \%$ contaminated highlands

\section{loss of jobs, income, inheritance, futures}

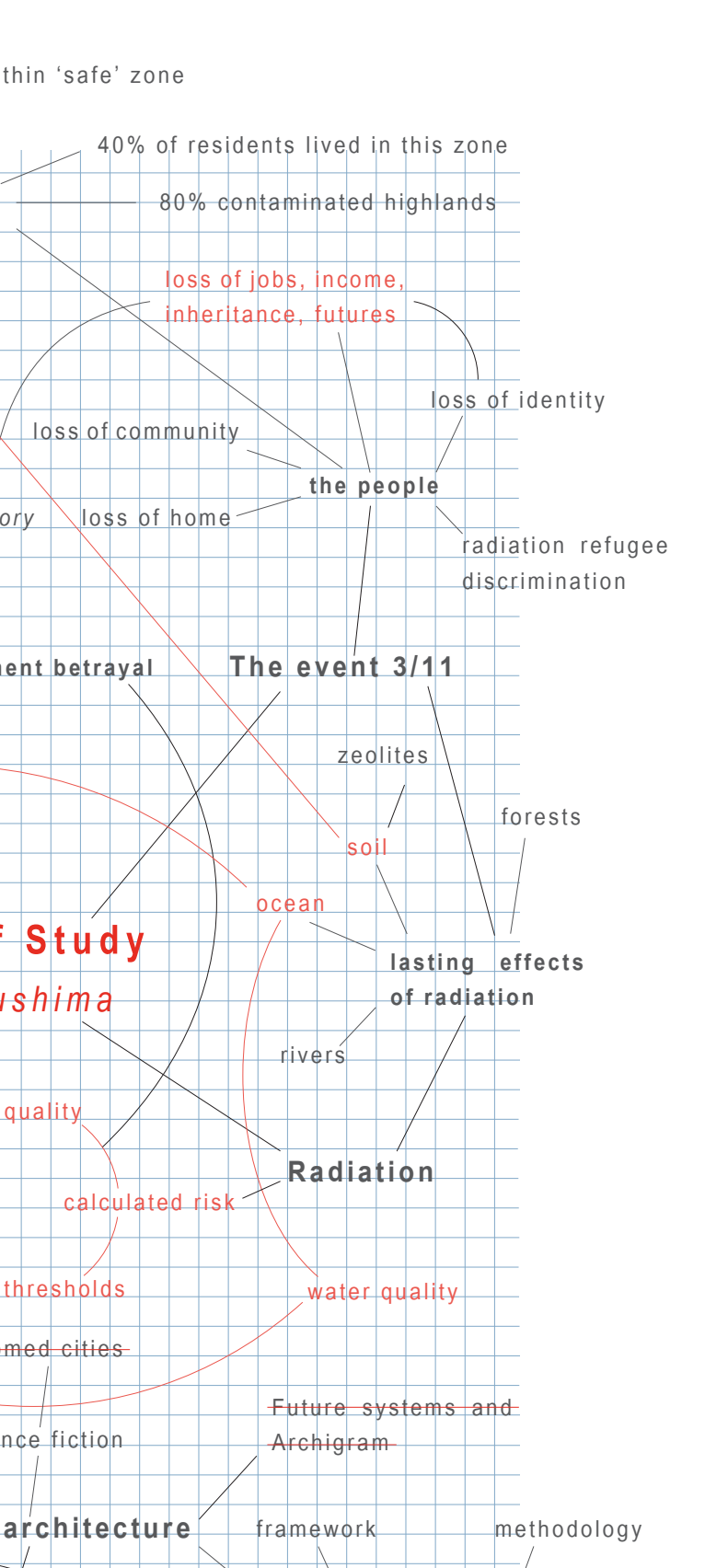

loss of identity the people

loss of home

10,000 lettuces/day radiation refugee discrimination

government betrayal The event $3 / 11$
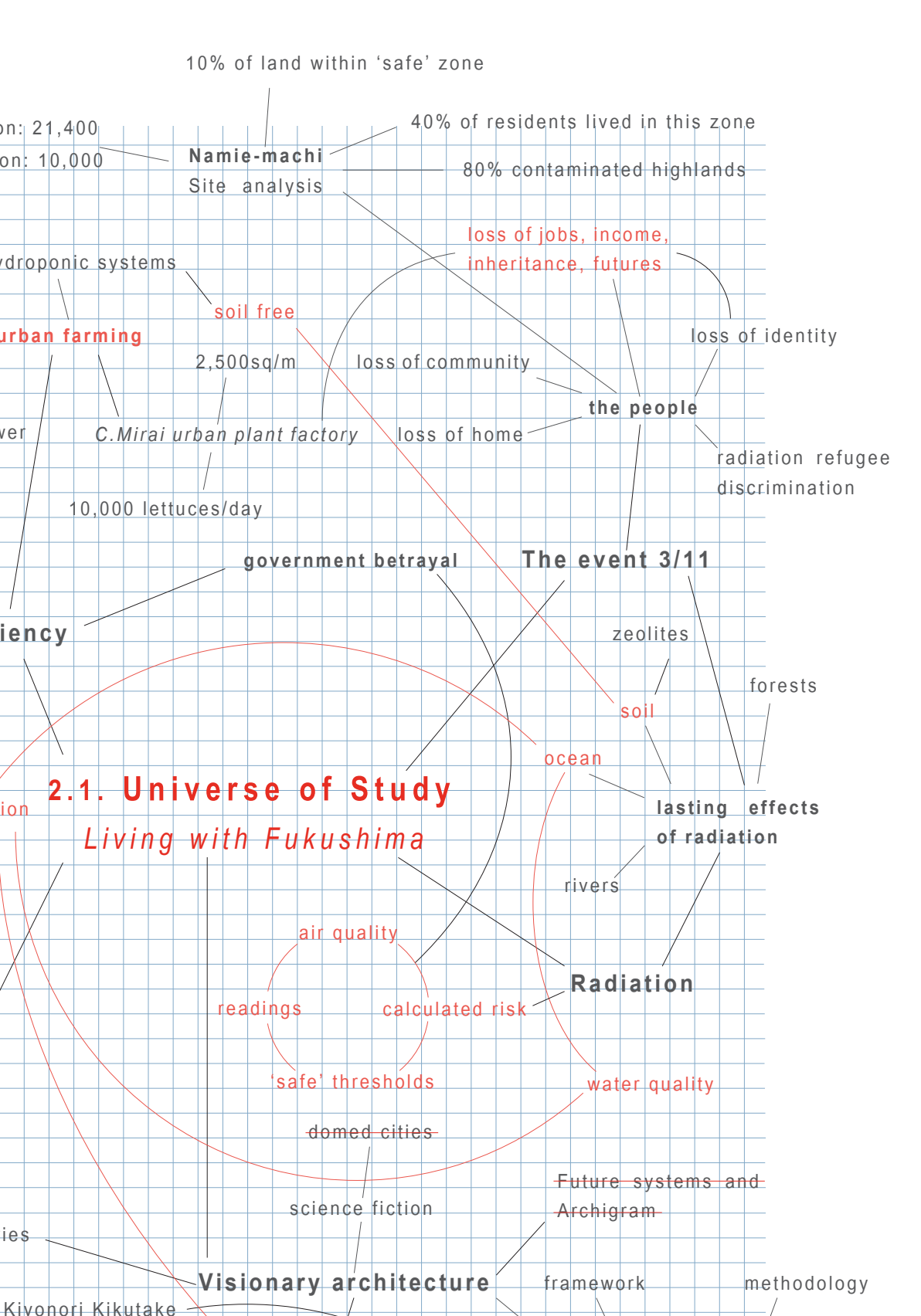

2.1. Universe of Study

rain water system

desalination

\section{Living with Fukushima}

colour palette

drawing styles

art

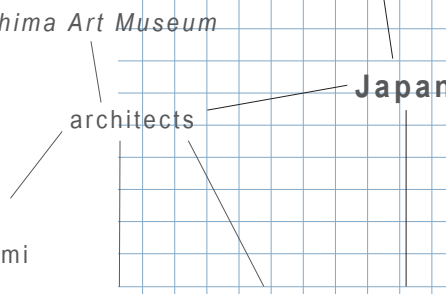

Tadao Ando

Japanese visionaries

C.Water Temple

\begin{tabular}{l|l}
\hline Imegastructures' & The metaboliyon \\
\hline & Japanese architects designing \\
\hline
\end{tabular}

for Japanese society/people

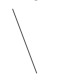

C.Kenzo Tange -

Visionary architecture

framework

methodology

lasting effects of radiation
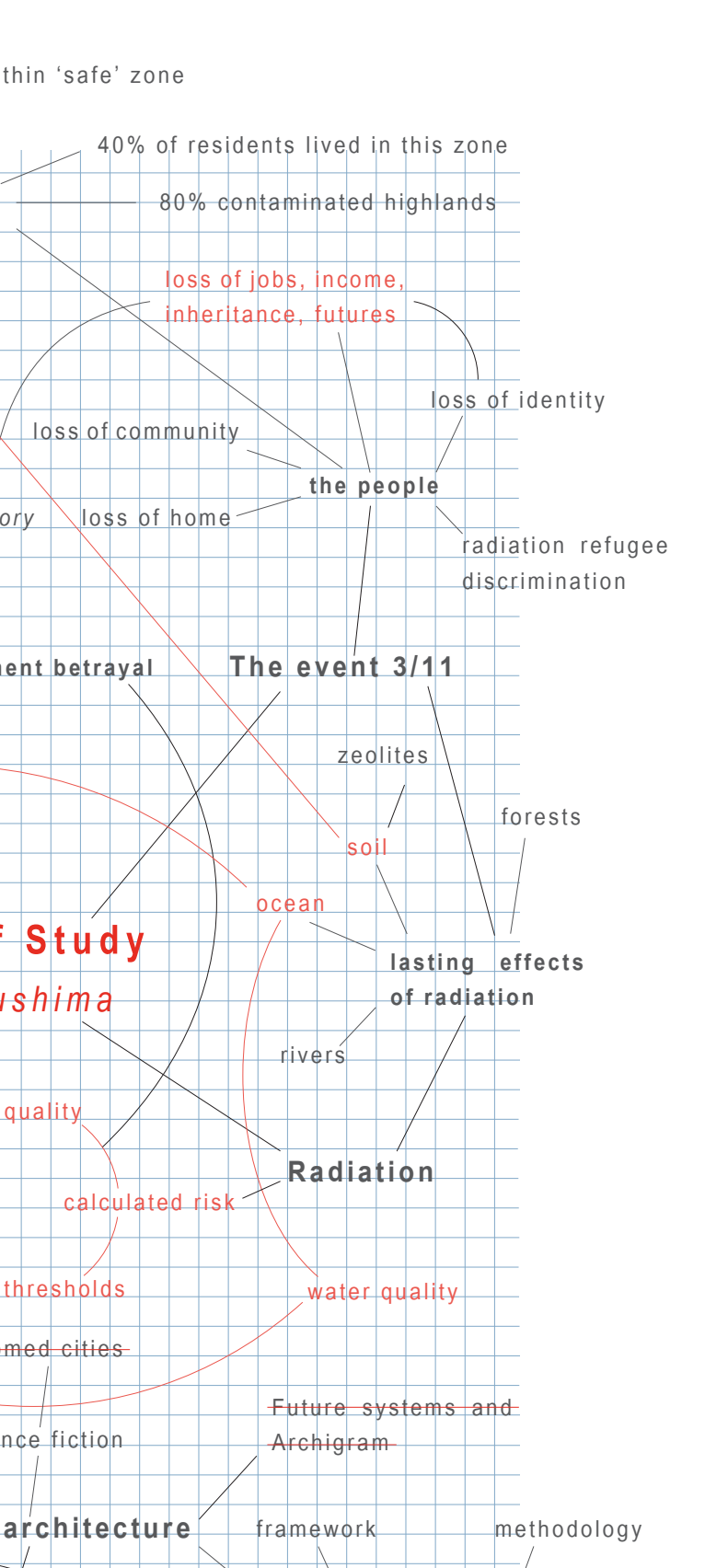

air quality

readings

Radiation

'safe' thresholds

domed cities

science fiction

Future systems and

Archigram

theses that deal with dystopic environments valuing the land

land as a resource connection with the sea

ocean as a source of life 


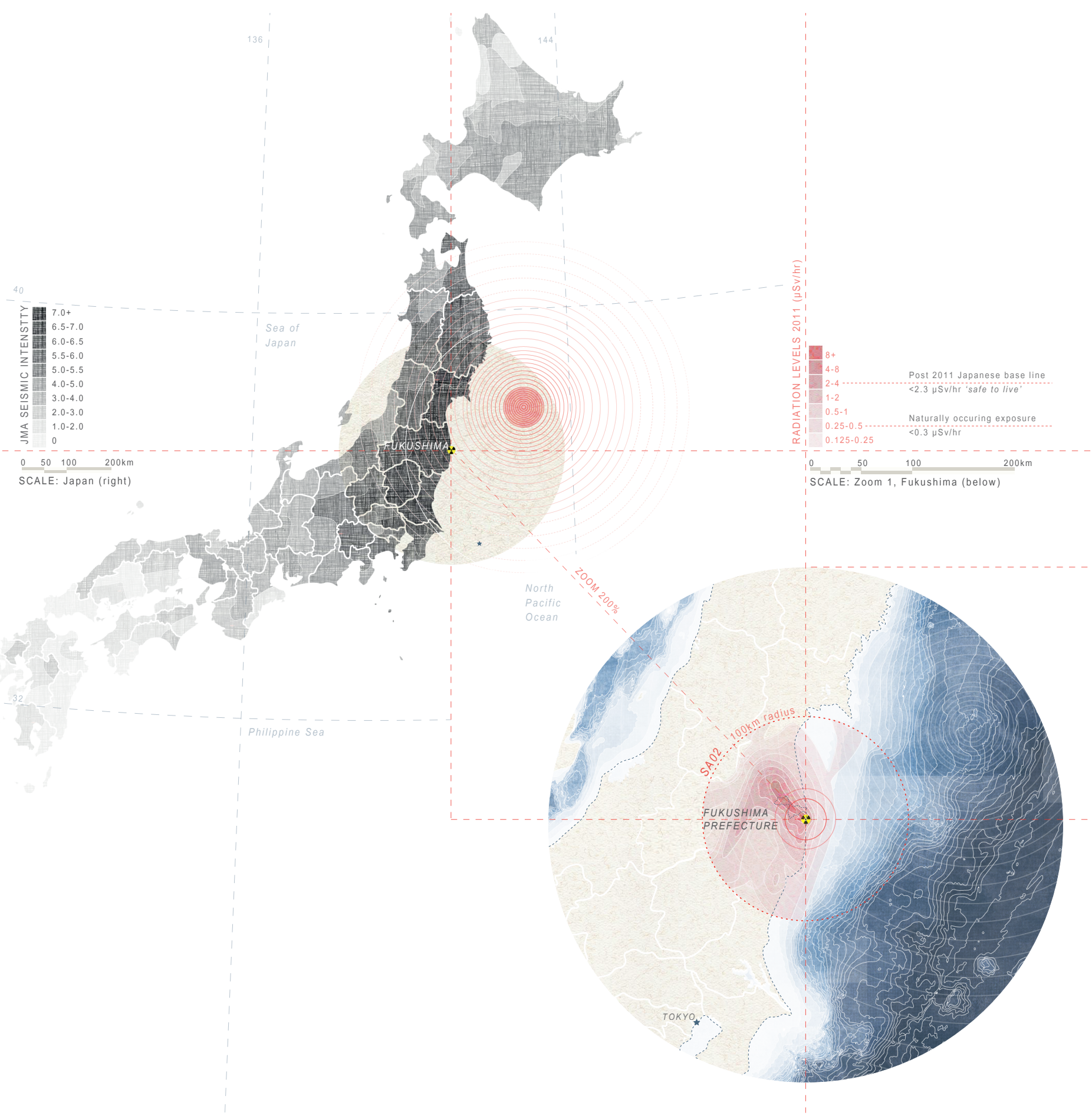




\subsection{Site analysis}

(S.A. 01)

Where is the project?

Japan is made up of $80 \%$ highlands, resulting in its large population being densely clustered, mainly along coastal regions. Although it is referred to as the Fukushima nuclear disaster, the plant is not actually based in Fukushima city but rather in the small coastal town Futaba. The Fukushima prefecture itself is made up of 13 cities and 59 towns/villages with Fukushima city as the capital (TANI Kenji Lab, 2017).

The map of Japan (refer to fig.05, far left) shows the seismic intensity felt across the prefectures from the Tohoku earthquake. The circular zoom region (fig.05, near left) shows the resulting radiation plume as it is thought to have dispersed from Tepco's nuclear plant (Gale \& Lax, 2013).

The whole Fukushima fallout region was far too vast to address in a nine-month thesis project. I decided to focus in on a single coastal town neighbouring Futaba, Namie-machi, in order to make the project more specific and to enable me to consider the effects of the nuclear disaster on the experience of individual people and families, rather than the entire prefecture or country. 


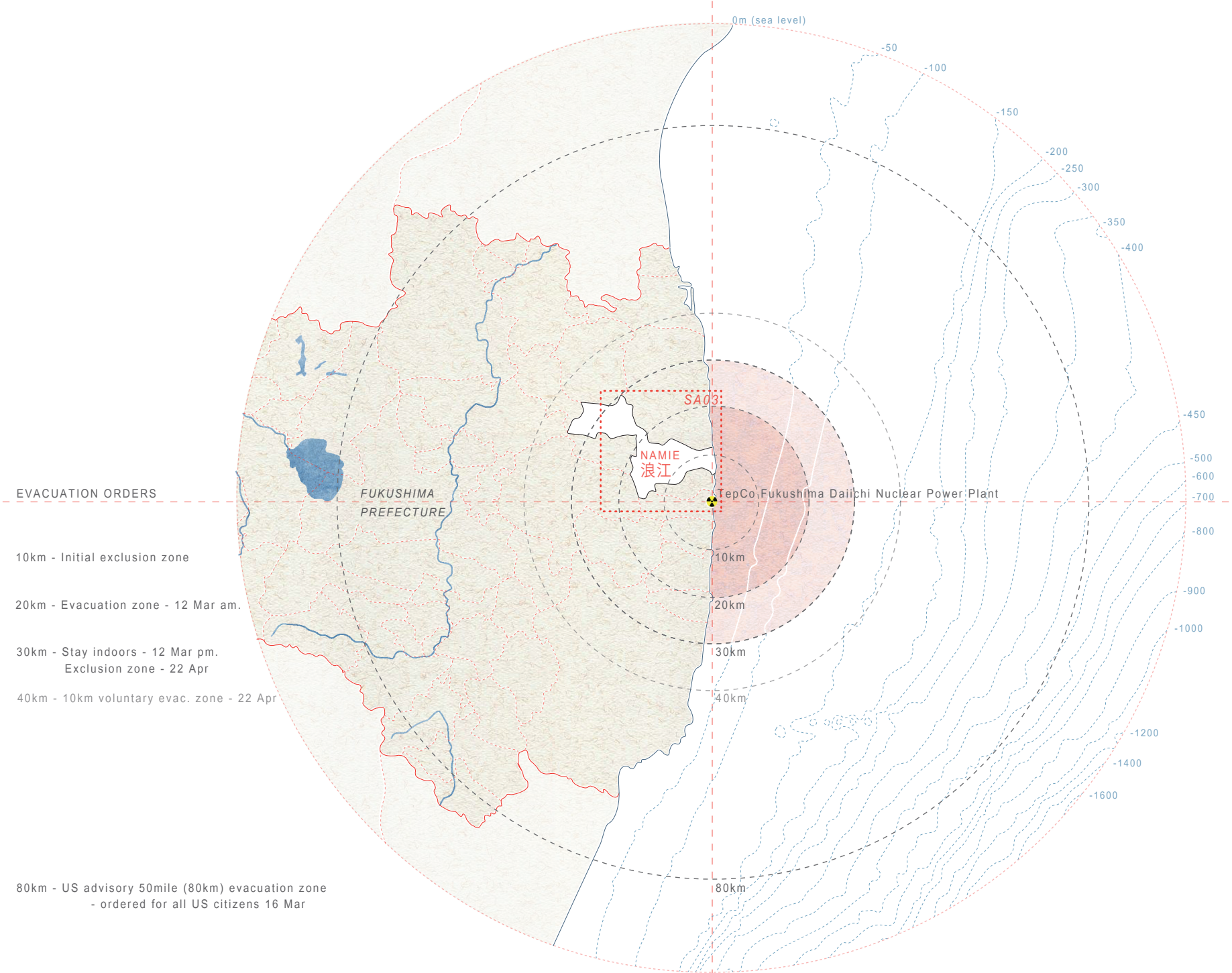


(S.A. 02)

\section{Evacuation and return}

Namie town centre is approximately $8 \mathrm{~km}$ from the nuclear plant. The current registered population is 18,500 . The populated area of Namie is entirely within the $30 \mathrm{~km}$ official exclusion zone that was ordered on 22 April 2011 (Namie Town, 2017). All inhabitants where forced to leave their homes. Of these people, $70 \%$ remained nearby within Fukushima Prefecture (Hirano \& Yuichi, 2017).

The analysis map (fig.08, left) shows the evacuation borders as they were ordered from the power plant. What is most shocking is the contrast with US regulations which mandate an $80 \mathrm{~km}$ evacuation zone. Compare this with Japan's $20 \mathrm{~km}$ evacuation zone. While the Japanese Government was considering all possible routes to quietly shut down the incident without having to reveal the full extent of the radiation threat, the US Government was globally broadcasting to their citizens in Japan to evacuate as far as a $100 \mathrm{~km}$ radius (Kadota \& Tokuhiro, 2014).

When maps S.A.01 (refer to fig.05, pg.12) and S.A.02 are compared it is of key importance to note how the evacuation zones that spread radially out from the Tepco plant are not reflective of the radiation plume which did not spread radially. This exposes a key flaw that parts of the exclusion zone may be completely free of radiation, and some areas beyond these zones may be radioactive hot spots. This highlights the inherent irrelevance of the exclusion zones (Broinowski, 2013). 
(S.A. 03)

\section{Livability zoning}

Following the announcement in mid-2016 of the impending reopening of the town the following year, the Asahi Shimbun newspaper conducted a survey asking residents if they intended to return once evacuation orders were lifted. Some $20 \%$ said yes, while $50 \%$ said no. Since March, it is said to be mainly elderly couples and single men who have returned (Tran, 2017). The zones are defined on Namie town's government website (2017) as follows:

A - Evacuation order lifted (sparse dot pattern)

A measurement of less than $2.3 \mu \mathrm{Sv} / \mathrm{hr}$ was determined by the Japanese government as safe to live after 03/11. As of March 2017 readings taken at the town hall, a central position in zone $\mathrm{A}$, are holding steady at approximately $0.1 \mu \mathrm{Sv} / \mathrm{hr}$.

$B$ - Restricted residence (dense dot pattern)

The readings are between $20-50 \mathrm{mSv} / \mathrm{annum}$

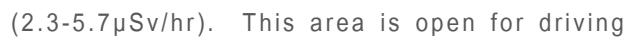
through and home visits by non-permanent residents.

\section{C - Difficult to return (red hatch)}

The readings are above those measured in zone $B$ and are expected to remain that way as the mountainous, forested terrain makes decontamination almost impossible.

Site analysis map 03 (fig.07, left) shows the coastline in dark blue, to the right of the image, and the outline of Namie region's border in red. The dashed red lines indicate the separation between the zones. 


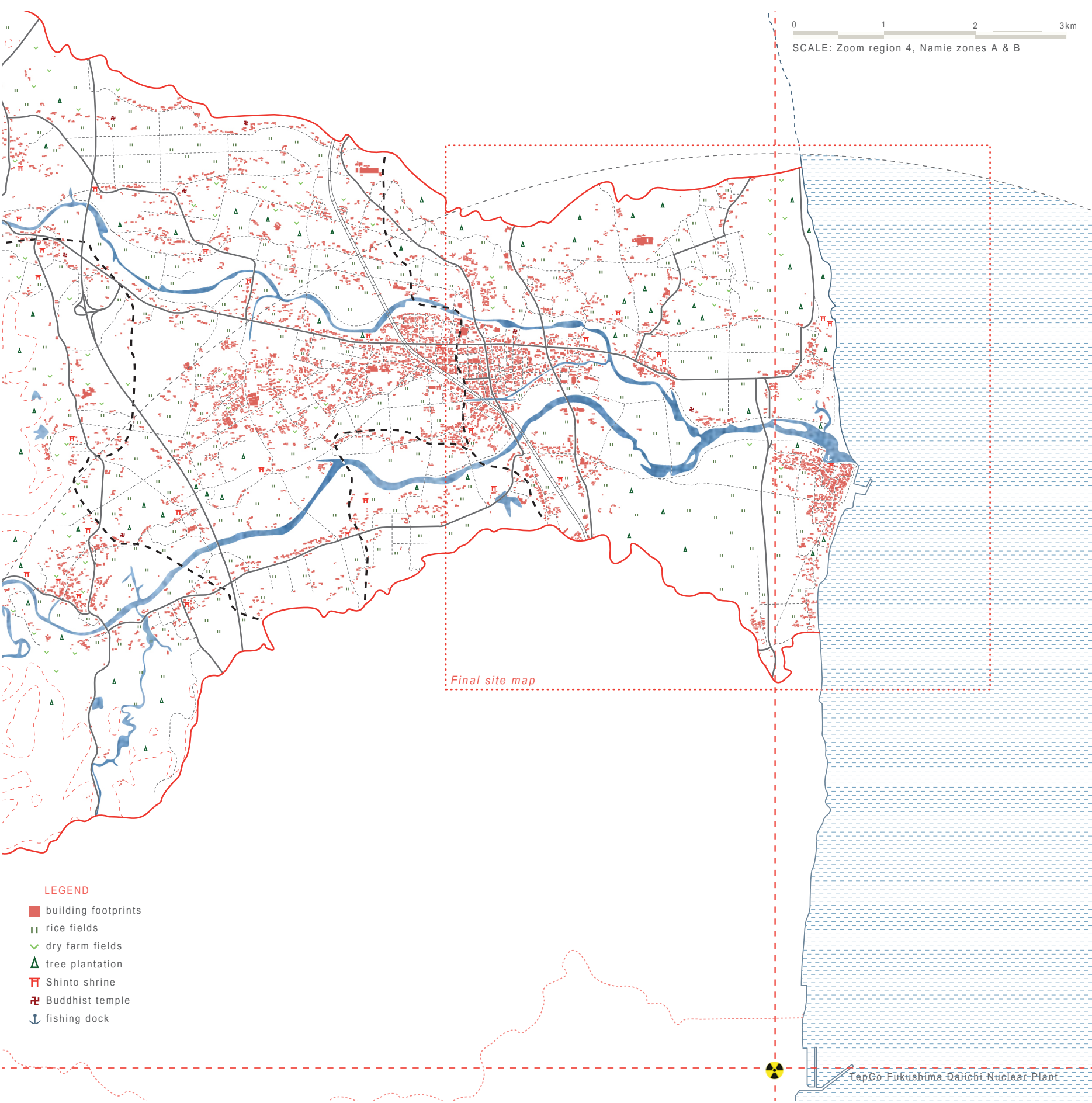


(S.A. 04)

\section{Town layout and key features}

Understanding the lifestyles of the people of Namie was key to discovering the most important aspects that were damaged by the disaster. Site analysis map 04 (fig.08, left) zooms in to more closely analyze the town.

The actual township is split between zones A \& B near the coast. $40 \%$ of the residents lived in zone $A$ and will be able to return to their original homes or (for those damaged by the tsunami) properties to be rebuilt (Hirano \& Yuichi, 2017). Zones A \& B have undergone full scale decontamination. This process involves the incineration of burnable tsunami debris and rebuilding of vital infrastructure. Roads, water and power supply and sewer lines have all been restored prior to the reopening in March (Tran, 2017).

Zone $\mathrm{C}$ is mountainous and densely forested. This region accounts for $80 \%$ of Namie region's land but only $10 \%$ of residents lived here. This area will remain highly contaminated as it is too vast and would require complete deforestation in order to remove the topsoil to decontaminate. The 'satoyama' (foothills that border the town) at the edge of zone $B$ $\& C$ and along the north and south boundaries used to be an integral part of rural life (Hirano \& Yuichi, 2017 ).

The main township is settled between two rivers. Before, families would go to the river for children to play and to fish. However, decontamination of these rivers is near-impossible as they run down from the permanently contaminated mountains, carrying radiation with them (Takenaka \& Kasai 2017). 


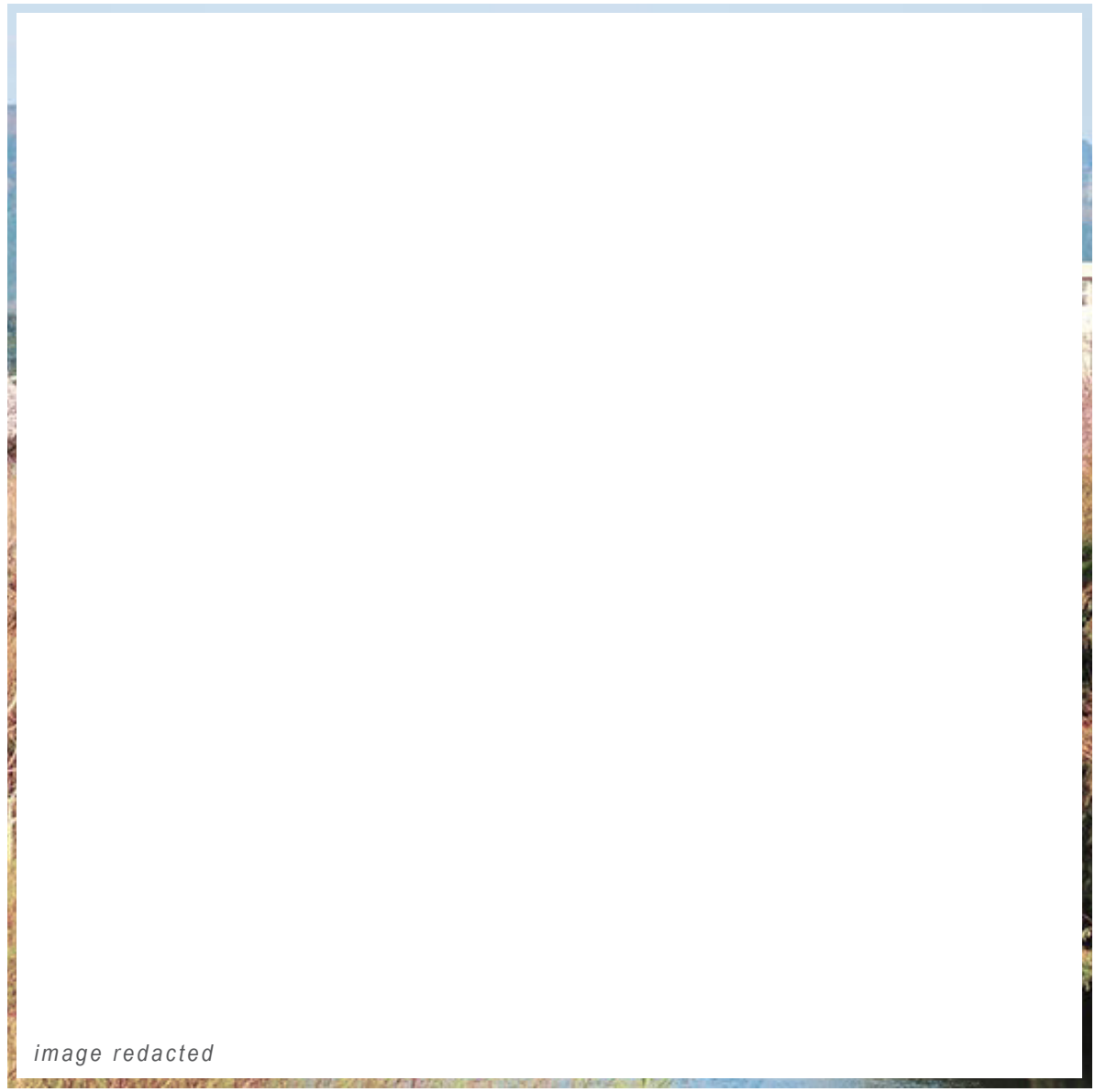


(S.A. 05)

\section{Land use and livelihood}

Namie was a rural township, reliant mainly on agriculture and fishing. The radiation leakage into the ocean has been greatly diluted and is no longer threatening, although constant testing is required (Gale \& Lax, 2013). The fishing industry can definitely be revived, through repair of the docks, and a great deal of patience waiting for the fear and discrimination against produce harvested and caught in the region to pass. The agricultural aspect is more complex and is explained in section 2.4. 04 , Radiation - Soil (pg.30).

Residents are saying that the fear of having no longterm prospects in the township is the main reason for uncertainty about returning (Tran, 2017). This notion is supported by the fact that to date only elderly couples and single men have returned. A temporary shopping arcade has been opened with assistance from the Government in an attempt to provide basic amenities for returning residents but these businesses are struggling to stay afloat. The lack of people returning means an insufficient customer base for those merchants attempting to rebuild, forming a cycle (lack of supply, lack of demand) that is hard to break (Grossman, 2017).

One resident described Namie as having been:

"A place with wonderful mountains and oceans, where you could harvest any food you want, surrounded by rich and beautiful nature."

(Hirano \& Yuichi, 2017) 


\subsection{Scenario}

What surprised me most was the number of residents willing and eager to return home. Although they have fears of radiation and doubts about the future, it is heard continuously (from surveys, interviews and chants at political rallies) that they want their old lives back (Funahashi, 2013).

What is also clear is that the 'clean up' of these towns that are reopening inherently cannot repair the lasting damage to the natural aspects that were at the heart of these rural lifestyles. Fishing at the river, picking mushrooms in the foothills, these parts of day-to-day life are now off-limits. They can no longer make a living from their land. Their lives here will be a shadow of what they were before.

These are the key issues my architectural intervention will highlight.

The scenario that I am proposing to address is that 10,000 residents eventually resettle in Zone A. This number is a starting point that could potentially increase with the eventual opening of Zone $B$. The project (like the nuclear plant used to be) will be a place of work for not just Namie but for all the surrounding towns in the prefecture. 
<smiles>[CH]1CCC1</smiles> 


\subsection{Radiation}

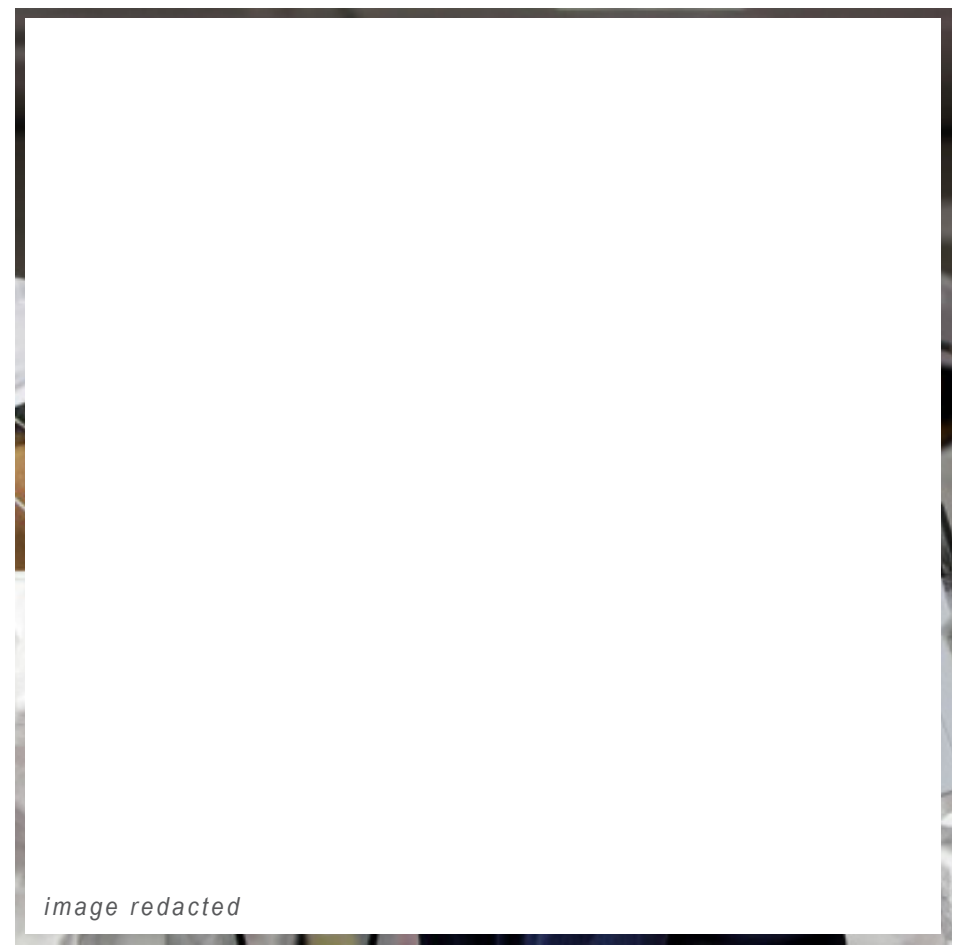

On March 14 2011, three days after the meltdown at the Fukushima Daiichi nuclear plant, the Japanese Ministry of Health, Labour and Welfare more than doubled the 'safe' exposure level for workers to 250 millisieverts per year (up from 100 milliseiverts over five years) (Broinowski, 2013). 
(2.4.01)

The key question that threatens the plausibility of my project is the debate over whether the current conditions in the Fukushima exclusion zone are livable. The following parts of section 2.4 will summarize this research.

\section{Radiation - Air}

The most important point I learned from my research into radiation is that 'safe' thresholds of radiation exposure are defined by governments (often influenced by wealthy nuclear power corporations) and often do little to honestly reflect the probable risk of exposure. Different countries define different levels of exposure as safe/not safe (Gale \& Lax, 2013).
\end{abstract}

The current readings of the air quality in Fukushima and the wider East Coast are difficult to obtain and reveal even less in terms of true safety risk. Refer again to S.A.01 (fig.05, pg.12), where the radiation plume and the zoning in S.A.03 (refer to fig.07, pg.16) clearly show the variation of contamination. The radioactive particles were carried in the wind and released when they passed over the mountains, resulting in stronger concentrations in these areas. This further supports the conclusion that the exclusion zones are misguided and provide a false sense of safety (Gale \& Lax, 2013).

Readings show that for many of the $70 \%$ of Namie residents who continue to live in the wider Fukushima region, or even as far away as Tokyo, the radiation readings they are experiencing outside the exclusion zone are similar/equal to those in Zone A (Broinowski, 2013). This shows that their 'safety' is peception as much as reality. It is what they choose to believe is 'safe', true or not. 


\section{Calculated risk}

Research shows that the effects of airborne and other radiation contamination are more accurately described as a spectrum where the levels of exposure are compared to other carcinogenic substances (Gale \& Lax, 2013).

In one of my key texts, Dr Gale (2013) introduces this concept of 'calculated risk.' If people understand the risks that come with a life decision then they are able to make the decision to continue doing that thing.

He compares the 1-in-10 lifetime chance of cancer from smoking as a baseline, to the risk of living within the Fukushima exclusion zone which he states to be 1 -in-10,000.

In another key text $\mathrm{Dr}$ Shimizu describes the thought process of residents who decide to return to evacuated regions.

They are faced with a difficult choice: continue to enjoy a comfortable and productive existence with neighbours they know and jobs that suit them, at the price of heightened risk of cancer for themselves and their decedents, or evacuate to some distant place and re-establish their lives in the face of ignorant local discrimination and uncertainty over employment and income (Broinowski, 2013).

Reading stories like this, the decision to return to their hometowns seems more obvious than I initially assumed. Dr Shimizu goes on to say,

the people who stay are prepared to take the chance, and, in accordance with human nature, they rationalise their decision by talking down the threat of ionising radiation (Broinowski, 2013).

Considering the downplaying of radiation threat by the Japanese media, coupled with the reality that they are experiencing similar exposure elsewhere in the region, it is much less surprising that residents will choose to forget about the exposure and just want to return to live their lives. 


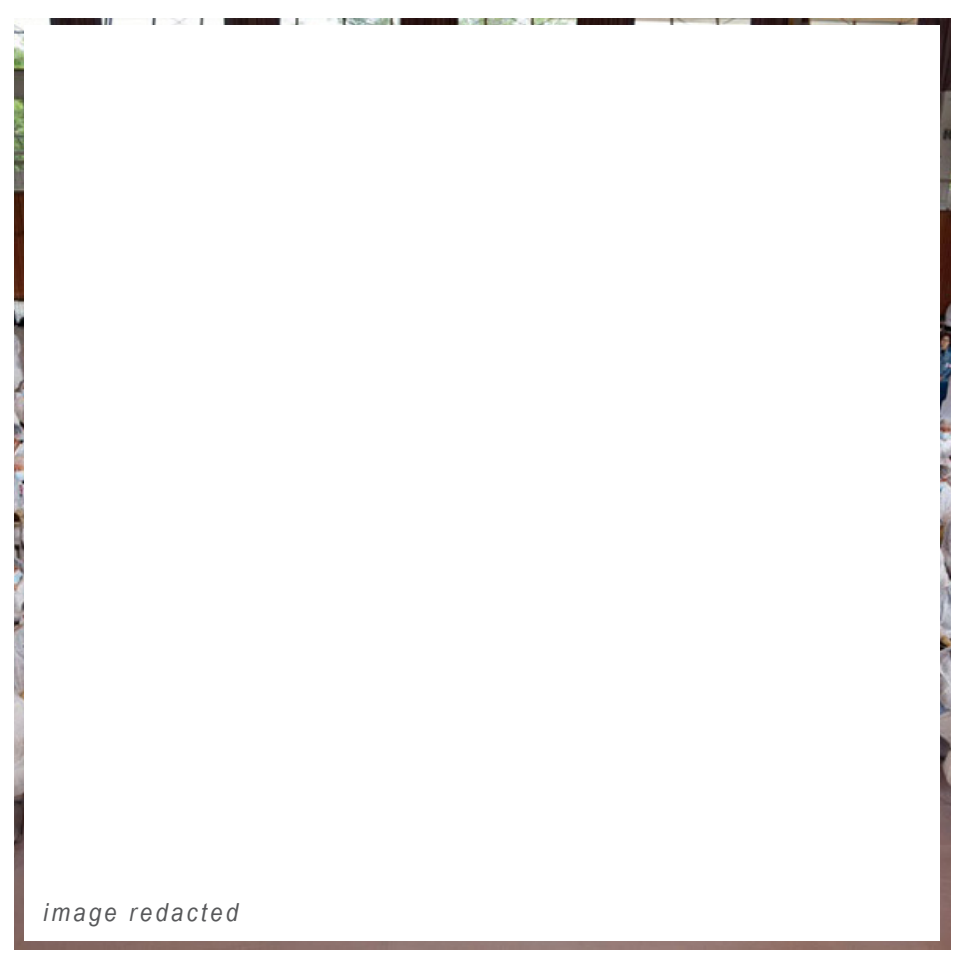




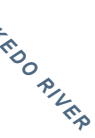

(2.4.03)

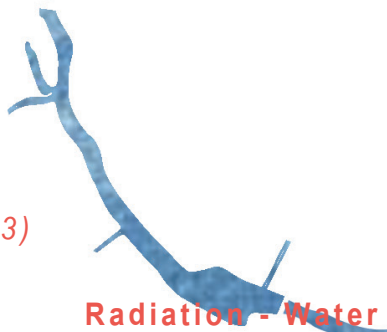

As my site analysis summarised (refer to section 2.2), these rural towns revolve around the key topographical features. For Namie these are the two rivers that it is settled between, and the coast.

The nuclear fallout has had devastating effects on both of these natural resource features.

The river was mainly used for recreation, a place for children to play and adults to fish. Although the river will visually remain a scenic feature of the town, it will no longer be safe for these activities. The huge quantities of radioactive particles that fell on the mountains are constantly being washed down the river. This makes permanent decontamination of the riverbanks extremely difficult, tuhing the river into a no-go zone that carves the town two (Hirano \& Yuichi, 2017).
The ocean has consistently been the centre of misinformation and scaremongering regarding the wider impacts of the Fukushima disaster.

wide

It was reported that the predominant offshore winds blew about $80 \%$ of the released radiation into the ocean (Lochbaum, Lyman \& Stranahan, 2015). There contikues to be considerable debate and concern over the accuracy of this information and the true extent of damage caused by this release. However the reality is that for 30 years many countrie intentionally dumped radioactive waste into the seas in much larger andmore concentrated quantities than anything released by Fukushima Jep Co in 2011. All this radioactive material is still only a fraction of the natural radioactivity in the sea. From a safety standpoint the hugedilution of these radioactive materials in the yart volume of the ocean massively

(1) 
decreases potential harm to living creatures than if the same radioactivity was dispersed over the land (Gale \& Lax, 2013).

Many of Namie's residents rely on fishing as their sole source of income. All the fishing docks in the region were heavily damaged by the tsunami, so new fishing hubs will be required. The greater issue caused by the disaster, however, is the damage to the reputation of seafood that has been caught in the sea off Japan's East Coast (O'brien, 2015). Extensive testing of caught produce and time for the memory of the incident to fade will be the only way to repair the reputation of this fishing district. 


\section{Radiation - Soil}

Agriculture was a very important source of livelihood that has been destroyed for the residents of Namie.

The Japanese Government has been experimenting with adding zeolites to the soil in the affected areas. The zeolites absorb radioactive particles so that they cannot be absorbed into the produce that is being grown. Although testing shows that this system successfully results in radioactive-free produce, the physical farming and cultivation of the soil is still very dangerous to the farmers. The radioactive Iaden zeolites remain in the soil and cannot be extracted, making these pastures unsafe to manually farm (Gale \& Lax, 2013). Fully automated farming systems are a long way off and anyway would lessen the opportunity of steady work for many of the residents who had worked in agricultural jobs. Soilless, aquaponic systems in a factory environment are a practical

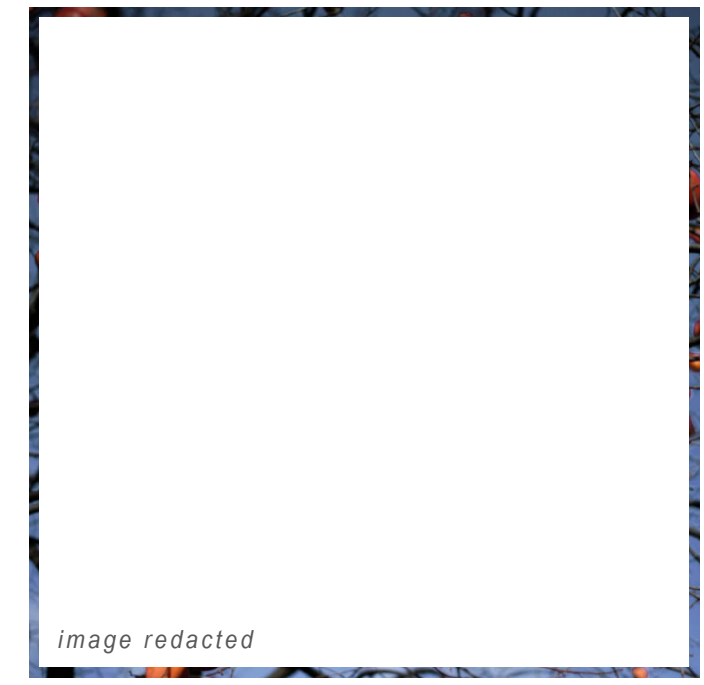
the land is now unfarmable. 


\subsection{Betrayal}

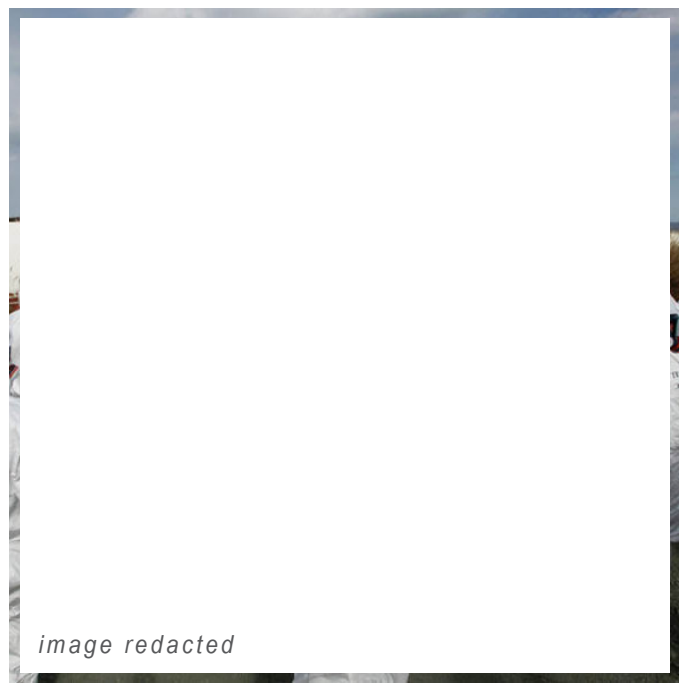

Although dystopian projects seek to highlight issues of the world around us, a critique of the Japanese Government is not why I pursued this topic. I am focussed on addressing the lasting damages caused by the nuclear industry, with Japan serving as an example. However the betrayal by the Government is one of the key damaging effects to the people created by the nuclear industry.
The facts are:

- The residents of towns were never educated on the risks of nearby nuclear facilities. They were told the plants were fail-safe and would bring their towns nothing but prosperity (Kadota \& Tokuhiro, 2014).

- Undeniable collusion between the Japanese Government, the regulators of Japan's nuclear industry and TepCo resulted in widespread misinformation about the risks of the nuclear industry and to some extent a 'cover up' of the worst effects of the disaster (Broinowski, 2013).

- The secrecy and manipulation of trust has caused Japanese citizens to feel betrayed, misled and to question the Government.

- This uncertainty has spurred opportunities for changes in direction and a shift in the culture in Japan that allows renewable resources to be properly pursued (Broinowski, 2013).

- The betrayal has resulted in a need for a lesser reliance on the Government. An emphasis on having their own source of power, water, food, and income are key to these towns regaining strength, independence and identity (Yoneda, 2012). 


\subsection{Self-sufficiency}

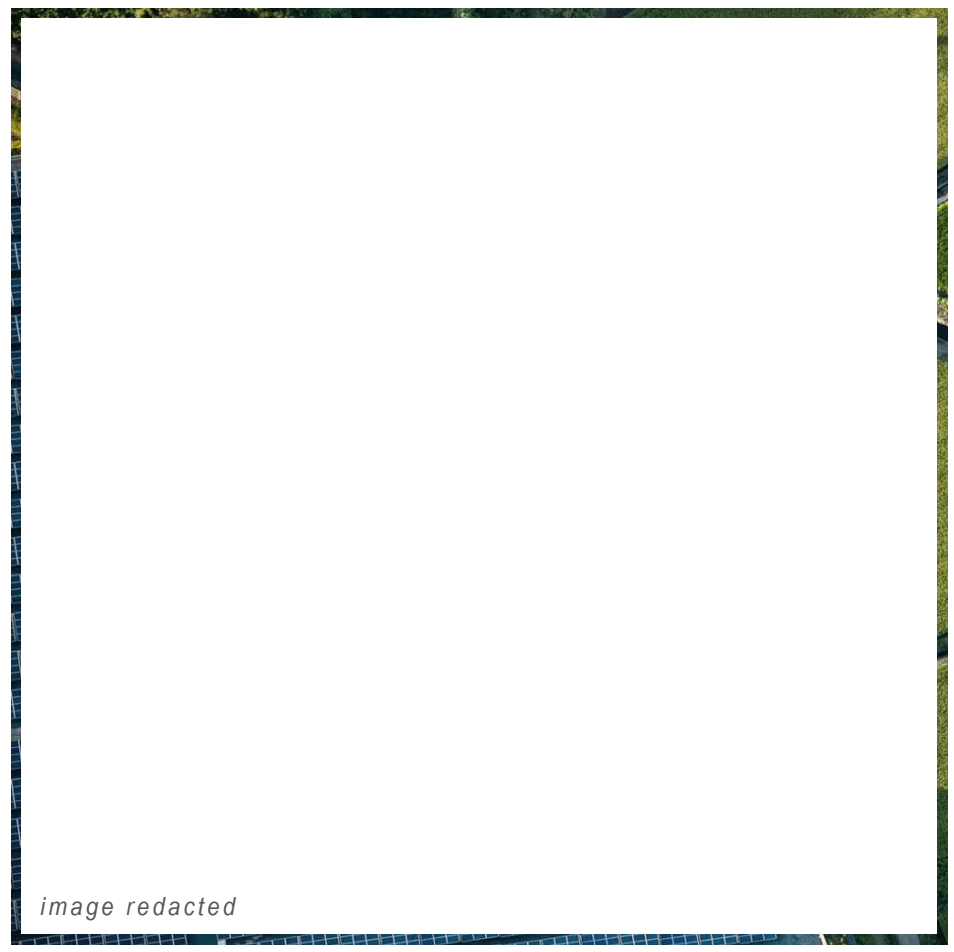

Following the Fukushima disaster it was reported that Japan's energy self-sufficiency was $4 \%$ and their calorie self-sufficiency just $40 \%$. Both are considered very low for a developed nation (Breacher, 2013). 
(2.6. 01)

\section{Solar power}

It is speculated the influence the nuclear industry had over the Japanese Government was Iargely to blame for the lack of investment in renewable resources in Japan, a country known for being on the forefront of new technologies. However, what is now being described as the 'Solar Boom' greatly accelerated in 2015/16 and is projected to keep up the same momentum in 2017/18. In 2016 Japan's electricity production from solar photovoltaics was a little over $5 \%$, (reflective of Japan's massive electricity consumption). To put it into perspective, in 2015 Japan had the third-greatest solar capacity of any country in the world, and has since nearly doubled that solar capacity (Pentland, 2017).
(2.6.02)

\section{Urban farming}

Japan has seen similar expansion in their production of indoor vegetable farms. Japan already has one of the largest urban 'plant factories' in the world, Mirai, (established shortly after the $3 / 11$ disaster in an abandoned Sony factory in Miyagi Prefecture). Urban farms are favoured for their ability to produce large-scale, pesticide-free produce for the domestic market with a production efficiency 100 times that of traditional farming (Nagata, 2014). Considering the hundreds of square kilometres of productive farmland lost to contamination, condensing these operations to controlled environments could be extremely valuable to these communities. 
2.7. Floating structure

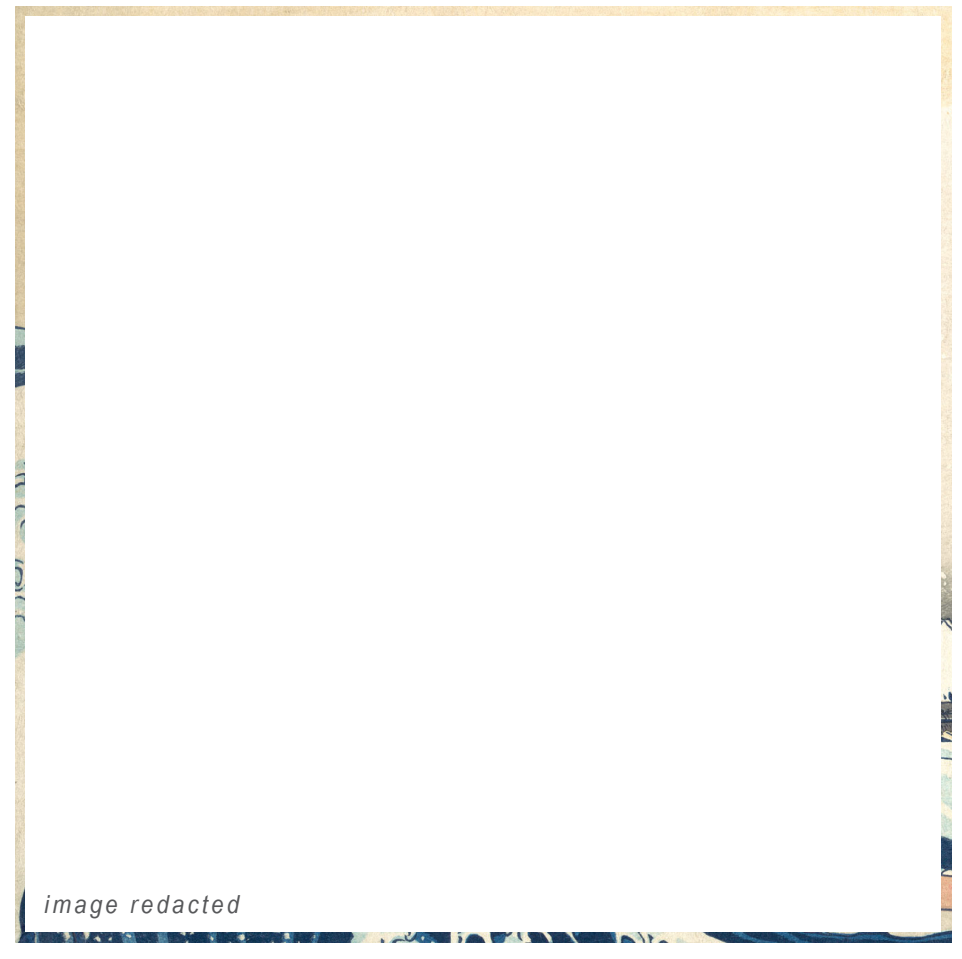




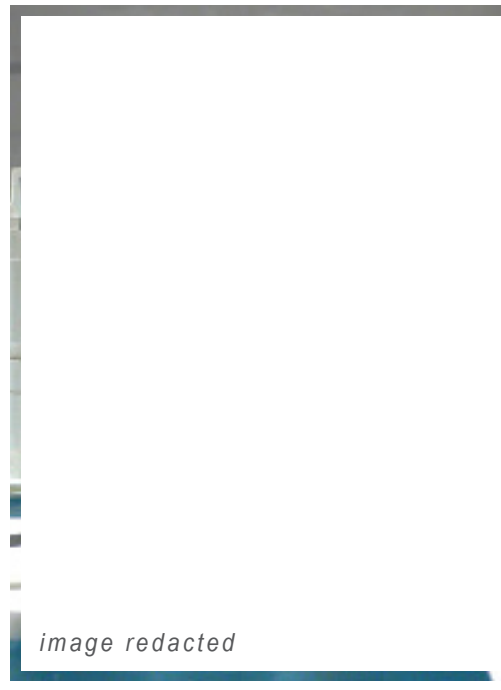

The concept of a floating structure first emerged (before any in-depth research into the current site conditions), when I assumed the land was not safe for habitation at all. The diluting effect of the ocean on the radiation made it a preferable site for the intervention.
Even after I discovered the town was habitable, my research into the Japanese metabolists intensified my interest in a floating structure. The Japanese metabolists often explored the physical environment of marine civilisation as they envisioned the cities of the future. This was a response to Japan's limited land. With habitable land being a scarce resource, the vastness of the ocean seemed an obvious platform for expansion (Lin, 2010). The metabolists also recognised that the ocean was deeply linked to the spiritual and material survival of Japan (Kikutake, 1998).

As this project evolved there continued to be clear benefits indicated for siting my project off the coast, the key drivers being:

- The continued threat of tsunami.

- The need to provide a new fishing hub.

- The ocean being the largest, safest, and most accessible water source.

- The large volume of water required to run a hydroponic urban farm. 


\subsection{Programme}

The final proposed design responds directly to the lasting consequences to the town of the radiation contamination. This, combined with the aspects of the town most valued by the residents, enables selection of programmes that increase the quality of life for the residents and build upon the historical spirit of the town. This culminates as six key programmes:

- An urban farm: in response to the loss of highly productive farmland

- A bridge: to highlight ongoing contamination of the river that was once the heart of the town.

- A market: to supply the returning people with reliable, safe produce.

- A desalination plant: to supply residents with a clean alternative water supply.

- A fishing hub: to replace the ports along the coast damaged by tsunami, and also to support the fishing industry whose market reputation has been destroyed by radiation fears.

- Recreational space: to highlight the natural recreational areas, mountain tracks etc, which are no longer safely accessible by the townspeople. 


\subsection{Project progression}

IDEA

An architectural response to the situation at Fukushima Daiichi Nuclear power plant.

- After initial research I started to focus less on the site and more on the displaced residents from the surrounding towns.

- Early radiation research pointed to the ocean as a safe haven from radiation contamination.

- Discovery that towns like Namie have reopened and residents are returning

- Summarize the lasting consequences of the radiation and directly respond with a set of programmes aimed to positively assist the town.

May review 01

Final review 03

Critiquers suggest that design should refocus on integrating with the town and branch inland.

- Form-finding models were used to create dramatic simplistic forms. This is used again to explore a complementary form for the inland anchor point.

- Exploration on turning the chosen urban farm form into a solid inhabited space introduces a range of circulation and programmatic issues.

Critiquers suggest that the sheer scale required to tackle such a huge issue has caused the project to stray from the human experience that initially inspired the thesis.

\section{RESPONSE}

An architectural intervention on site, possibly incorporating the water tanks and irradiated topsoil.

- Switch focus to housing, starting to explore ecovillage and self-contained community models.

- Concept of a floating structure offshore housing a village in a bubble.

- Completely throw out housing idea and change to intervention that aids the residents' return

- An urban farm and supporting desalination system with a fishing hub and public recreational space are proposed as a floating structure offshore from Namie town.
Urban farm, fishing and desal. remain offshore and a second anchor point bridges the river in the heart of the town to house a market and public green space.

- Precedents Chichu Art Museum and the Brazilian Congress inspire an overall composition between the two forms across an ambitious $3 \mathrm{~km}$ stretch.

- The final planning results in splitting pedestrian flow from buses and delivery trucks and splitting the level between the stepped urban farm and the fishing factory at sea level.

Final exercises refocus on a smaller scale, first at $1: 200$ to tackle key thresholds in the urban farm design.

- Final rendered compositions imagine the human experience and feel of the space despite the low level of design resolution in several areas due to the massive scope of the project. 


\subsection{Programme research}

When the scope of the thesis was finally refined (refer to pages 77-81) the six programmes were given a hierarchy of importance. Although not all of the spaces were fully resolved, understanding of how these programmes would work and interrelate was a vital underpinning of my overall proposal. The most design focus was given to the urban farming floors, followed by the market / green space. The fresh produce factory and seafood factory were carefully considered so they would work successfully in plan, although architecturally these factory spaces were not highly detailed. The desalination plant fell beyond the scope and was researched only on how the systems would influence the other programmes.

image redacted
(3.3. 01)

\section{Urban farming}

After researching several aquaponic urban farming systems I decided to design for the vertical farming systems implemented by the likes of Fujitsu (refer to fig.19, left) and Toshiba in Japan. This was justified by the likelihood that the urban farm would be owned by one of these industry leaders who are currently leading the way in the growth of Japan's urban plant factories (Greene, 2014).

Aquaponics is a soilless system for crop production. Water is cycled between vegetable farming trays and fish farming pens. The waste from the fish provides nutrients for the edible plants and the plants cleanse the water for the fish. Many of Japan's most popular urban plant factories forgo the fish farms, opting to add macro and micro nutrients artificially to the water flow (Matsutani, 2014). For this project, due to the inclusion of the seafood factory programme as part of the fishing hub, it made sense to include fish farms as part of the cycle.

The process of urban farming impacted the overall planning in the following ways:

- A sanitation zone is required where workers shower and suit up prior to accessing the farming floors (Nagata, 2014).

- A clear zone is required to separate the farming floors from other factory programmes.

- Vertical growing towers are maintained using 'cherry pickers' (refer to fig.19, left). Clear, level circulation paths are required to access all towers (refer to fig.48, pg.71).

- Controlled artificial lighting is preferred over natural lighting resulting in the farm not being glazed like a greenhouse space. 
(3.3. 02)

\section{Fresh produce factory}

Both factory programmes were extensively researched to ensure that there was adequate provision for each stage of processing when designing the overall plan. The key stages of the fresh produce factory were defined as: (refer to fig. $51 \& 52$, pg.74 \& 75)

1. Aquaponic growing system

2. Harvesting

3. Sorting

4. Quality inspection

5. Peeling \& cutting

6. Packaging

7. Labelling

8. Stock check

9. Cold storage

10. Dispatch, loading \& delivery (FAO, 2017)

The key thing to note from this research is the separation of the quality inspection, peeling and cutting, packaging and labelling stages that are often combined in the factory process. This is due to Japan's preference for highly aesthetic, heavily packaged, flawless produce (refer to fig.20, right). This mentality is largely attributed to why urban farming has become so popular in the country, as factory grown, aquaponic produce is never tarnished by dirt, insects, or scarred by weather (Nagata, 2014). Each of the defined stages has been delineated by tiered floors stepping up the slope of the open plan factory space.
(3.3. 03)

\section{Seafood factory}

Similar to the fresh produce factory the seafood factory processing was researched and the following stages delineated in plan across a series of tiered floors. The key difference is the inclusion of scientific testing facilities that will ensure all caught produce is free from radioactive substances.

1. Testing laboratory and sorting

2. Preparation

(scaling, gutting, filleting etc.)

3. Packaging and labelling

4. Stock check

5. Cold storage

6. Dispatch, loading and delivery

(Marel Fish Corp, 2016) 
(3.3. 04)

\section{Desalination}

In the end the Desalination programme fell beyond the scope of the thesis. The initial research justified that desalination as a reliable source of fresh water, being implemented globally in climates where ground water sources are not dependable or have been contaminated in some way. In $201655 \%$ of Israel's domestic water supply was from desalination, turning one of the world's driest countries into the unlikeliest of water giants (Jacobsen, 2016).

Desalination technology is developed and constantly improving, in fact, floating desalination plants were planned for Japan in 2014 in the hopes that the manufacturing would breathe life back into Japan's stagnant shipbuilding business, and help the Japanese fulfil short-term freshwater needs (Kloosterman, 2014). With the concept well justified, the secondary research was to understand how the system would interlink with the other programmes, and the effect of this on planning. The basic process is:

\begin{tabular}{|c|c|}
\hline SEAWATER INTAKE & $\begin{array}{l}\text { A below-water seawater intake } \\
\text { Seawater is pumped to a holding tank }\end{array}$ \\
\hline PRE-TREATMENT & $\begin{array}{l}\text { Pumped through a multimedia sand filter } \\
\text { Held in a filtrate tank }\end{array}$ \\
\hline $\begin{array}{l}\text { MAIN BODY OF } \\
\text { DESALINATION } \\
\text { PLANT }\end{array}$ & $\begin{array}{l}\text { Pumped through a reverse osmosis module } \\
\text { Brine is removed and expelled into the ocean } \\
\text { Treated water held in a fresh water tank } \\
\text { Water is tested for any radioactive substance } \\
\text { Necessary chemicals are added prior to drinking } \\
\text { (ACE Water, 2017) }\end{array}$ \\
\hline
\end{tabular}

The influence on the final planning (refer to fig.53, pg.76) was mainly diagramming how the flow of water would be reticulated around the plant, allowing for adequate space for the desalination treatment plant and noting that the counterbalancing, below-water structure would be used for the seawater intake processes. 


\section{(3.3. 05)}

\section{Fresh produce market}

The concept is that the market will sell some of the fresh produce grown and packaged in the urban farm, while the rest of the produce would continue on to outlets throughout the wider Fukushima area.

The design of the market space was not highly research influenced; rather it was inspired by my own experience of Japanese food markets. The nature of these markets is very organic, chaotic and particularly resourceful - many requiring nothing more that an open patch of space to spring up in, as in figure 21 (below), where boxes of produce have been stacked to create a table height display.

My design played off this notion of providing flexible space to be inhabited (refer to fig. 54 , pg.77 \& fig.65, pg.92). I focused on creating a tiled, open surface that was shaded by a canopy and situated half-way between the main pedestrian and vehicle access points, on one of the flattest sections of the site. These treatments provide the basic environmental factors for a market to thrive.

image redacted 


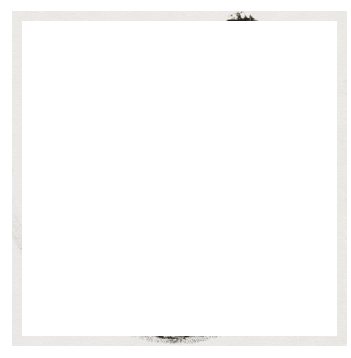

\section{$\left(\begin{array}{ll}4.1 & 01\end{array}\right)$}

\section{Calligraphy}

Alongside the research phase at the beginning of my thesis I began curating a collection of Japanese imagery that I hoped would inspire a representation style or design language during the concept phase of my project.

I began by looking at Japanese calligraphy and was drawn to the subtle textures and tones of the paper which was used. This I thought could translate into a monochromatic material palette that has varying textural finishes. The simplicity and directionality of the linework also seemed very powerful (Sato, 2014). I thought this could be explored as forms that are very simple, with a bold gesture that defines the form.

\section{$\left(\begin{array}{ll}4.1 & 02\end{array}\right)$}

\section{Illustration (right)}

I started to see similar things in the Japanese illustrations that I was drawn to. Particularly, I liked how forms were simplified into a single stroke or block of colour. The bold use of reds and blues against the neutral tones of the paper also attracted me and became a feature throughout my entire thesis presentation. 

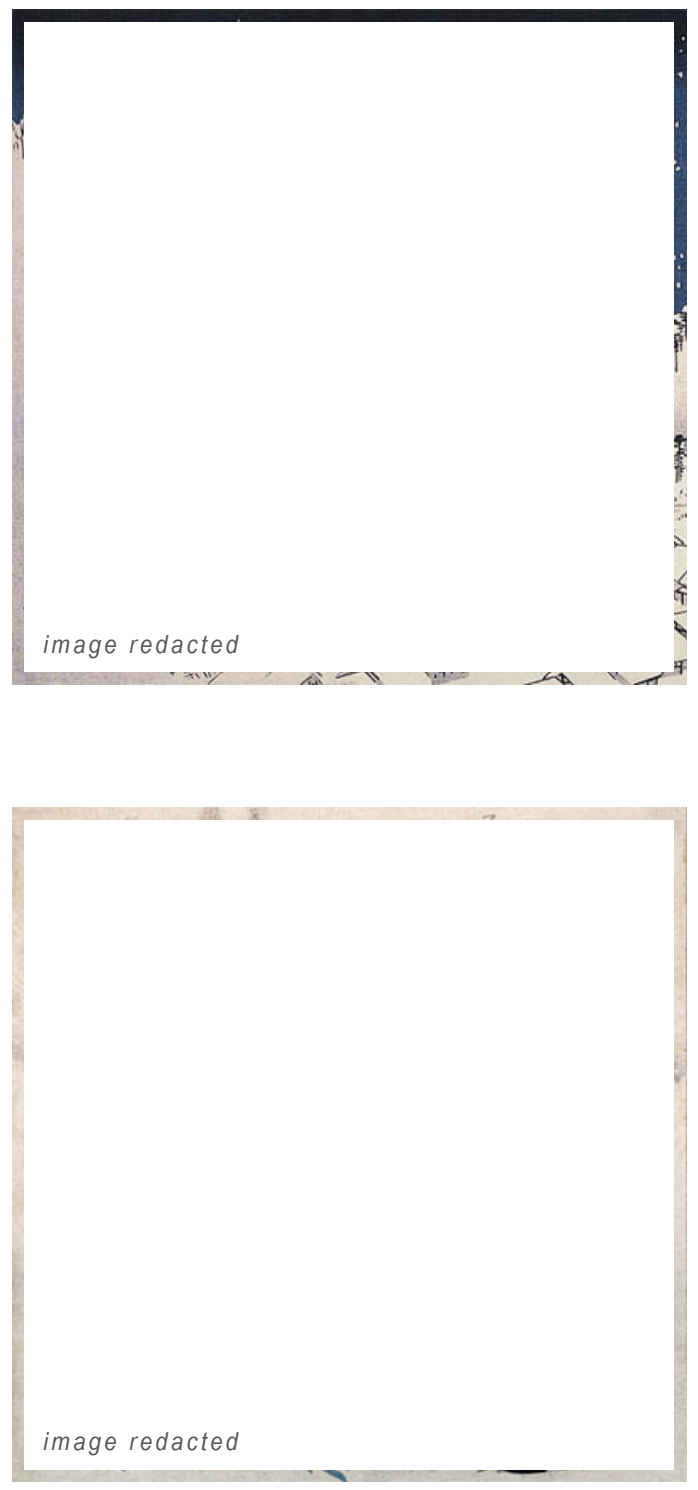

(Figure 23, top)

Snow Falling on a Town, Utogawa Hiroshigi. 


\section{(4.1 03 )}

Personal explorations

Artwork like Yayoi Kusama's (fig.26, right, top) inspired me to do a series of drawing explorations (fig. 25 below \& 27 below, right) that I hoped might progress throughout my project. Although this was not the case, the way the textured surface of the paper slightly distorted the image being drawn on it interested me and led me to print all my final imagery on textured watercolour paper.

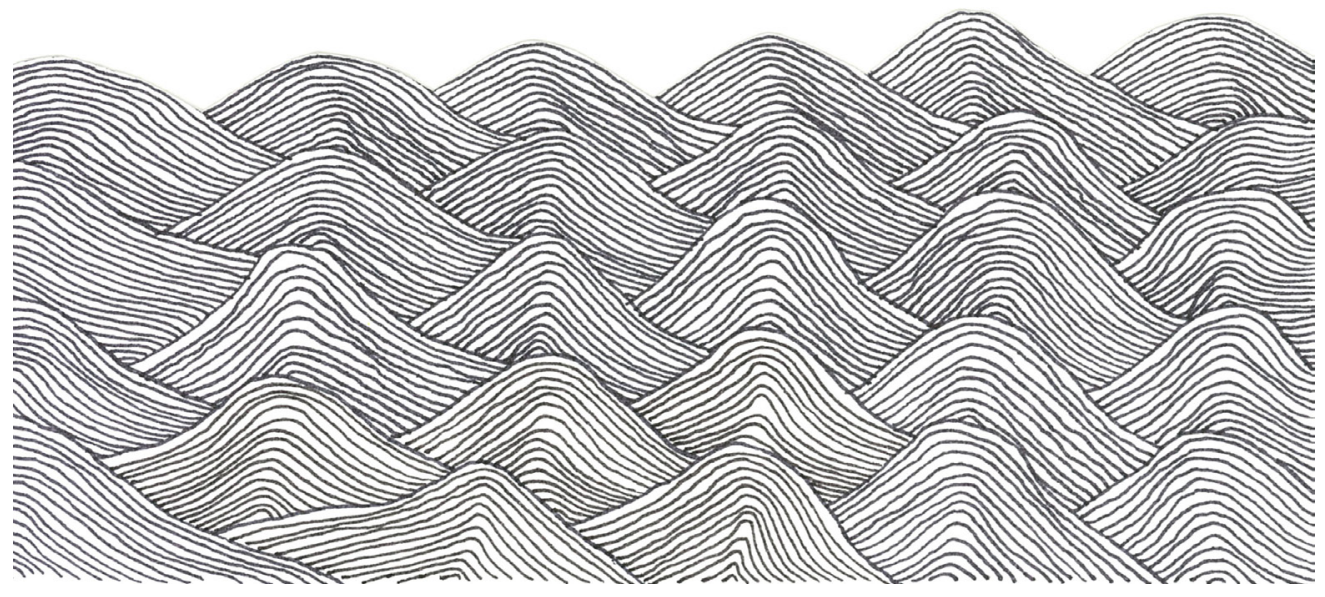



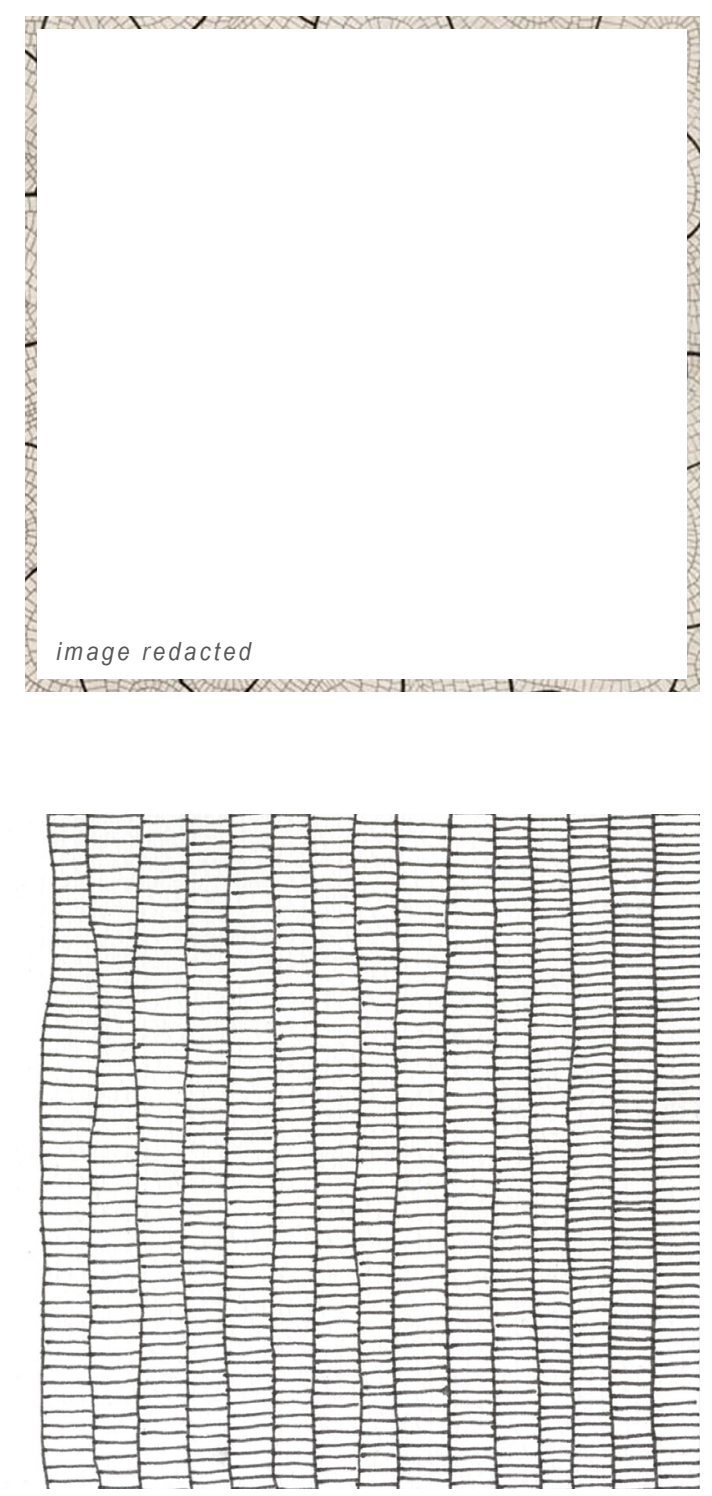


\subsection{Precedents}

\section{$\left(\begin{array}{ll}4.2 & 01\end{array}\right)$}
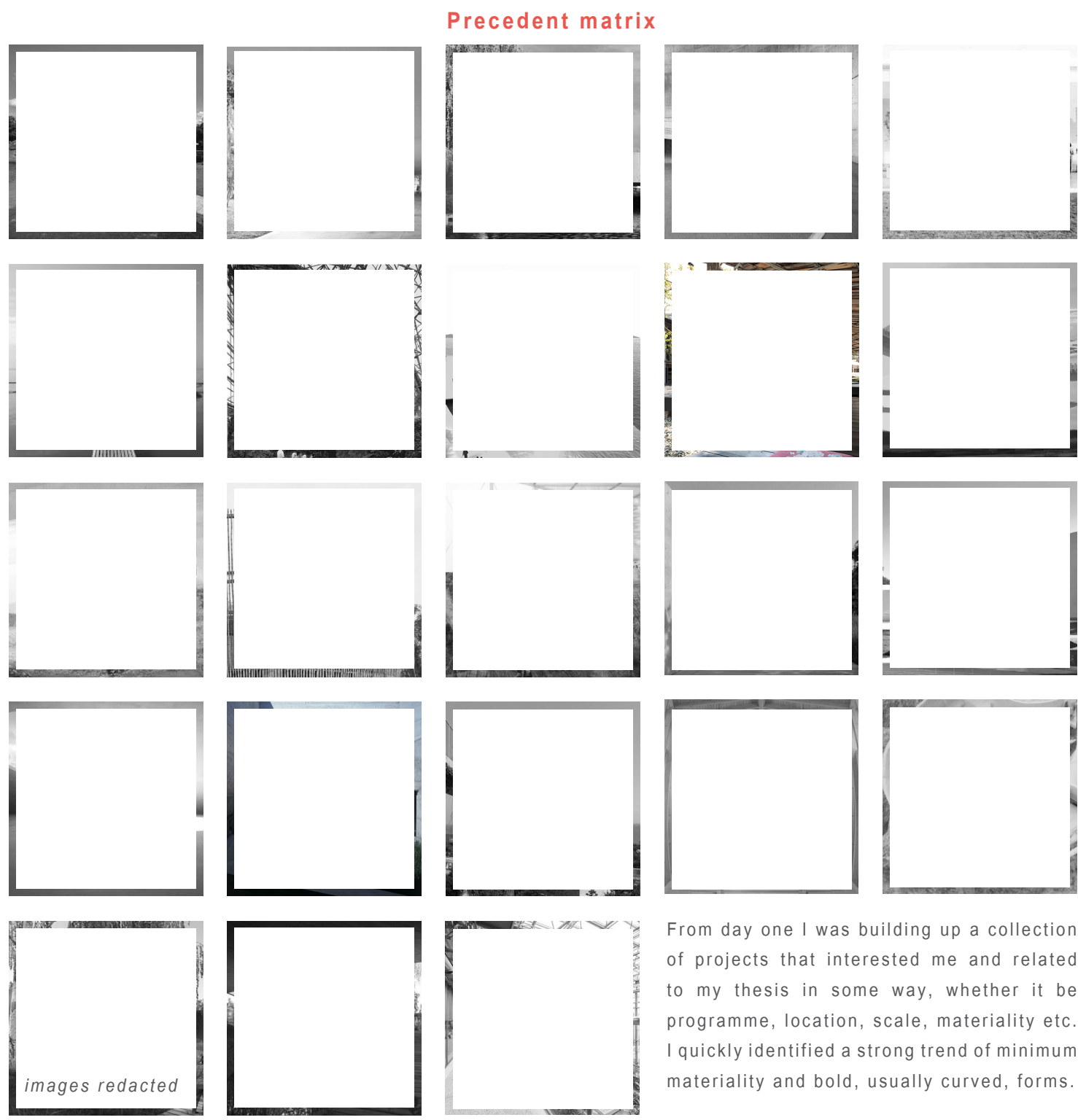

From day one I was building up a collection of projects that interested me and related to my thesis in some way, whether it be programme, location, scale, materiality etc. I quickly identified a strong trend of minimum materiality and bold, usually curved, forms. 

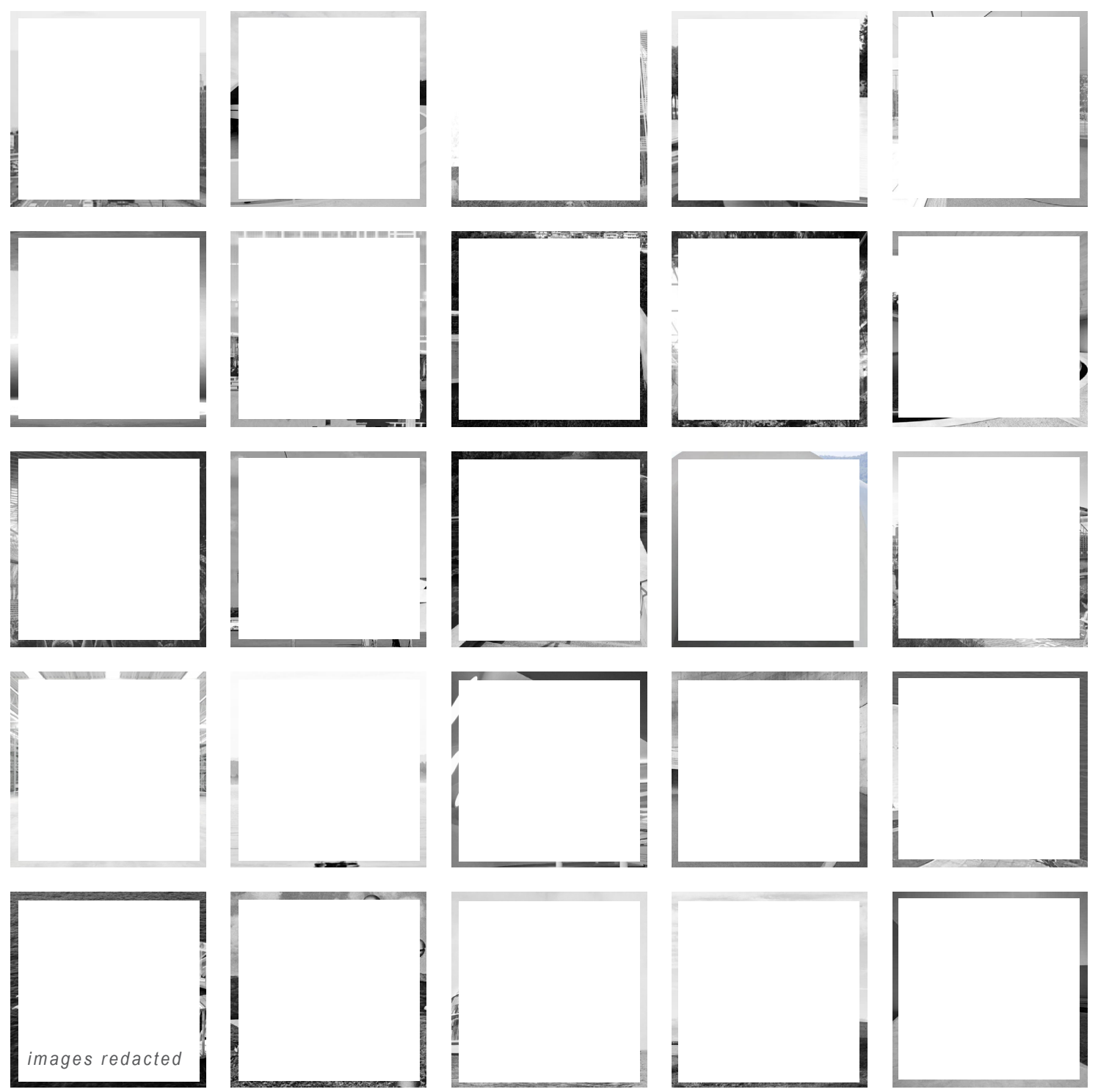
$\left(\begin{array}{ll}4.2 & 02\end{array}\right)$

\section{Key precedents}

My key precedents focus fully on the type of architectural environment I hoped to create. In some ways they are very distant from the practicalities of the actual project, in the sense that they do not share the same programme, scale or purpose as what I am proposing. Although I am proposing an urban farm (among other programmes), none of my key precedents are urban farms. Instead, my three key precedents focus on the formal compositions, feeling and quality of the space that I knew I wanted to capture in my own design. They are all Japanese architectural works that I visited in Japan last year when I was first starting to think about my thesis. They are all spaces that resonated with me and felt so different from any architecture that I had experienced elsewhere. At one scale I was trying to achieve an overall composition that was a dramatic single gesture swiped across the Namie landscape. At the other end of the scale I wanted to create intimate, personal moments similar to what was experienced in person at these projects.

image redacted

Precedent 01: Teshima Art Museum

Teshima, Japan - Ryue Nishizawa 


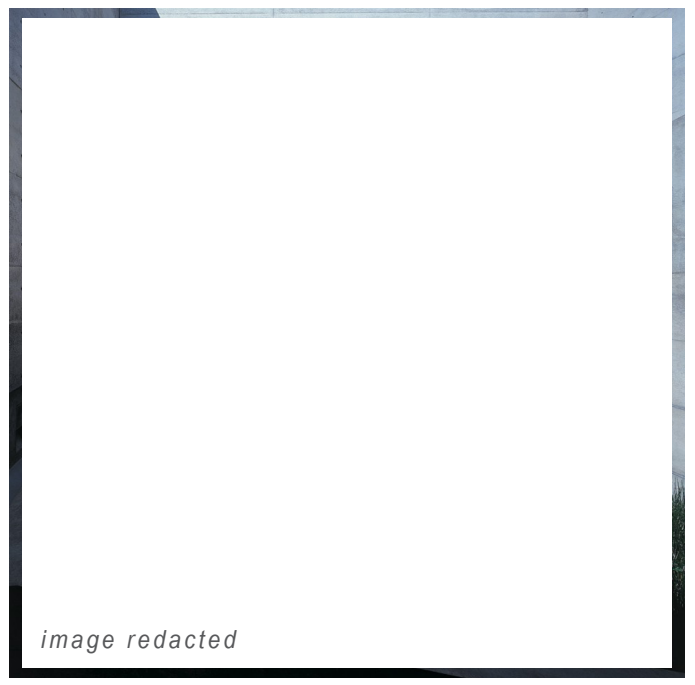

Precedent 02: Chichu Art Museum

Naoshima, Japan - Tadao Ando
The features that drew me to both of these projects are very similar. Both are located within the Setouchi Triennial Islands. These are tiny fishing townships that mirror Namie very closely. These townships were at the centre of a major scandal involving the worst case of illegal dumping of industrial waste in Japan's history (Jodidio \& Ando, 2009). Similar to what we see in Namie, the fishing and agricultural industries (their main source of livelihood) were devastated and these small communities took a heavy blow. The Setouchi Triennial is a series of art and architecture scattered throughout the islands in order to revitalise and bring a new tourism industry to save these towns (Auping \& Tadao, 2002). I liked the optimism that surrounds these projects; the minimalist use of concrete and strong geometry gives the designs a sense of purity that stands out against the rural backdrop, yet seems to make sense within their context. I liked the dramatic effect of the architecture as a whole, which also consciously creates intimate moments and compositions throughout the larger design. 
$\left(\begin{array}{lll}4.2 & 02\end{array}\right)$

\section{Key precedents cont.}

Seemingly more humble than my other two precedents, the Shima Kitchen has a sense of pure, simple design intent that $\mathrm{I}$ feel is at the heart of much minimal Japanese architecture. The design is a rustic canopy that dips right down near the ground, with a simple void in the centre surrounding a tree. It is the sort of design that I feel inspires grander concepts like my other two precedents. It was that clarity and purpose of design intent that I chased throughout my own design exploration, constantly trying to refine my ideas down to a basic concept of surface and void, or light and shadow.

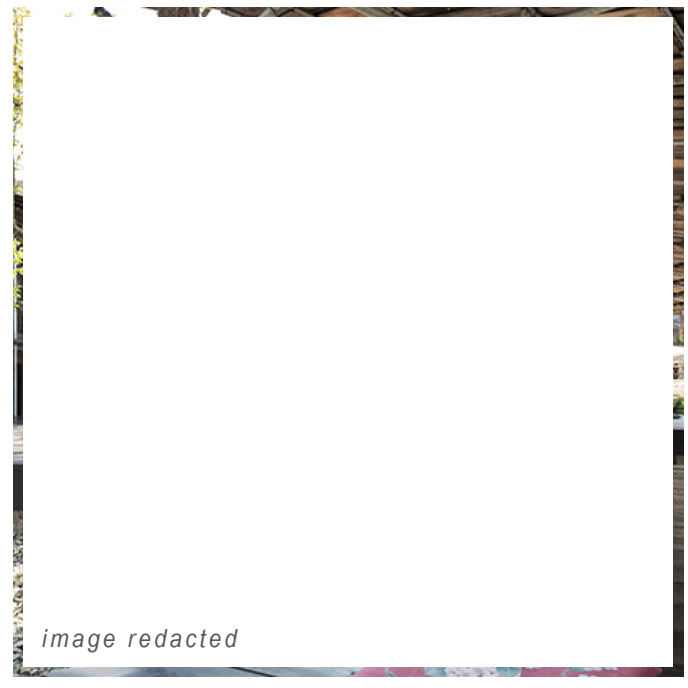

Precedent 03: Shima Kitchen Teshima, Japan - Atelier Ryo Abe Works 


\section{Design phase}

The following sections include images from the final design review and explain in depth the thought process and reflect on the range of explorations I went through to uncover each part of this design. 
SECTION 05: SKETCH PROCESS

Throughout my thesis I used sketching as a tool to quickly explore / record design ideas as they came to me. This sketching ran concurrently with the other design explorations presented in the final pin-up, from day one through to my final render. The majority of my sketches are for my own understanding, as a way to feel out or process ideas, and often may do little to represent an idea to an outside party. For this reason I have collated a sample of all my sketching throughout the year into one succinct section of this thesis. A sample of sketches from each key stage of this project has been included and annotated to provide better understanding of this informal, personal form of design exploration. 


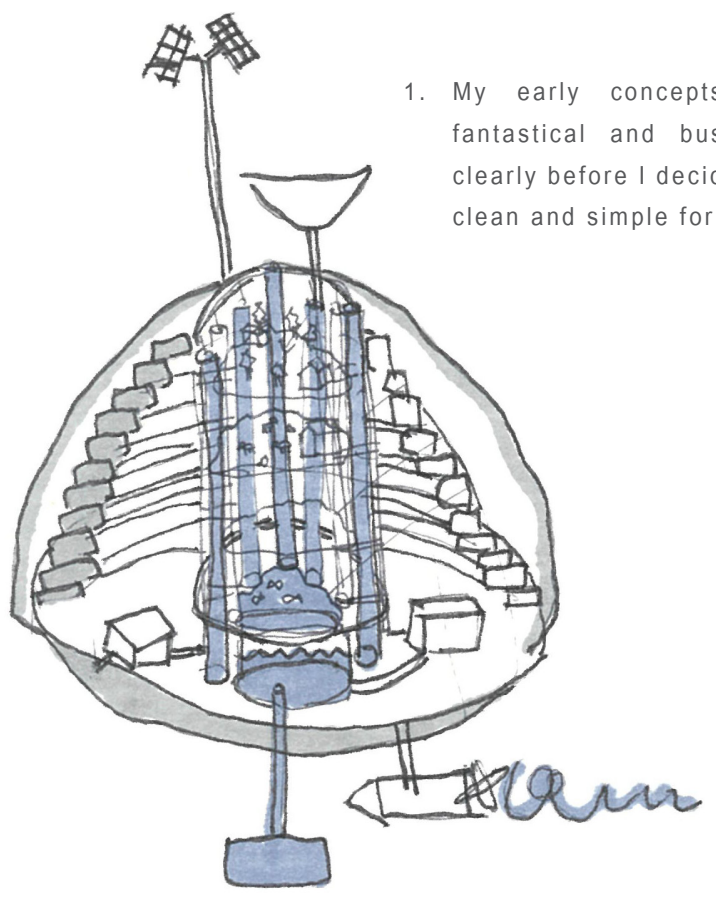

My early concepts were very fantastical and busy. This was cided I wanted a ean and simple formal language.

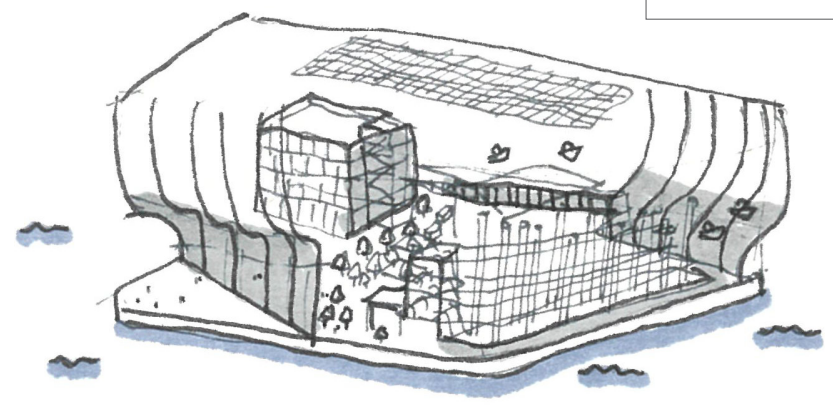

\subsection{Early concepts}

2. They mainly consisted of various programmes inside of a blobby bubble. There was an obvious lack of architectural intent.

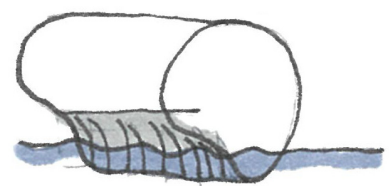

4. This sketch (above) was the first time I tried to play around with the form of the outer shell but there was still a lack of a vision.

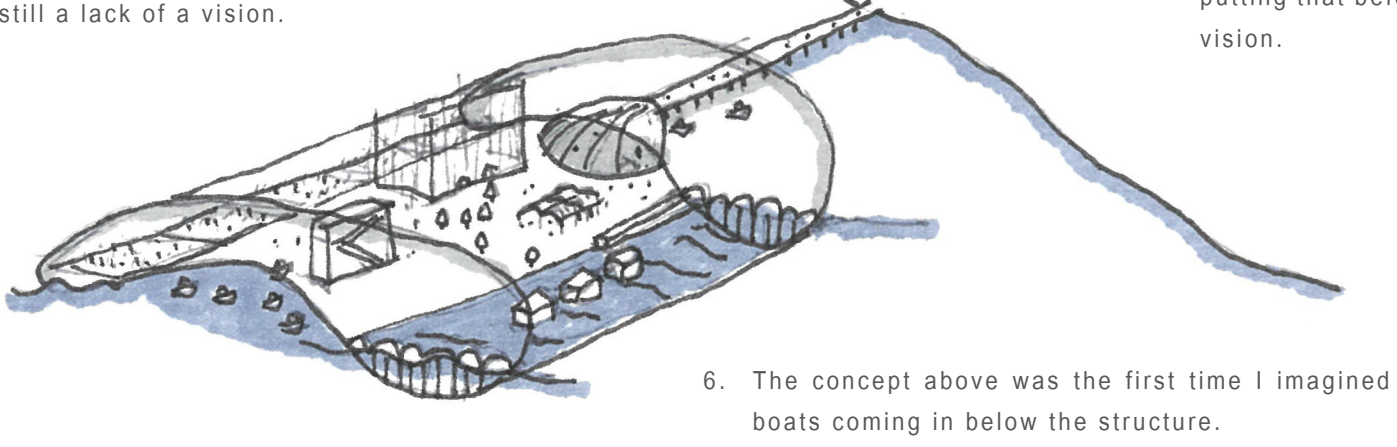

5. I was very caught up with the programming and I was misguidedly putting that before an architectural had the idea of having a form that did not sit flat on the surface of the water.

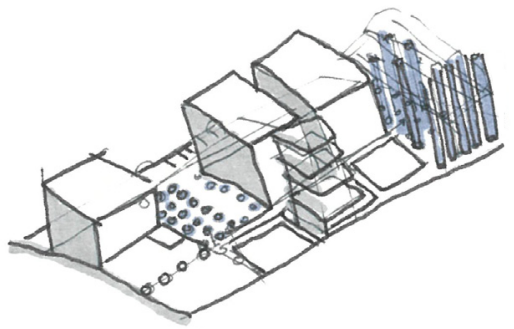



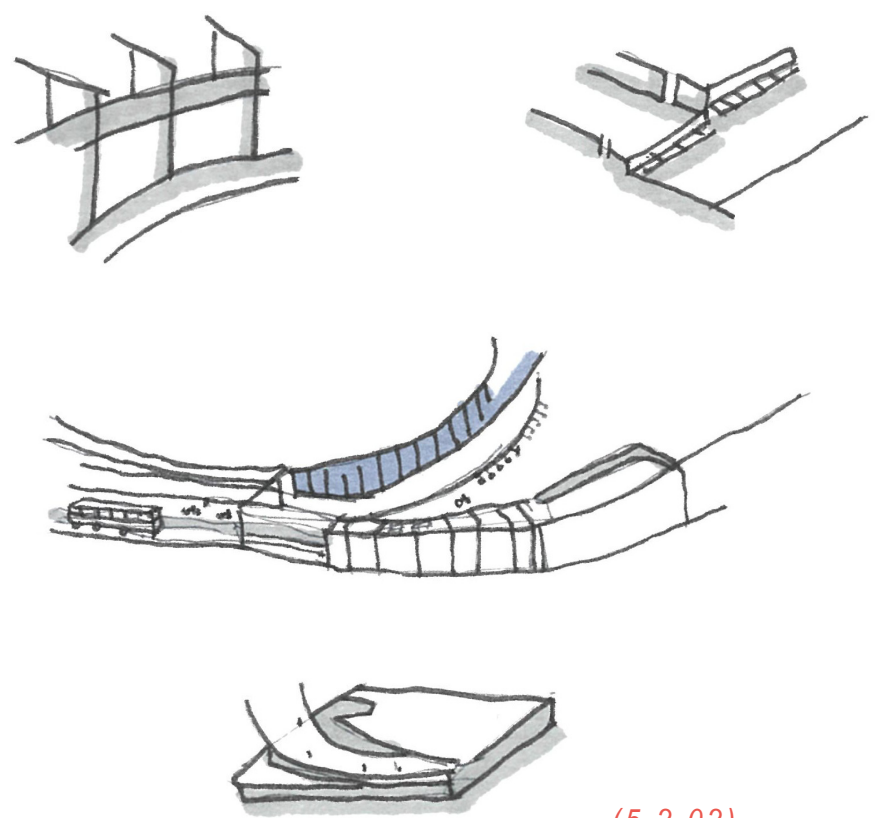

$\left(\begin{array}{lll}5.2 & 02\end{array}\right)$

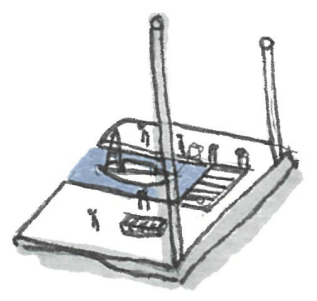

Interior spaces
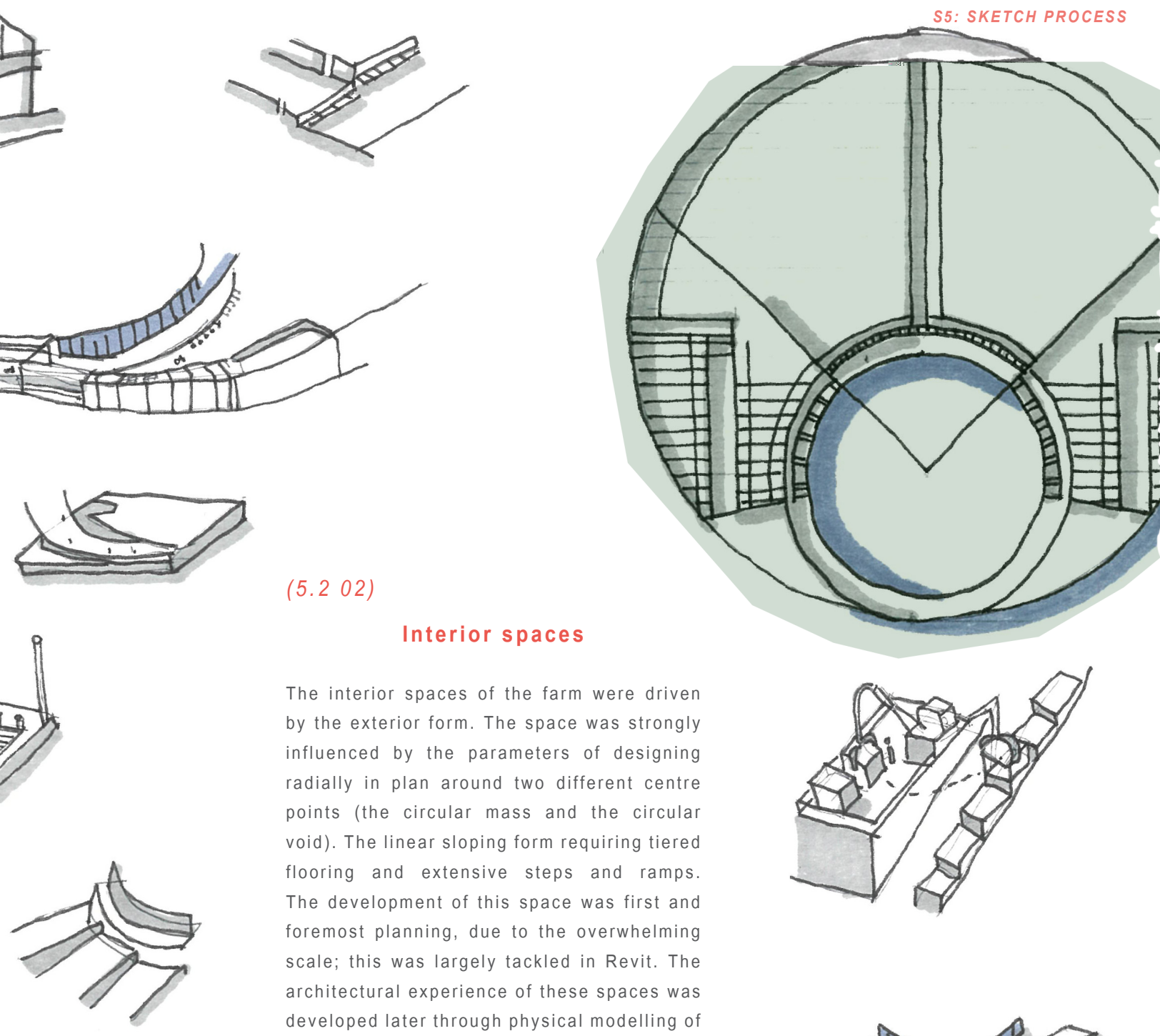

The interior spaces of the farm were driven by the exterior form. The space was strongly influenced by the parameters of designing radially in plan around two different centre points (the circular mass and the circular void). The linear sloping form requiring tiered flooring and extensive steps and ramps. The development of this space was first and foremost planning, due to the overwhelming

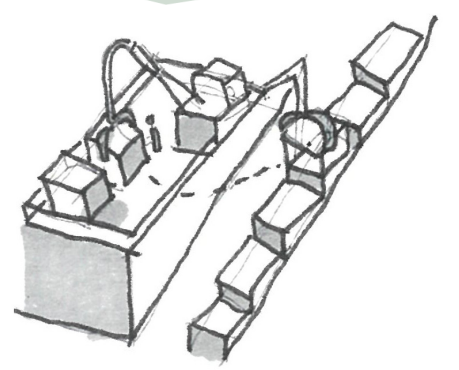
scale; this was largely tackled in Revit. The architectural experience of these spaces was developed later through physical modelling of smaller spaces.
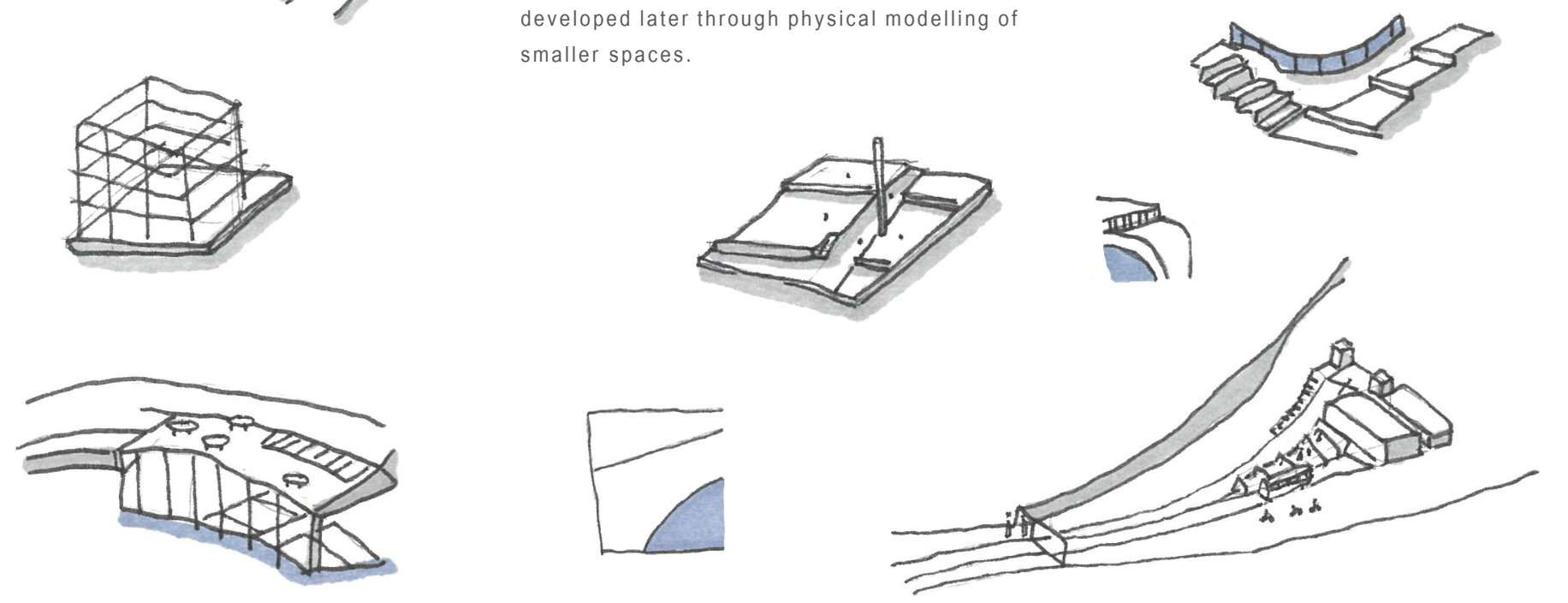

(Figure 35) 


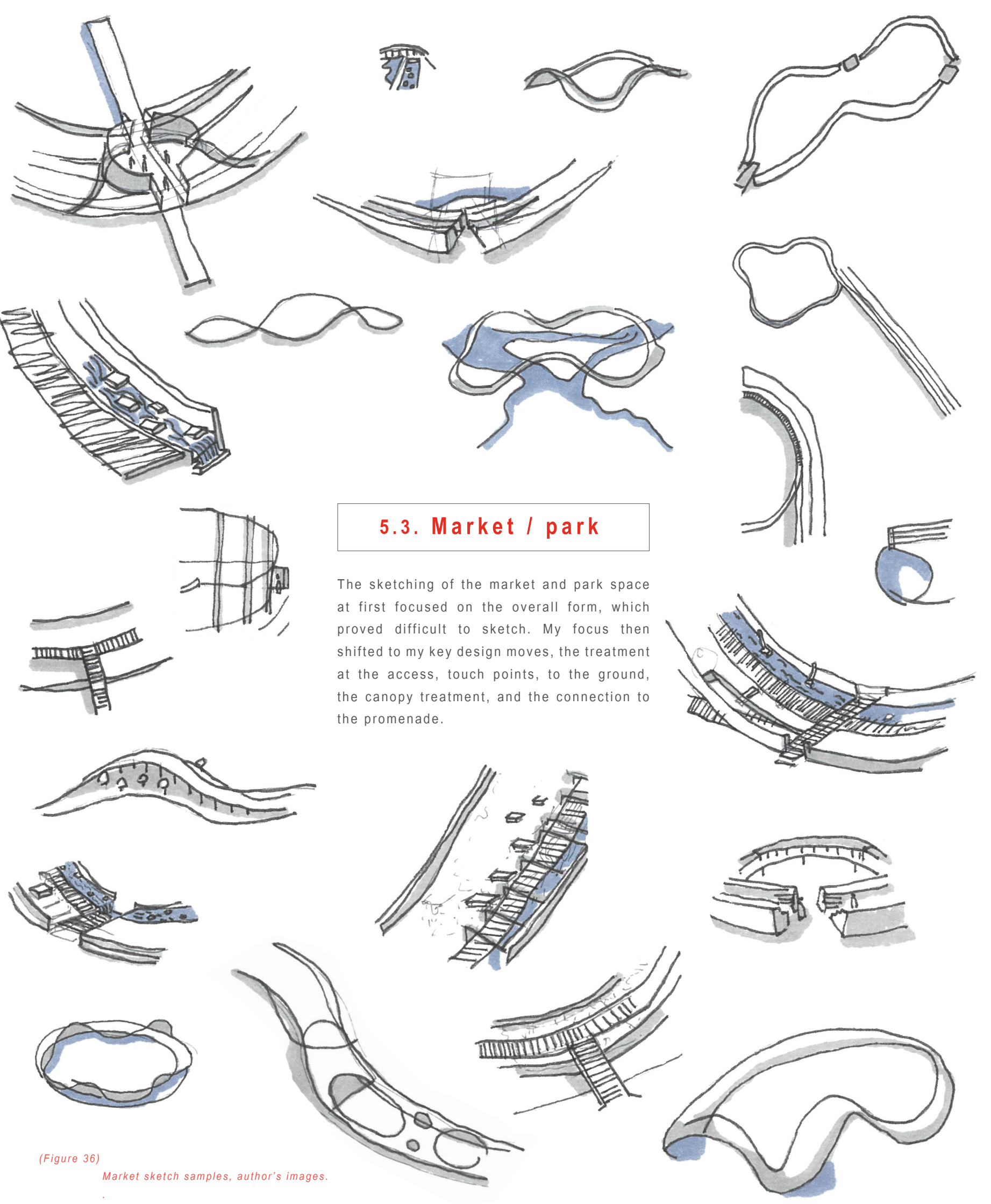


0000
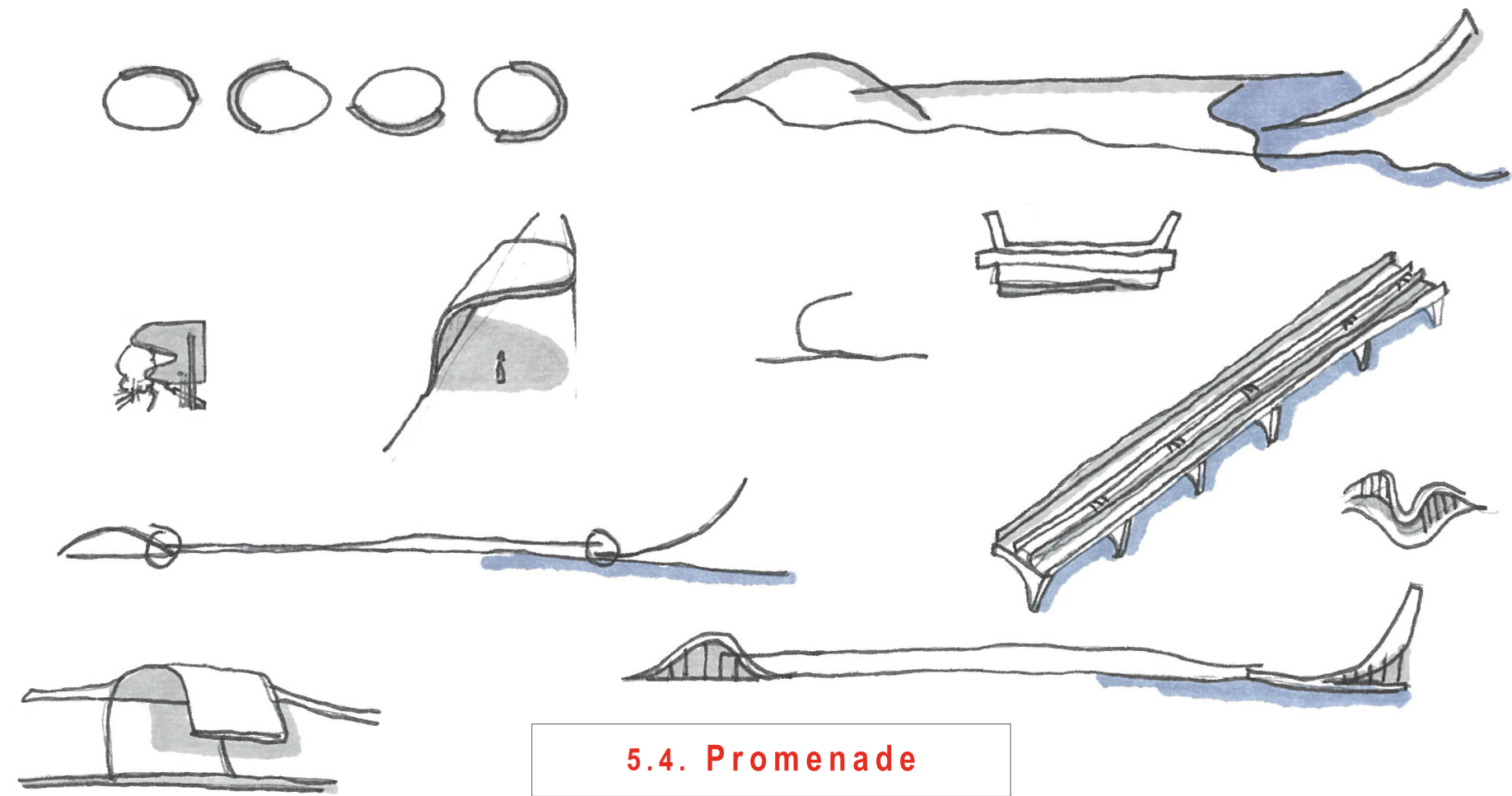

\subsection{Promenade}

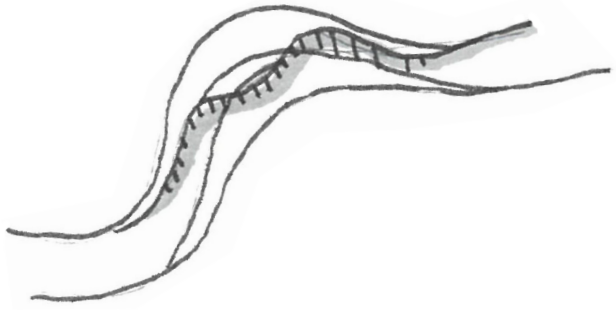

The sketches of the promenade capture the dual focus of the thesis. Half of the sketches show how I was focused on detailing the canopy and balustrade treatments along the journey of the promenade (the human scale) before I removed this from the final detailed scope. The other sketches show how the promenade plays into the overall site composition, developing from an arc to

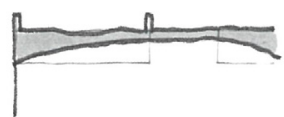
a delicate linear line that links the forms at each end (the megascale).
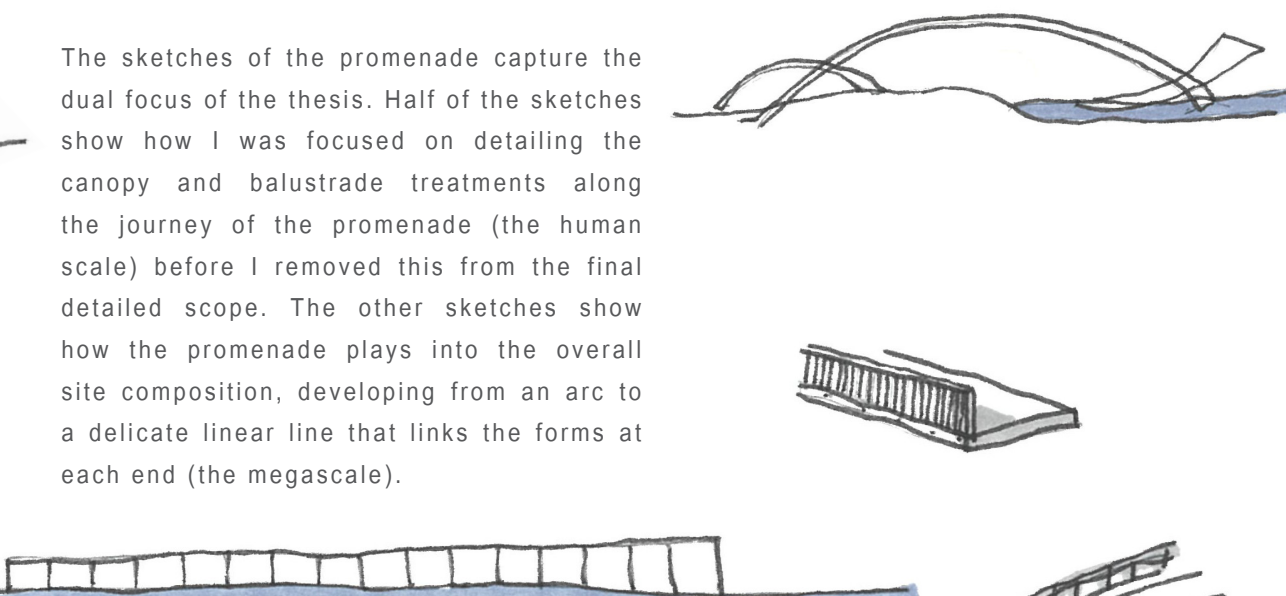
SECTION 06: FORM EXPLORATIONS

\subsection{Form-finding 01}

A few key points led me to begin my initial formfinding exploration:

1. The lack of shape in my early sketches suggested I needed to identify a focused formal intent.

2. My sketching led me to a concept where the form slopes up off the water. However, I was struggling to fully explore this in $2 \mathrm{D}$.

3. My precedent matrix showed I was naturally being drawn to circular forms and voids.

4. My exploration of Japanese calligraphy and other illustrations inspired me to pursue a very simple deliberate formal gesture.

Based on these points I decided I wanted to do a very simple exploration where I cut out 15 circles of paper and manipulated the paper in the simplest ways to come up with a basic formal gesture around which to centre my design development. 


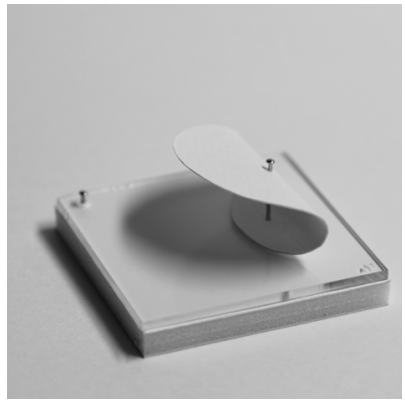

FFA1

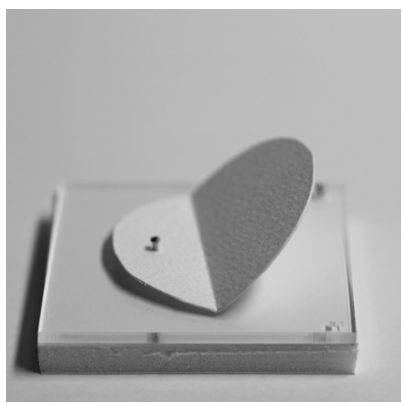

FFB1

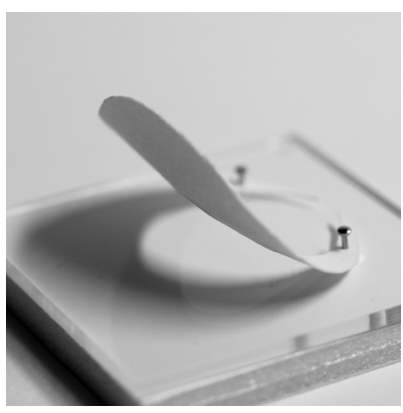

FFC 1

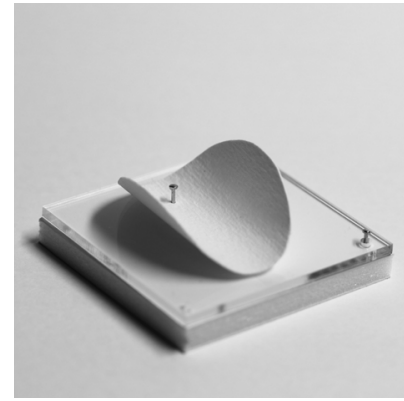

FFA2

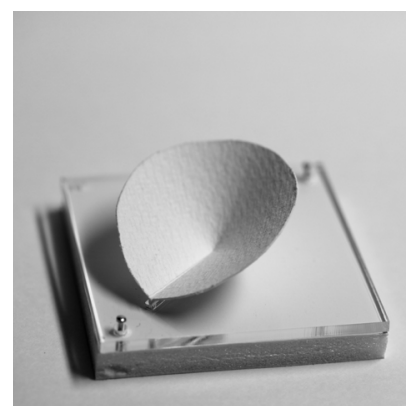

FFB2

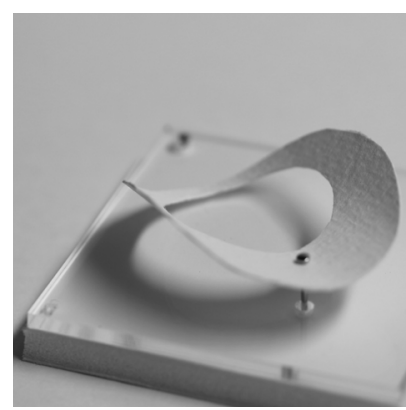

FFC2

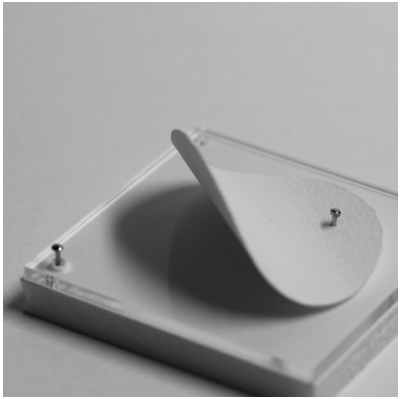

FFA3

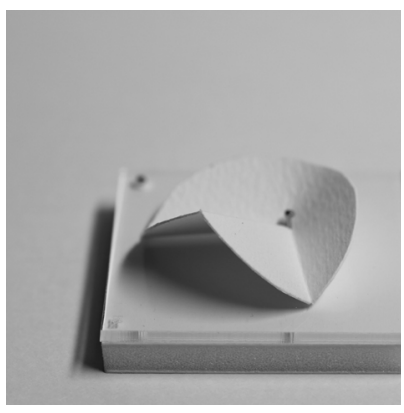

FFB3

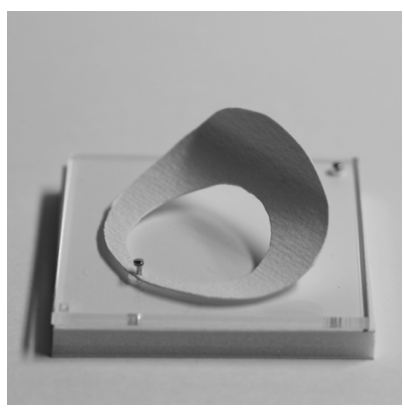

FFC3 


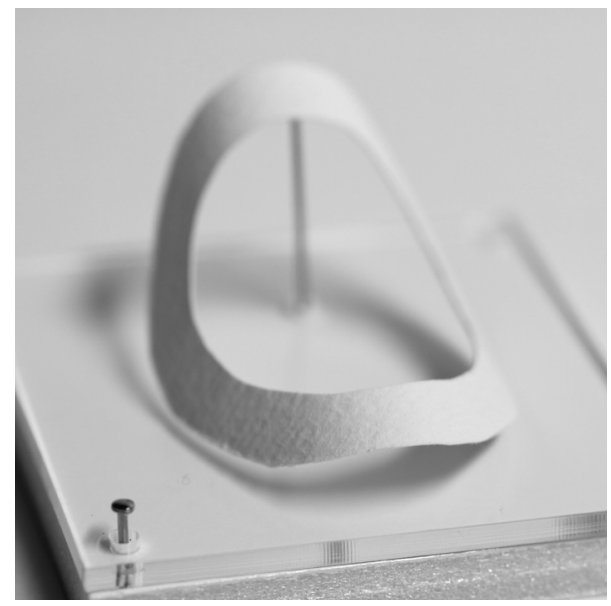

FFD 1

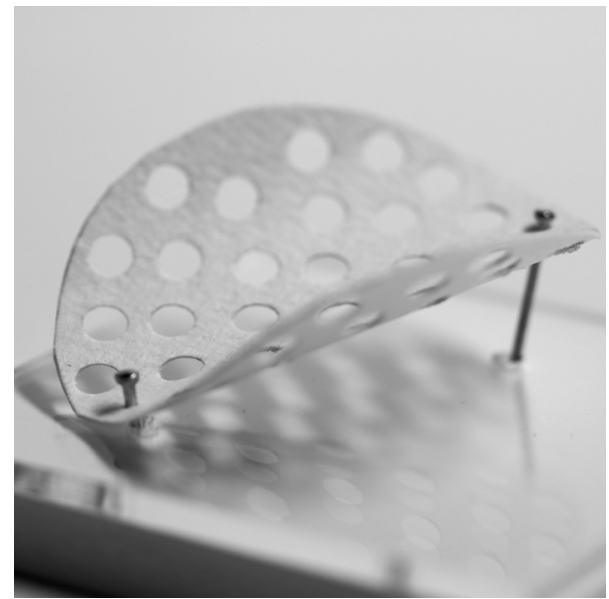

FFD3

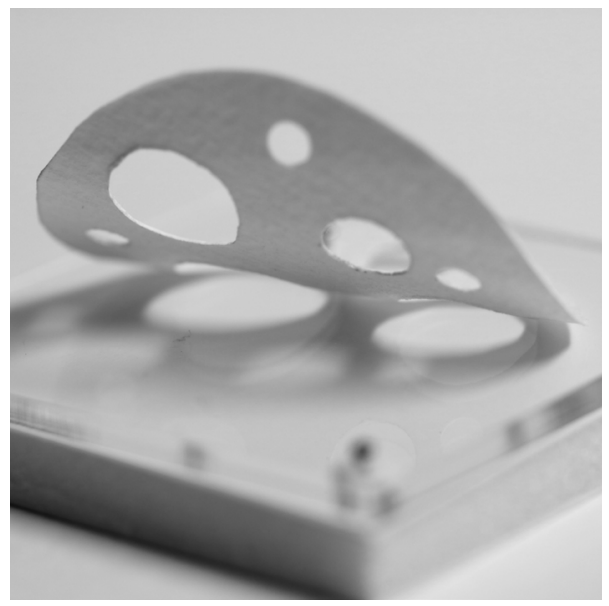

FFD2

solid / void

light / shadow

surface / reflection

I was captivated by how the voids would allow circular pools of light to cast across the base. The clear acrylic also created a very subtle reflection. These elements, the mass, void, light, shadow and reflection combined in different ways from each angle, affecting the composition of each photograph. I knew from this point that I wanted to create similar effects across the surfaces of my final perspectives. 


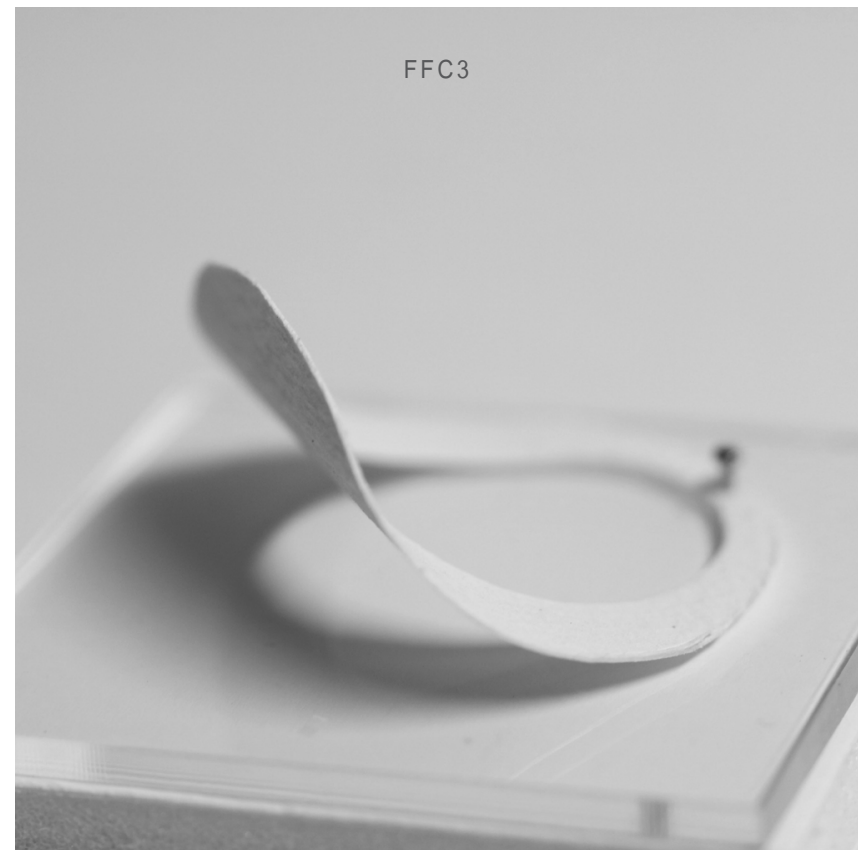

I ended up being most drawn to iteration C3. I liked how the large void created a defined pool of light below the mass, and how this created a feeling of a bay on the water surface for the fishing dock programme. I had a strong vision of the mass swooping up just high enough for the boats approaching to pass below into this void space. I also liked the strength of the vertical swooping gesture and how it was gravity defying. This played into my concept of the architecture being both a monumental and hopeful gesture across the landscape. I had a clear vision of how this would face the shoreline and would create a semicircle silhouette when viewed from the land (refer to fig.67, pg.94). 


\section{Fishing dock}

I used the last series for the 15 form-finding models to take three of the manipulations from the other 12 and pair them with different forms for the fishing dock. I found that this added an additional element to the interesting light, shadow and reflect play on the surface. For this reason I was drawn towards the very slender option because it left the most open surface for reflections while still dramatising the effect by framing it.

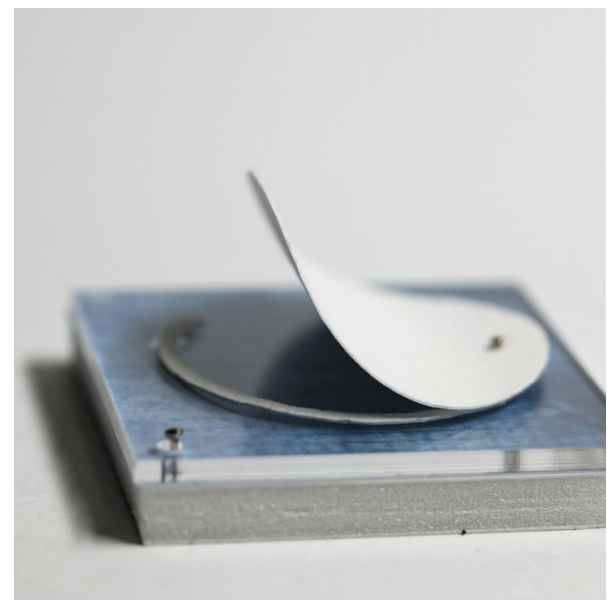

FFE2

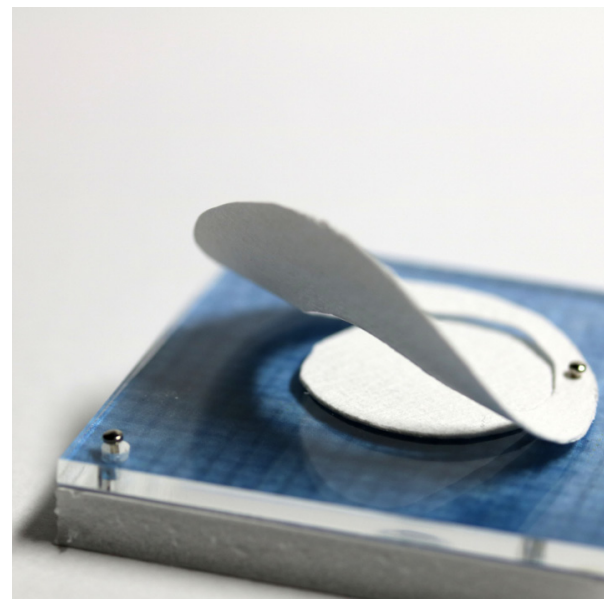

FFE1

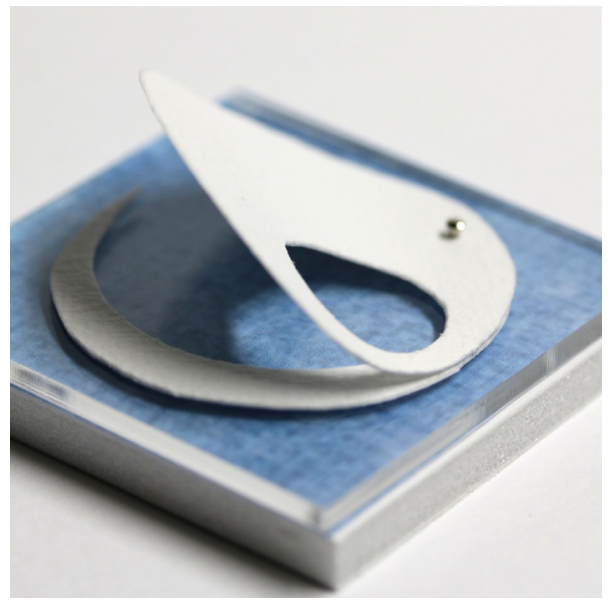

FFE3 


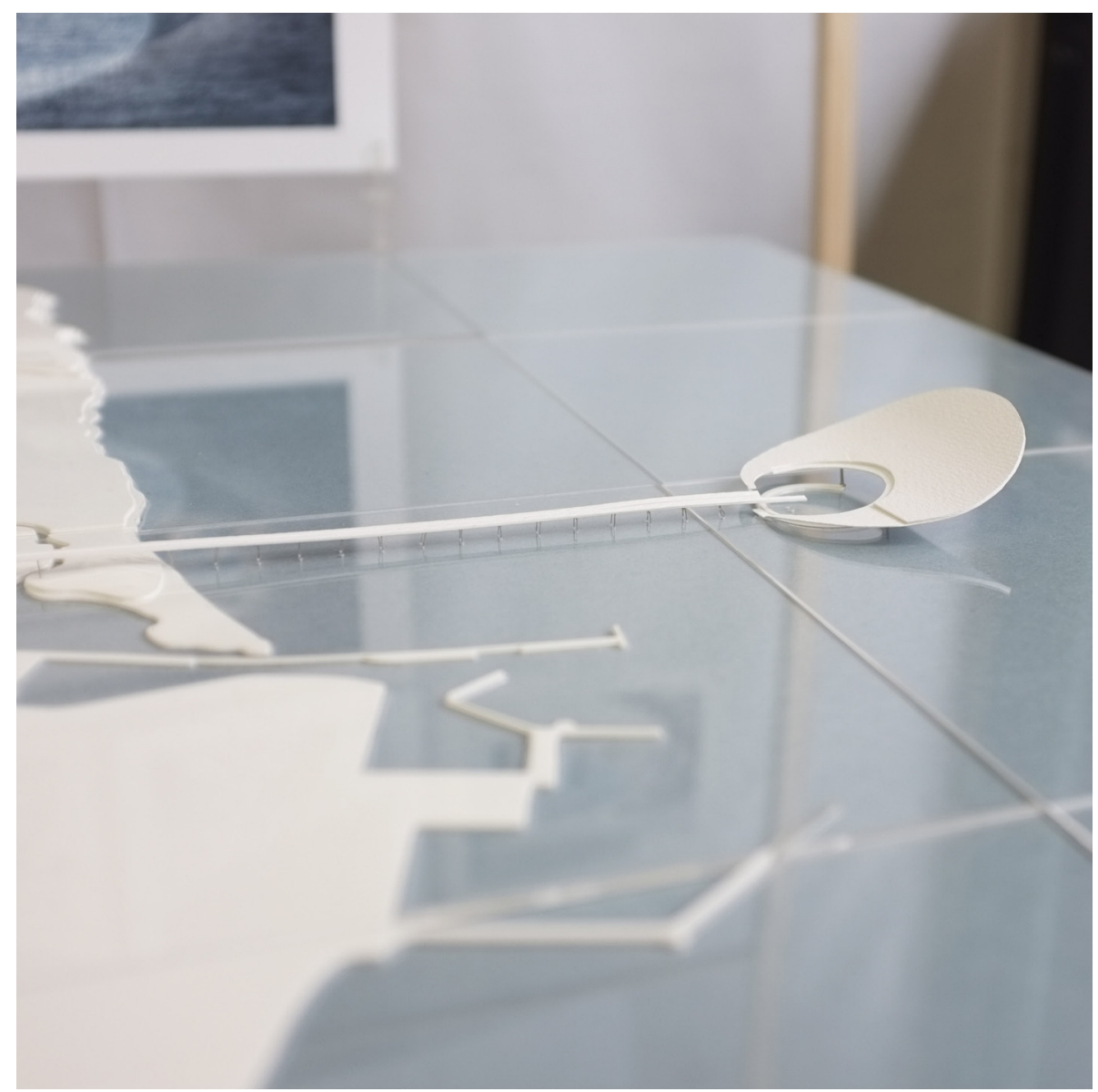




\subsection{Form-finding 02}

\section{Critique 01 - reflection}

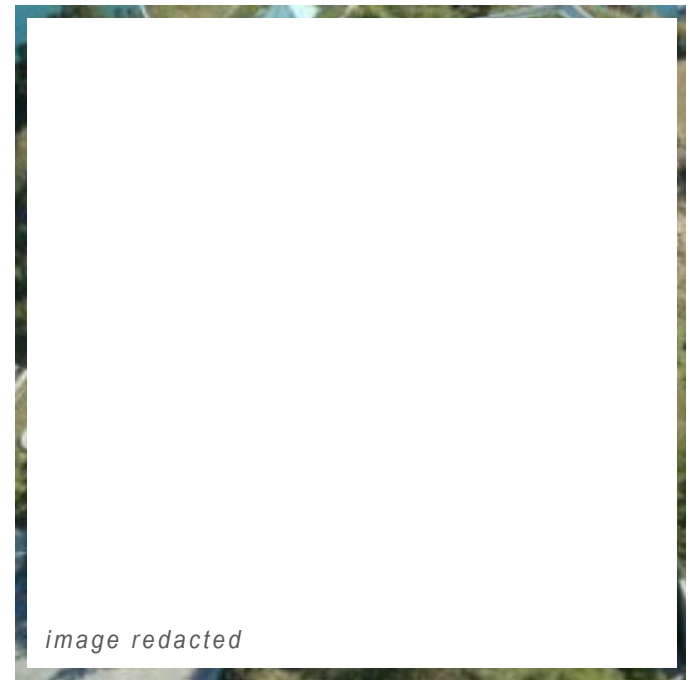

Precedent 02: Chichu Art Museum Naoshima, Japan - Tadao Ando
The first critique's feedback supported that the project scenario and the selection of initial programmes were justified. The main criticism was that although some of the programmes intuitively suited being offshore, such as the fishing hub and desalination plant, it created a 'dead end' design whereby the residents could not simply pass by and experience the architecture as part of day-today routine. It was encouraged that some of the programmes be brought inland to engage with the people living in the town, as they were the justifying inspiration for the project. I took this feedback as an opportunity to introduce a sixth programme to address the issue of the contamination of the river (once the natural and recreational heart of the town). I decided that a structure would bridge the confluence of the river and house the public green space and fresh produce market, linked to phase one of the design by a promenade and roadway. 
Inspired by many strong, geometric architectural precedents I wanted the overall composition of the two structures to have a satisfying yin \& yang type relationship. Where the phase one design was around $3 / 4$ mass to $1 / 4$ void I wanted phase two to be about $3 / 4$ void. In plan I wanted the structure to read as equal and opposite designs. My idea originally was that the phase two structure would be a smaller shell (roughly half size) with a steeper inverted gradient.

I made the decision to take the manipulations from my first form-finding experiment and, where they were manipulated in one direction, I would manipulate the second explorations in two directions. This was inspired by the river confluence. I had the idea that the structure would touch down on each of the three banks, creating a series of archways reflected over the river below.

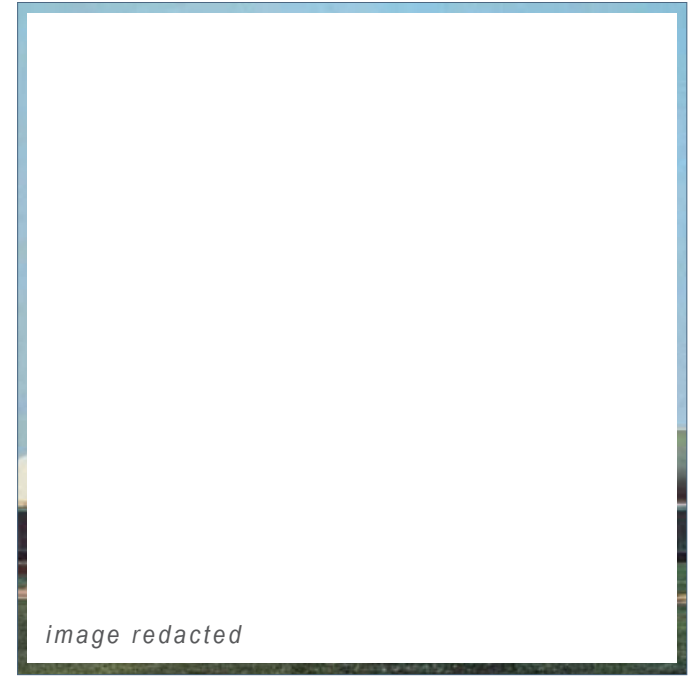

Precedent 04: Brazilian National Congress Brasília, Brazil - Oscar Niemeyer 
FORM-FINDING 02

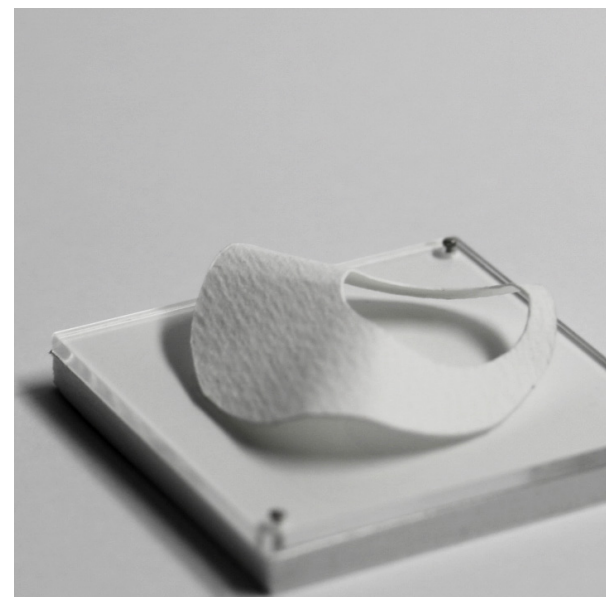

FFF1

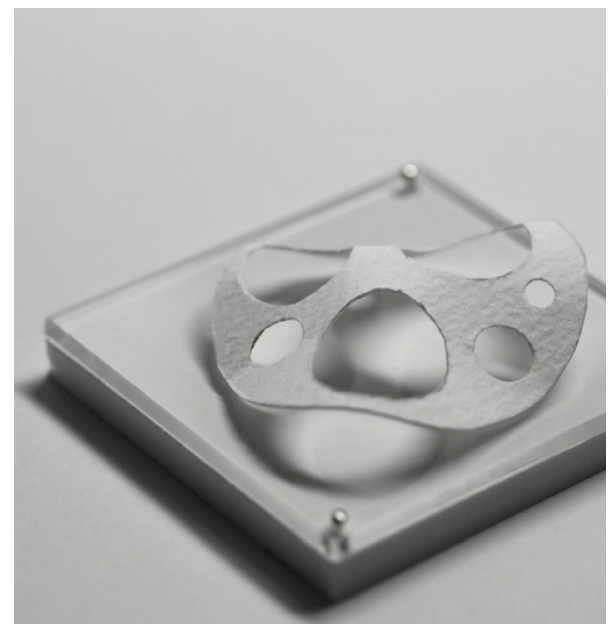

FFF3

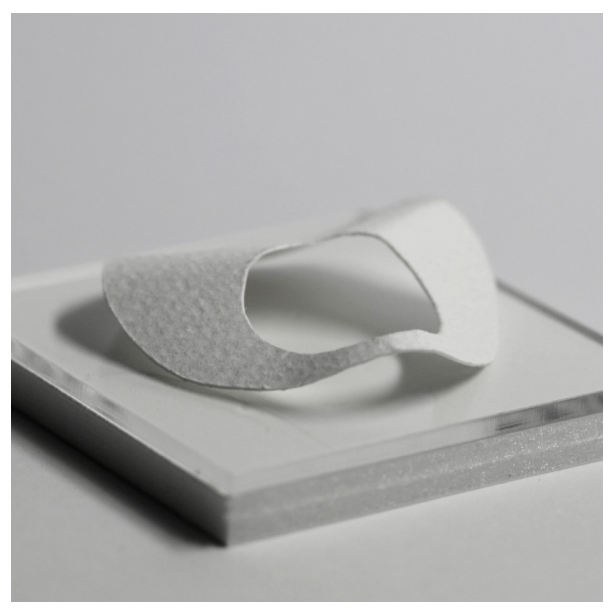

FFF1

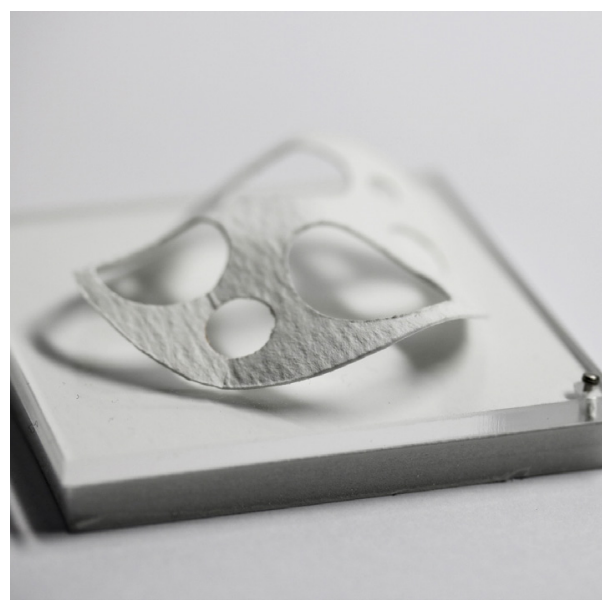

FFF3 


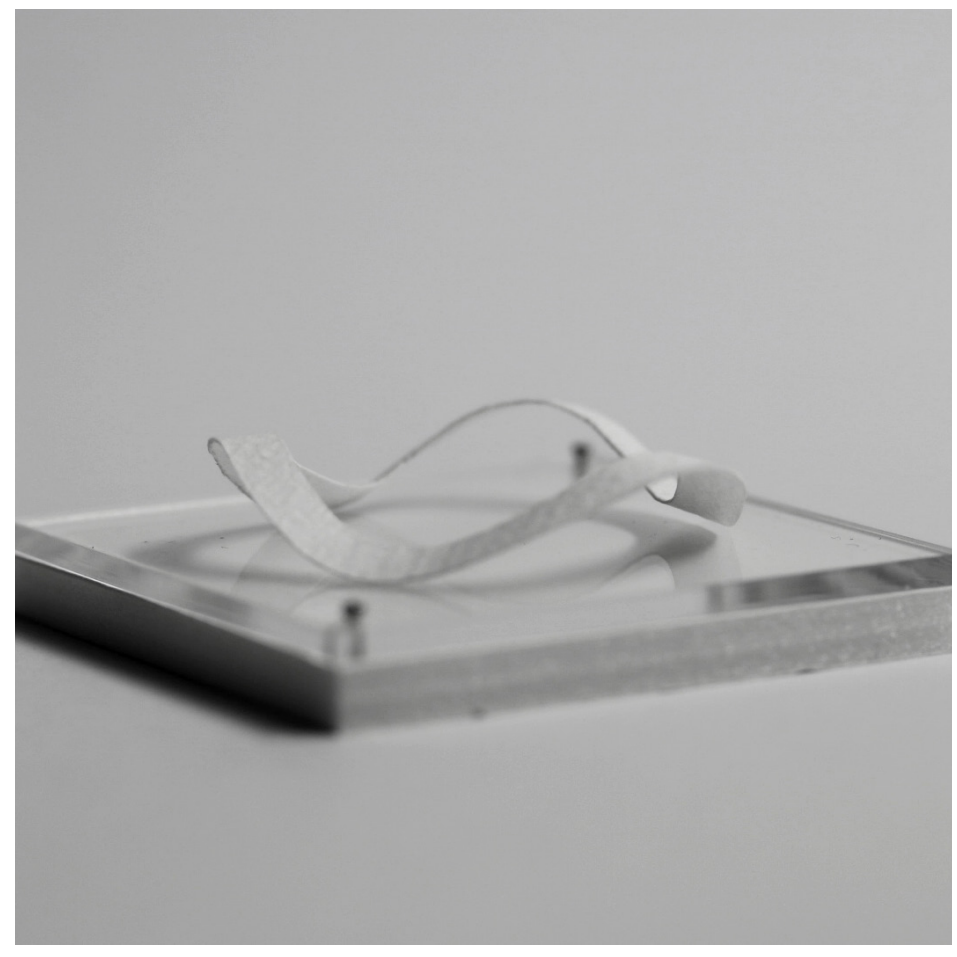

FFF2

I decided to proceed with a thin band because it had the mass to void proportions I was looking for. However, I further developed this to have one heavier edge for more park space (refer to fig.53, pg.76). The band was also best suited to being manipulated in more than one direction and threw the most dramatic reflections in the photos which would be seen clearly on Namie's wide flat river surface. 


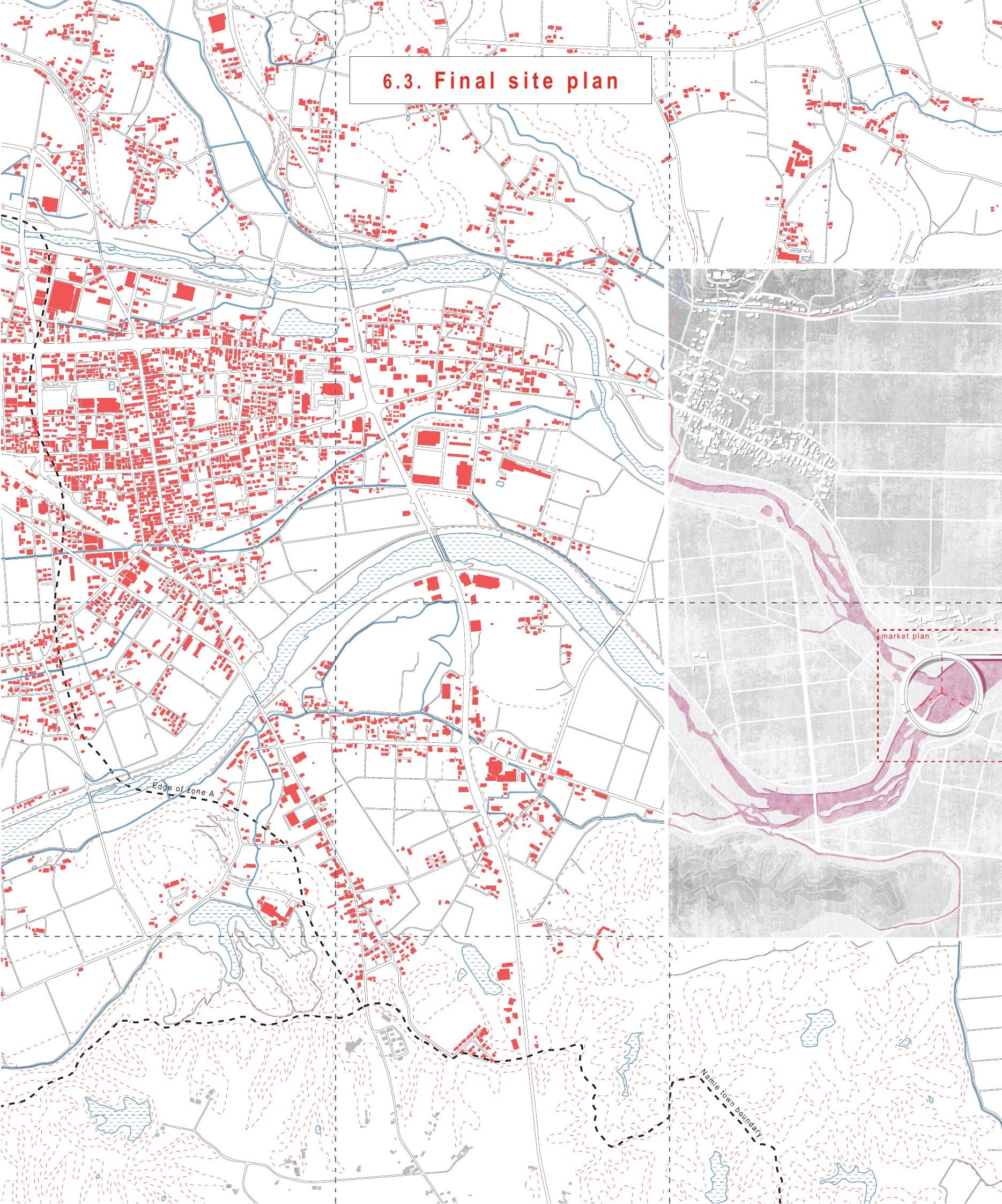




\subsection{Urban farm plan}

I spent a month or two fully developing the overall planning of the urban farm / fishing dock structure. There were a few issues to address from the beginning:

1. Due to the shear scale of the structure, and the size of the void at the entrance $(200 \mathrm{~m}$ dia.) I felt as though both sides of the void would need to be accessible on foot rather than having to circulate right around. This made the design a reflected plan which I found very dull and quickly moved on from.

2. I was having trouble with paths crossing between the delivery vehicle access and the pedestrian access. In line with splitting up the symmetrical nature of the plan I decided to have the right side accessed by pedestrians and the left side serve as the loading area for trucks.

3. This meant that workers in the urban farm factory would have to circulate right around the void to access their work stations. I combatted this by specifically addressing the experience of this circulation ring in my final renders.

4. Similarly, $I$ split the fishing and farming programmes to have clear separation of working types, with the fishing being on sea level, below the access ramp for the farming. 


\subsection{Axonometric programme}

\section{ACCESS}

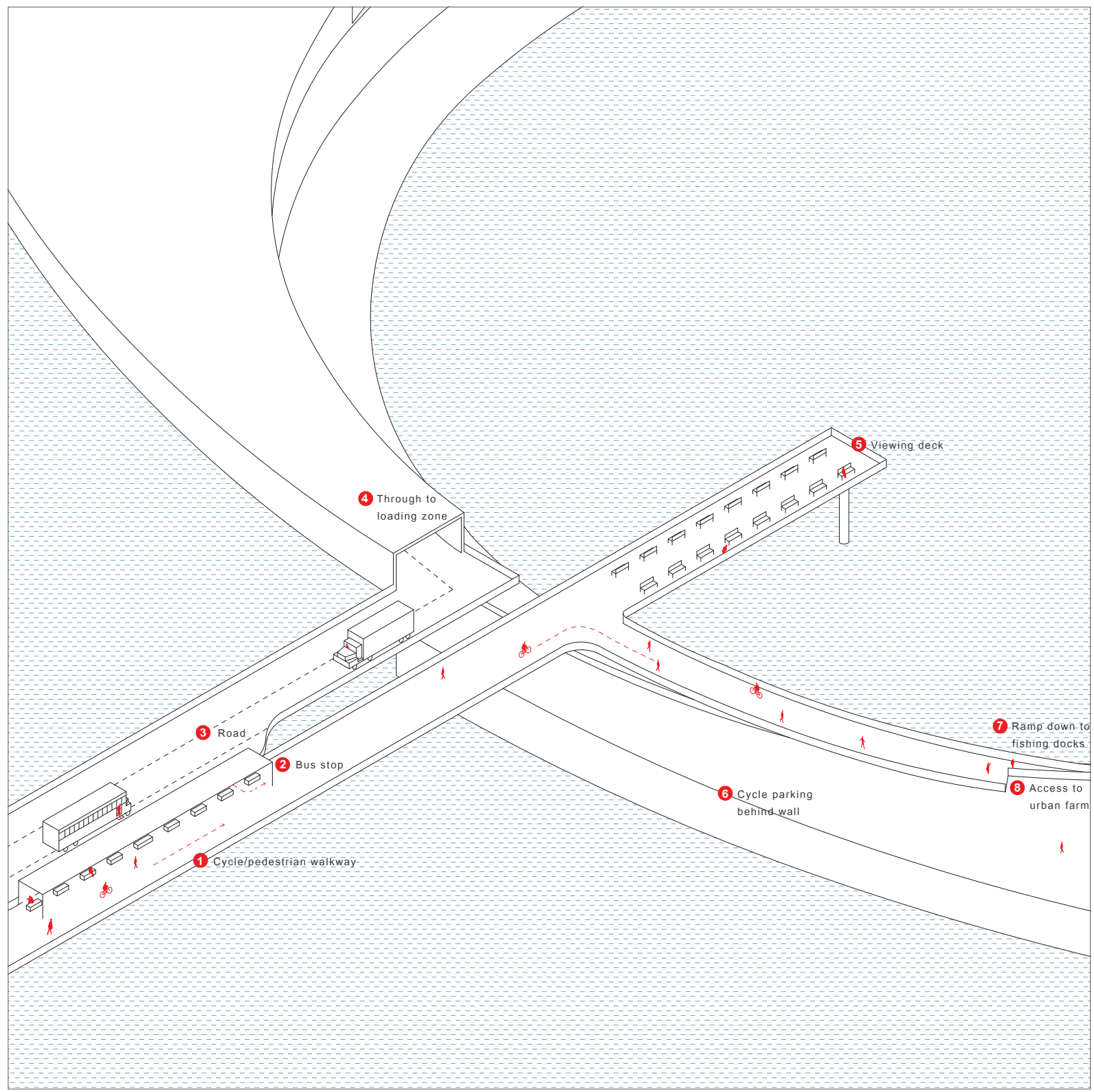

The key focus of this space was separating the vehicle and pedestrian flow and creating an attractive approach to both the urban farm and fishing levels. 


\section{ENTRY}

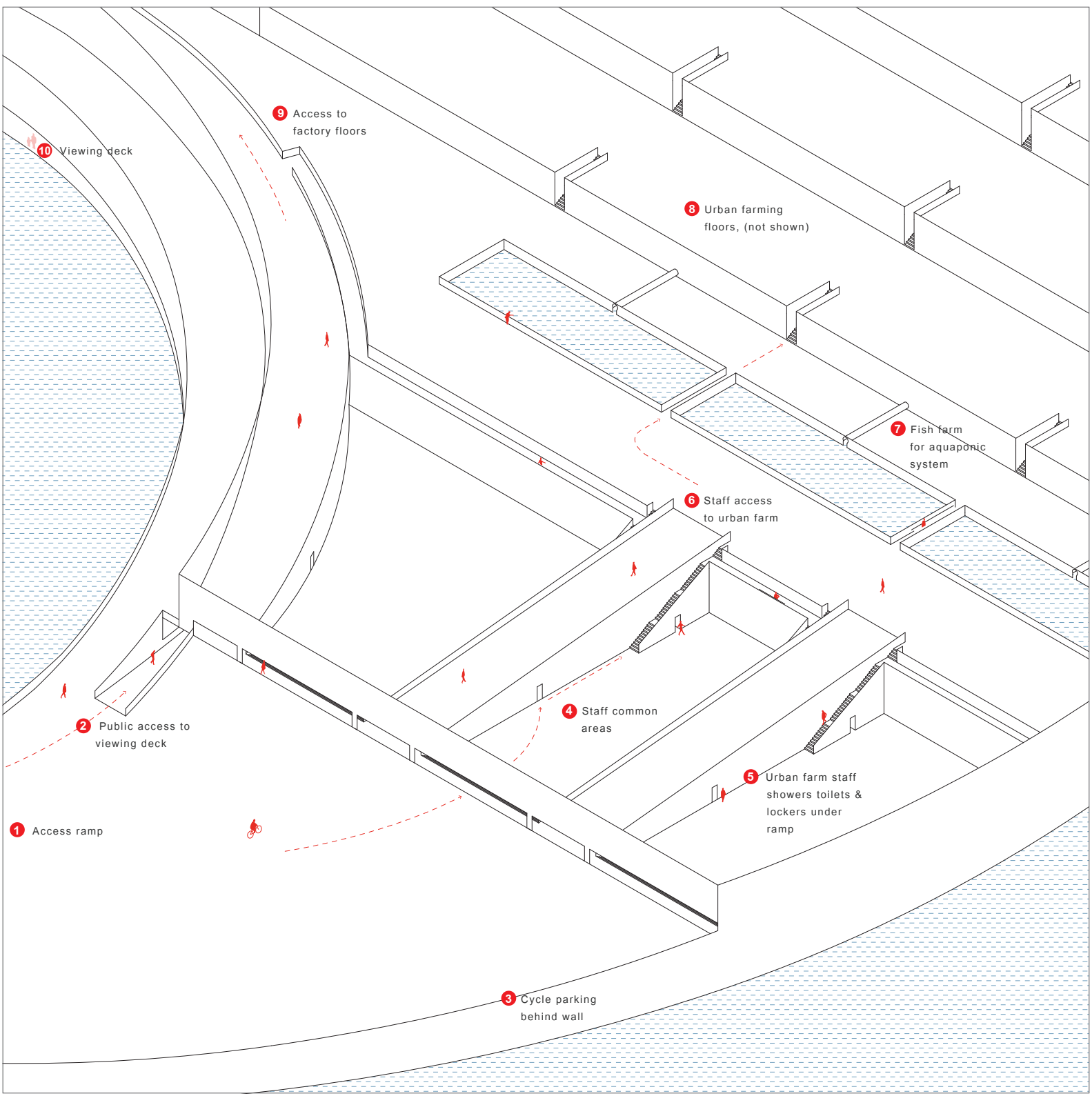

The focus here was creating a buffer zone when workers first enter the urban farm space where they shower and suit up for sanitary work conditions. 


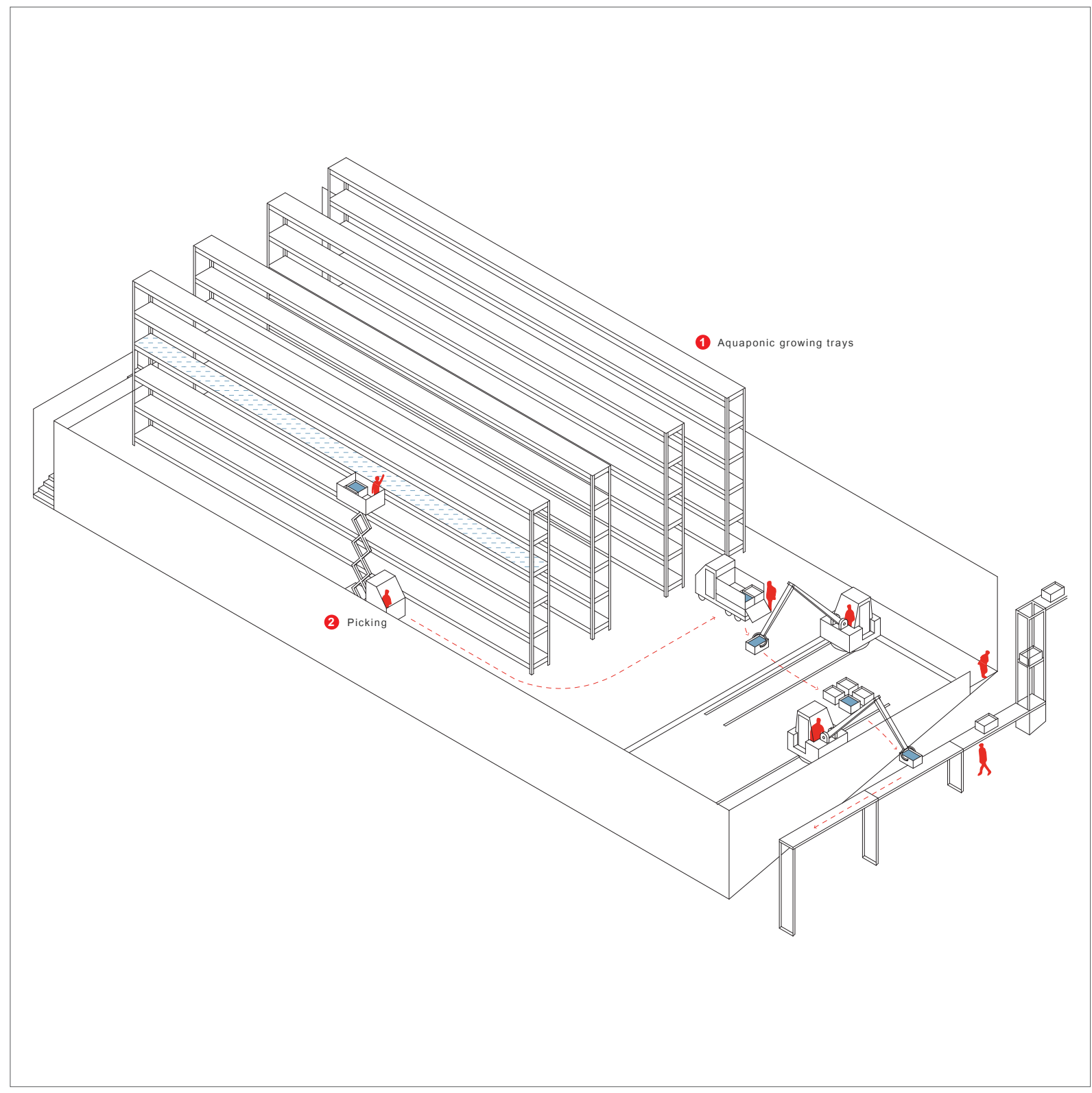

The urban farm floors are tiered up the slope of the main body of the structure. This is an artificially lit, climate-controlled space based on existing models. 


\section{FACTORY}

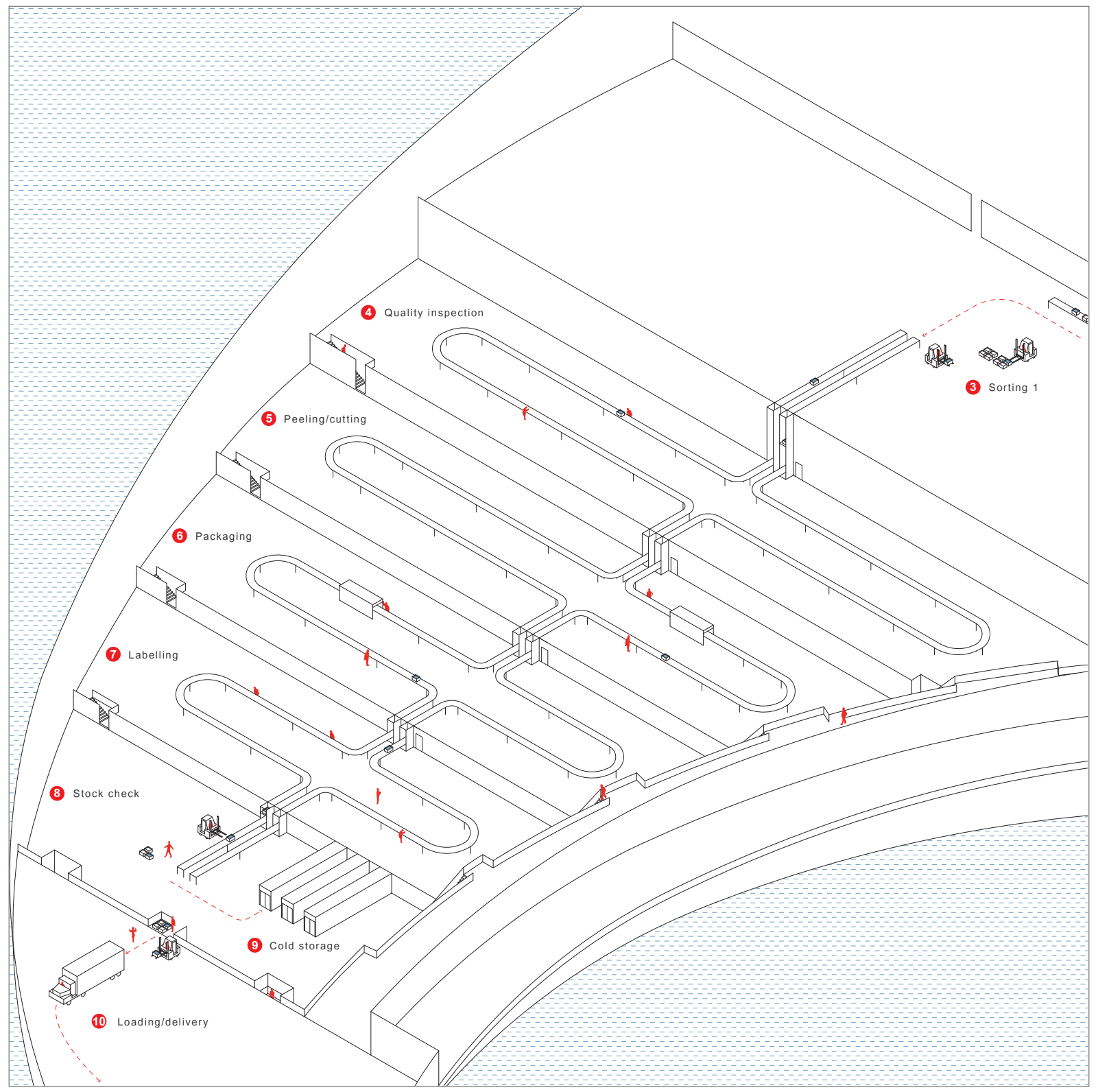

The farming floors feed directly to the factory floors where processes are taken to prepare the produce for delivery to the fresh produce market in town. 


\subsection{Market plan}

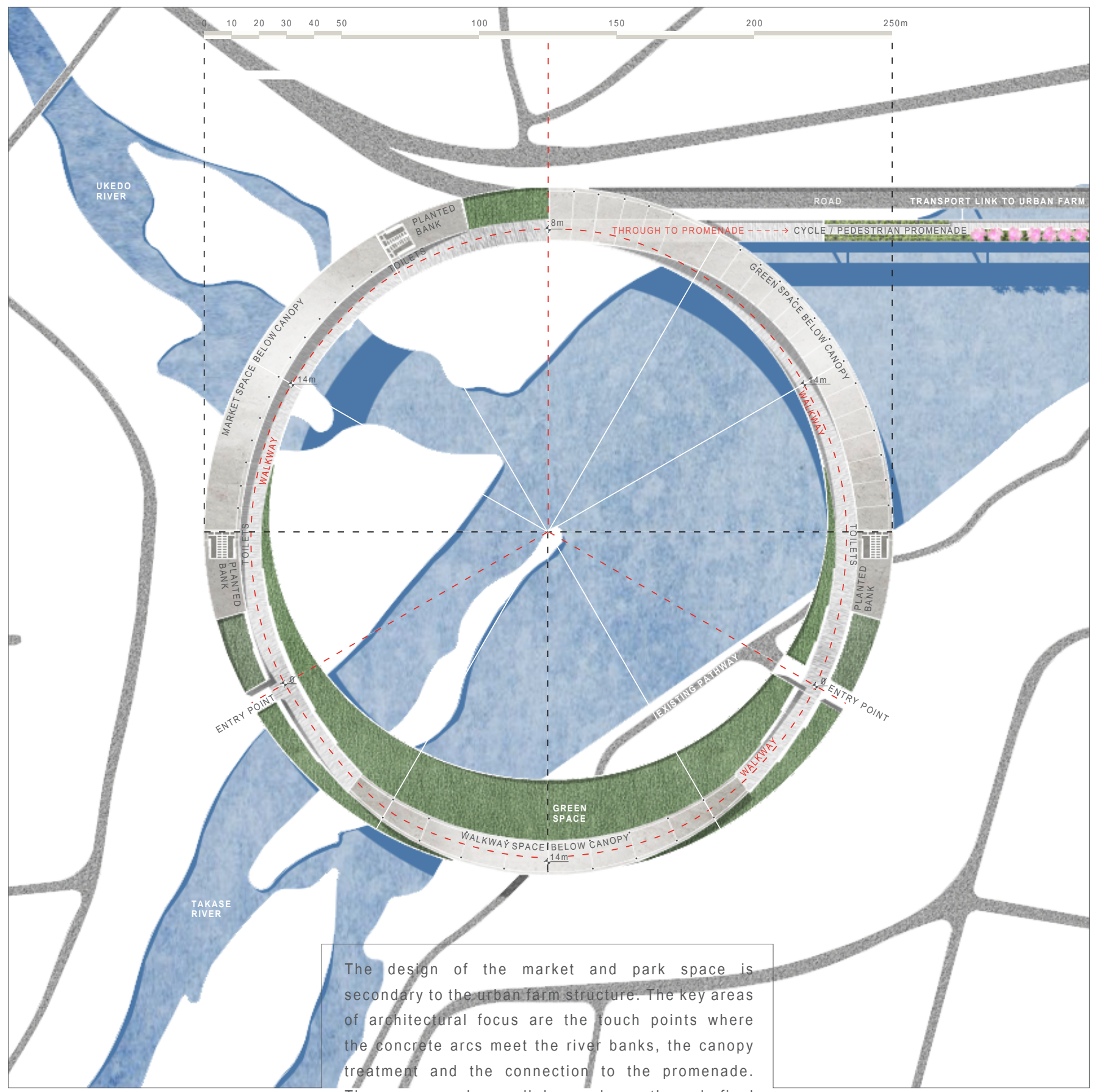

These spaces have all been shown through final rendered views.

(Figure 53) 


\subsection{Promenade plan}

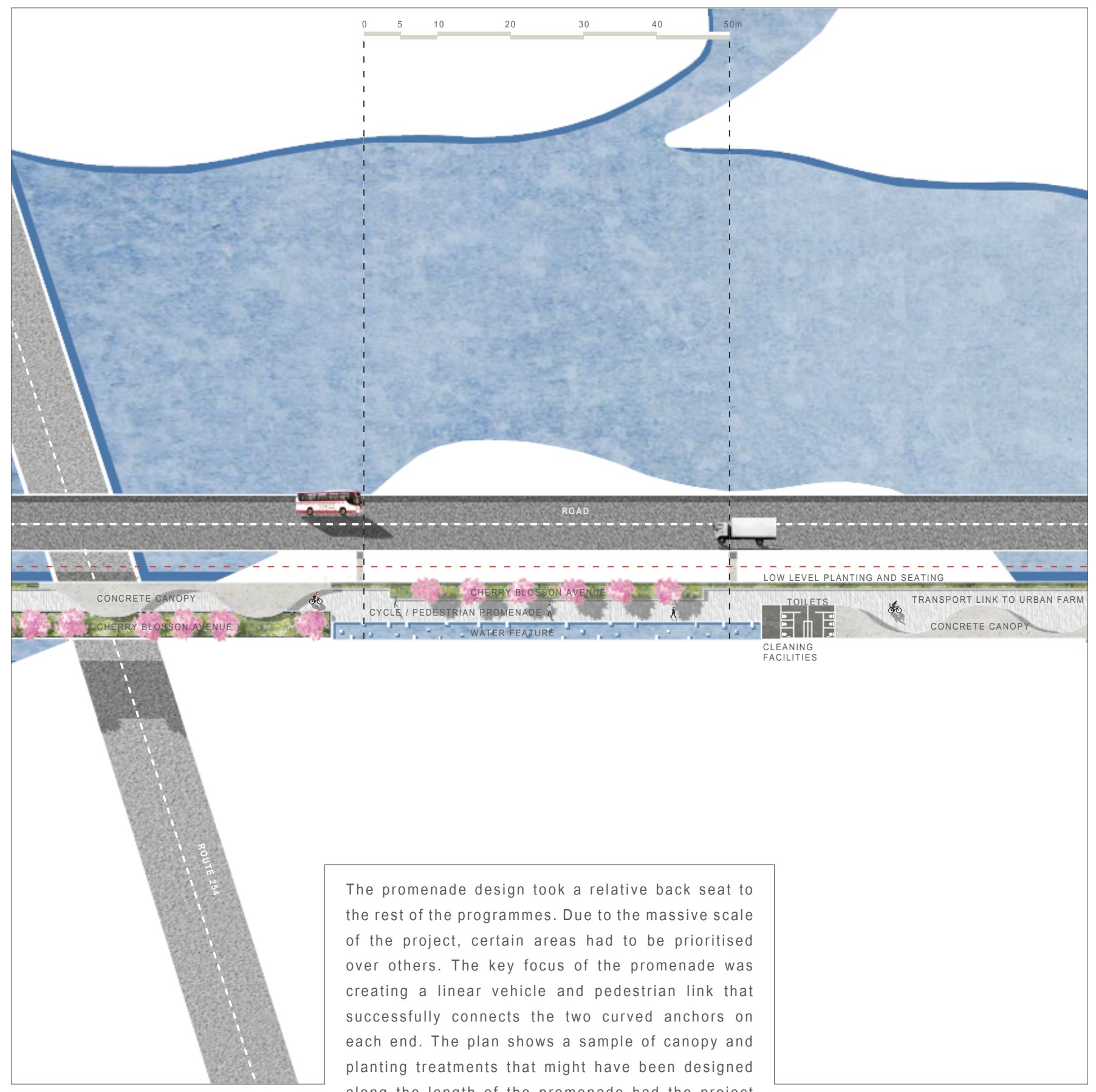
along the length of the promenade had the project been developed further. 


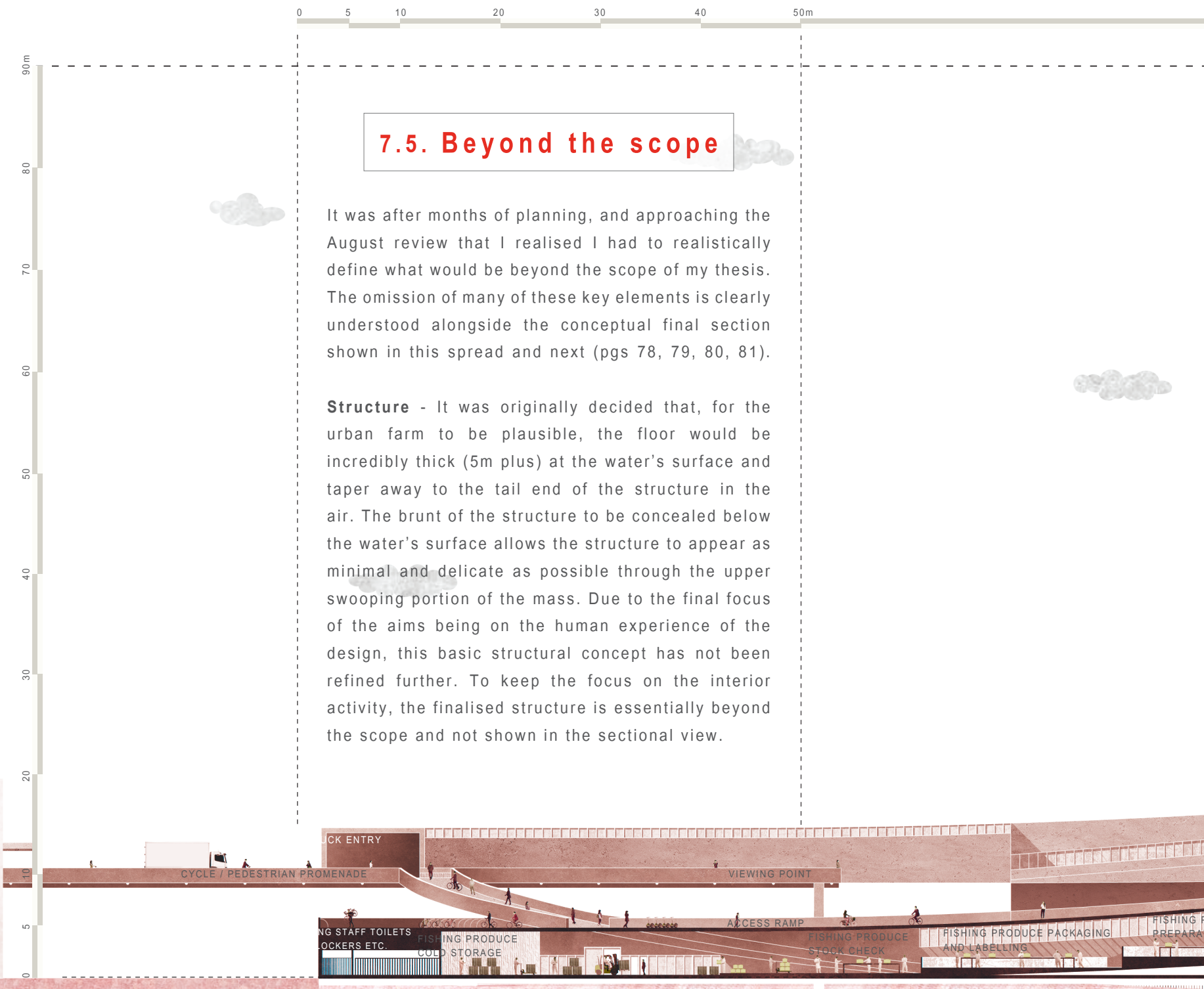




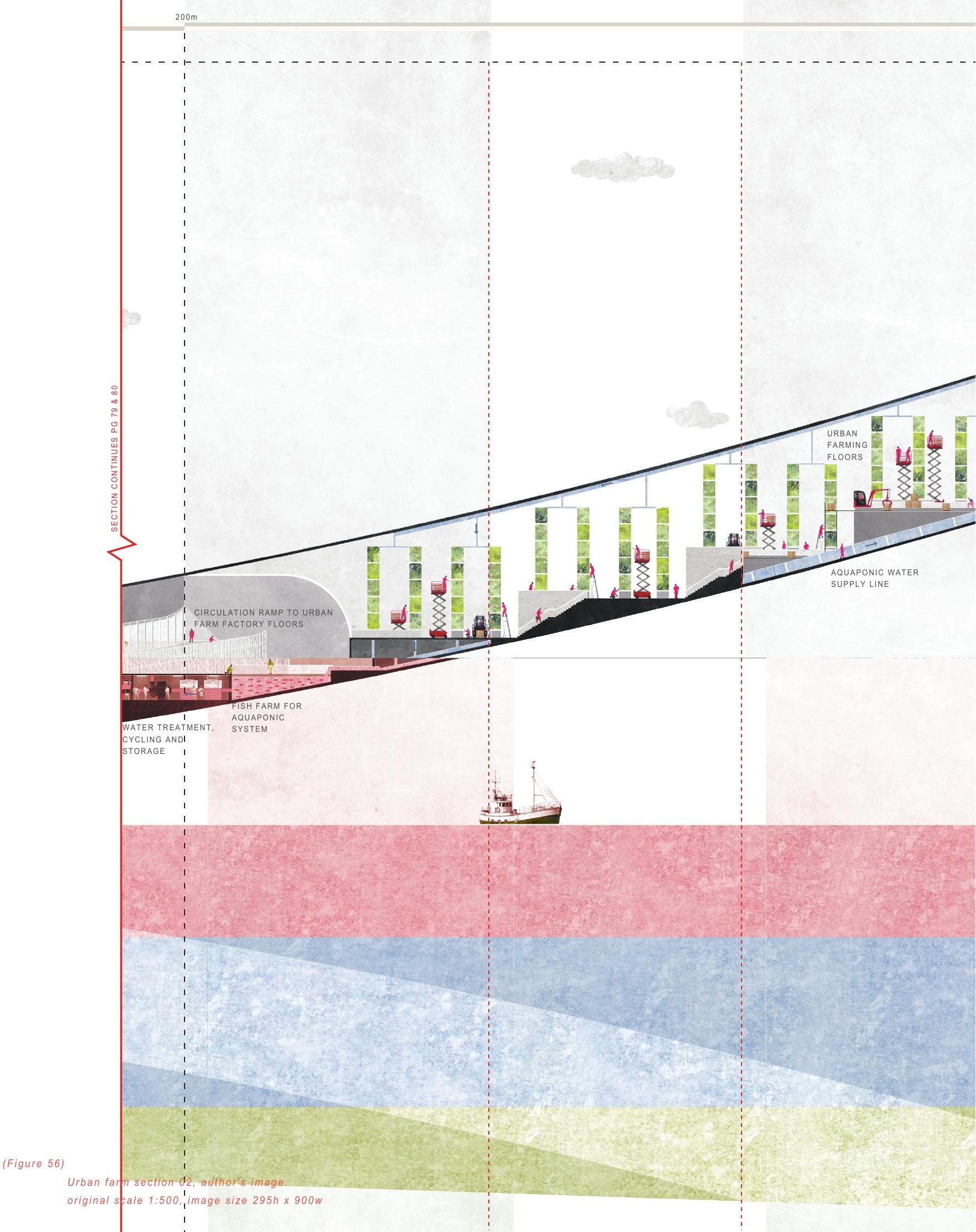




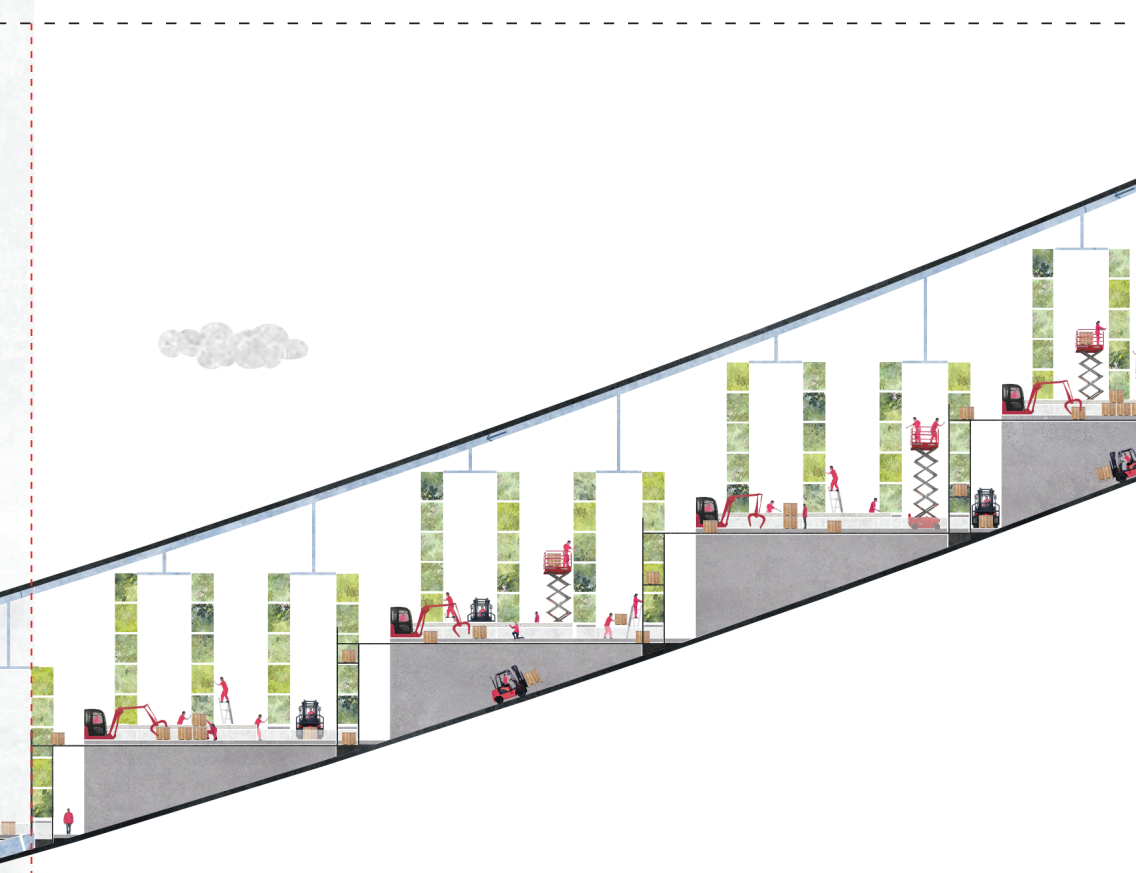

\section{BEYOND THE SCOPE cont.}

Floating \& Desalination - The original concept was that the vertically swooping form would be possible because there would be a counterbalancing structure below the water's surface. Precedent examples of floating oil rigs were discussed to support this concept. As noted on page 78 of the section, this fell beyond the final scope of the project. It was decided that it is possible to engineer such a structure and so a line was drawn at the water's surface where the design development stops. The counterbalance would house the desalination extraction pumps, so they also have not been developed beyond planning phase. How this system operates was researched in the programme analysis section (refer to page 40).

Promenade - As noted, the promenade design focuses solely on the overall composition, a linear thread connecting the two radial anchors of the design. For this reason the areas of design focus centre on the practical separation of pedestrian and traffic flow and the points at each end where it connects to the market and farm. The design of the journey along this promenade was removed from the final scope and would be delegated to a landscape architect if the project was to be developed further.

Inhabitation of green spaces and factory floors - Similar to the promenade, large areas in the market, such as the green recreational spaces, were not developed beyond basic plan. Leaving these areas out of the scope allowed the focus to remain on the architectural elements such as canopy treatments and ground connections. The factory floors, like the desalination, were researched in the programme analysis section and resolved in plan but were not represented in the final renders. This is due to the decision to develop the architectural experience in areas largely free from strict programmes. This allowed the greatest architectural freedom in a constrained timeframe.

\section{Conclusion:}

The strict, and at times narrow, scope of this project does not mean that I constrained my design and chose to ignore practical necessities like programme and structure. These elements were extensively considered and discussed along the way; they simply were not fully resolved or visualised three-dimensionally. I made many concessions to my design to allow the project to be plausible, like greatly decreasing the slope of my market to a manageable 6 degrees. The realistic component of my design was an essential part decided early on in the thesis. Allowing the project to act as a gesture of hope for these real people who continue to suffer these conditions. The element of reality has been challenged along the way with the need to push the boundaries and create a monolithic architectural gesture of strength and purpose for this region. 


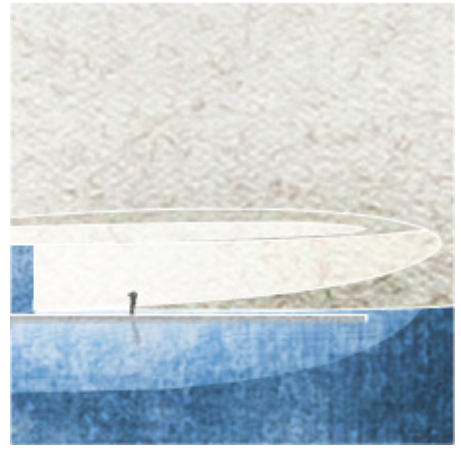

M1

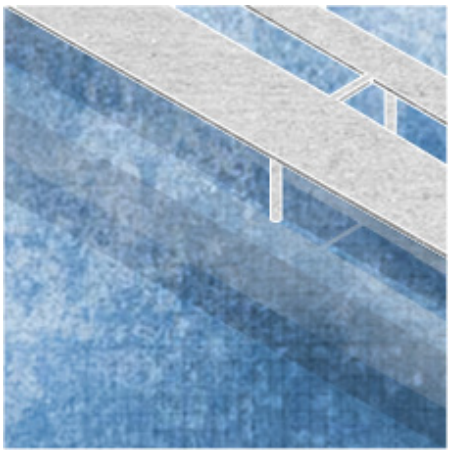

M4

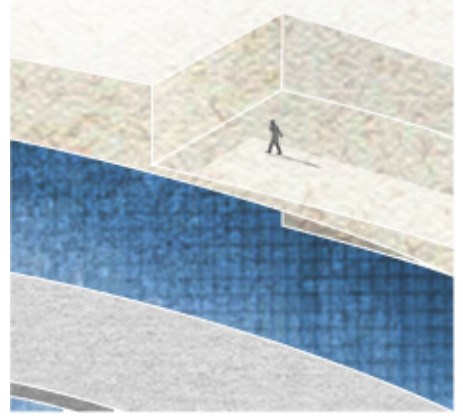

M7

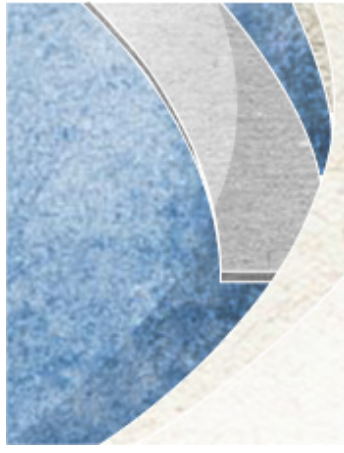

M2

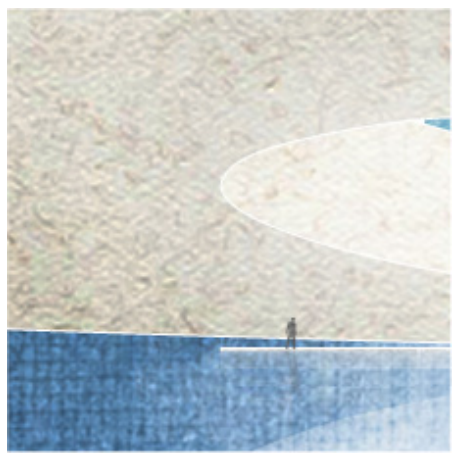

M5

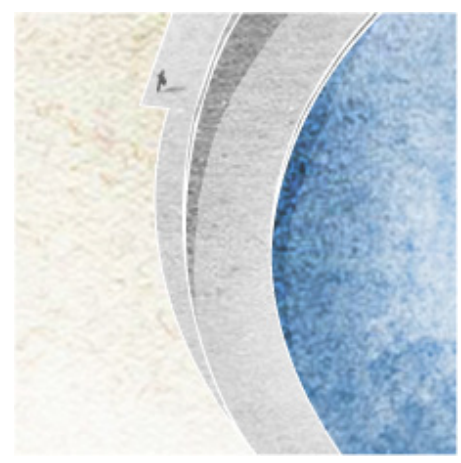

M8

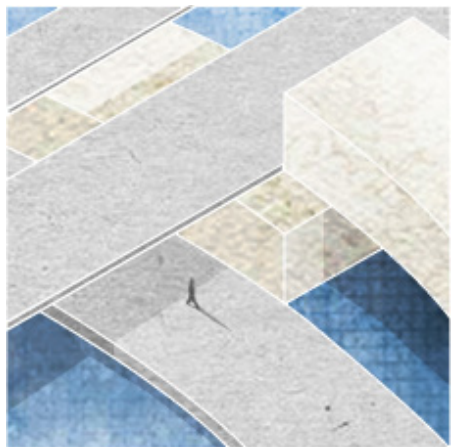

M3

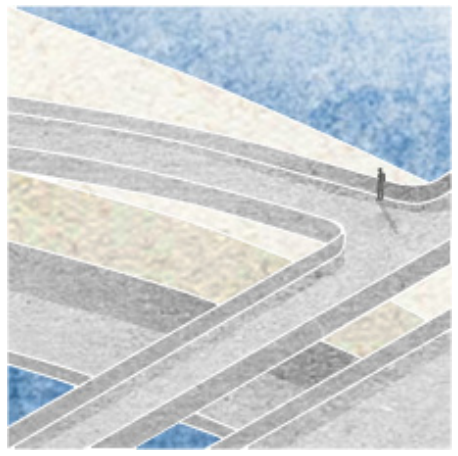

M6

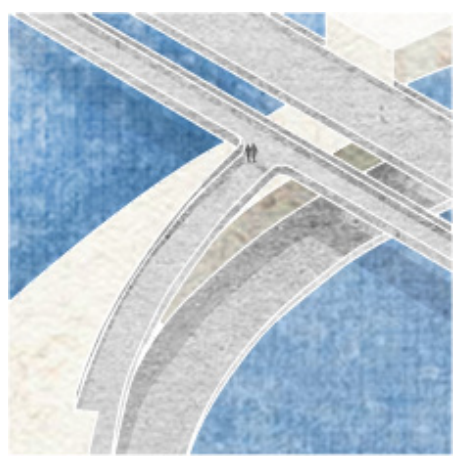

M9 


\title{
8.1. Moments - digital
}

\begin{abstract}
After extensively working on the programme of the urban farm space and having to make several concessions on the form I wanted, (mainly making the slope much more subtle than I originally envisioned), I felt very disappointed, as if I had lost something special about the design.

I was also incredibly overwhelmed by the sheer scale of the design and had come to accept that large portions of the design would never progress beyond concept phase, such as the desalination plant. Even my final renders would be slightly abstracted, and not in the realm of fully detailed space.
\end{abstract}

The digital moments series was an exercise in restoring faith in my design. My original vision was an incredibly clean, geometric, minimal project, and all the time spent designing factory systems had me panicked that my renders would be cluttered and chaotic. This exercise helped me refocus on the inbetween, circulation and threshold spaces that I still had full design control over, that were not overtaken by programmatic requirements.

Although this exploration was very quick, it marks a pivotal point in the project's development. It was at this stage I decided to fully focus the detailed spaces of my project on those areas relatively free of programmes. This process of focusing in on a smaller composition within a much bigger system was one of my key discoveries and applied to both my development models and my final renders. 


\subsection{Moments-precedents}
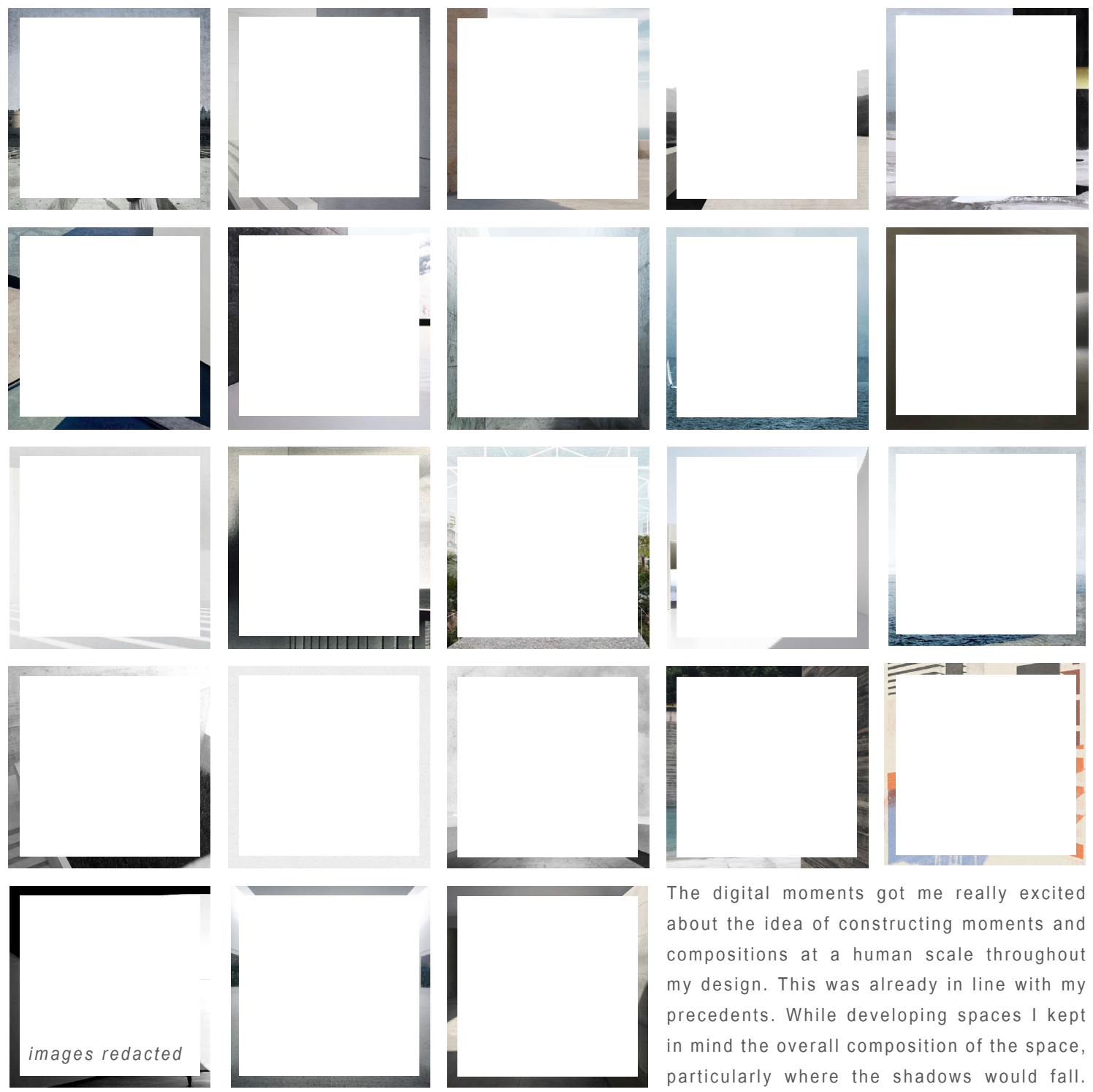

The digital moments got me really excited about the idea of constructing moments and compositions at a human scale throughout my design. This was already in line with my precedents. While developing spaces I kept in mind the overall composition of the space, particularly where the shadows would fall. 


\subsection{Moments - models}

MM01

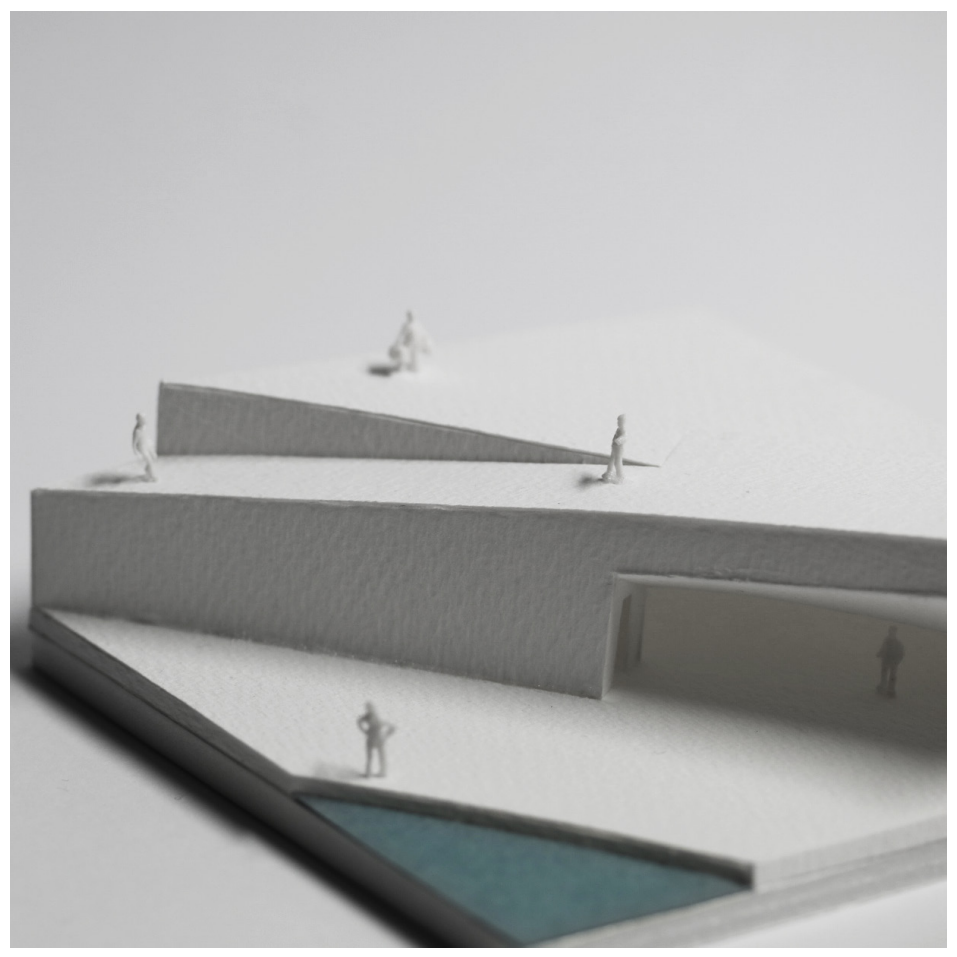

The digital moment experiment led me to select six points of interest to further develop at 1:200 in working models, thinking about the scale of the structure comparative to the people. 

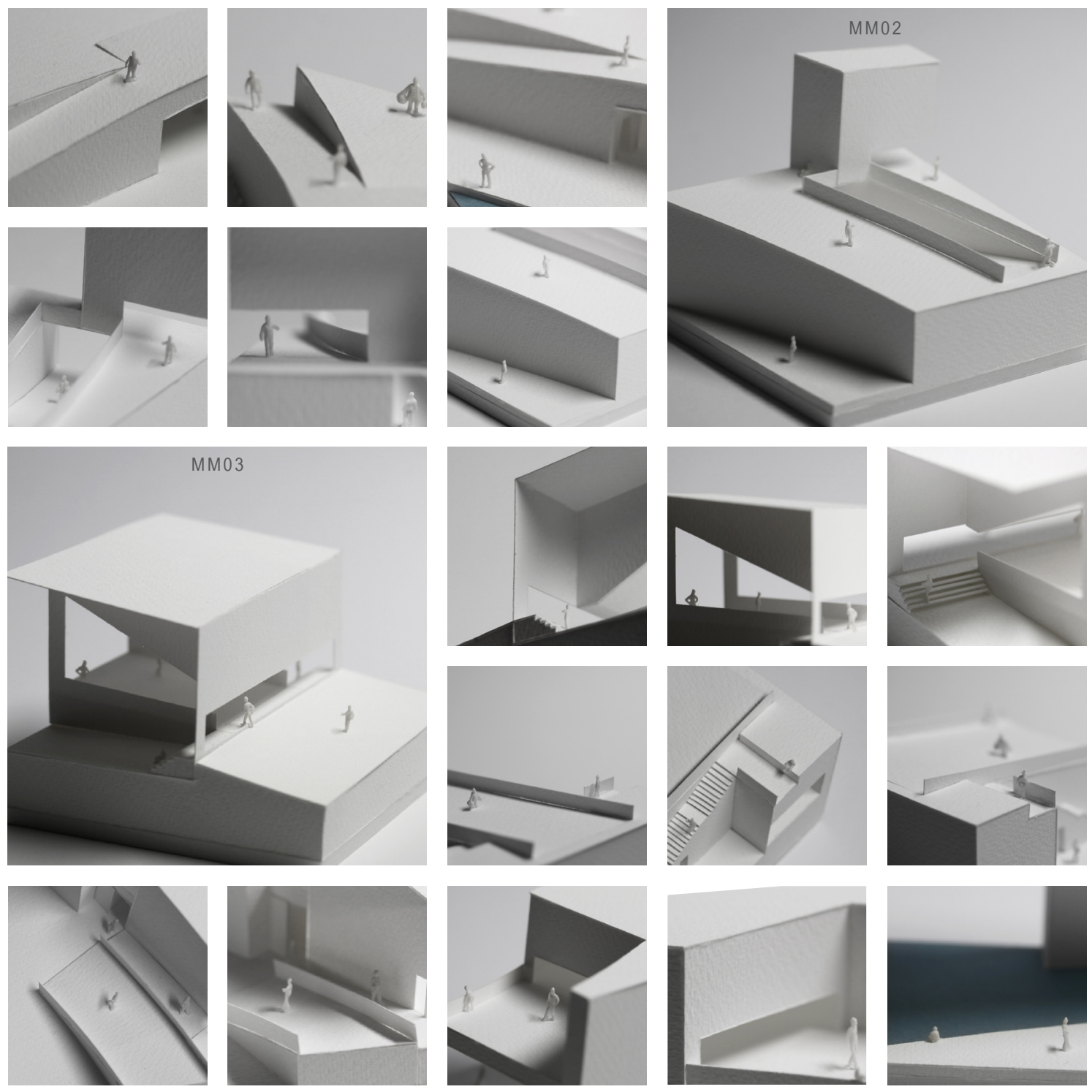
The physical moment models helped me in two main ways:

- Modelling the geometry physically forced me to simplify the shapes, compared to what can be achieved digitally, resulting in cleaner, more deliberate forms.

- The exercise of working on each space as a separate installation helped me to worry less about how the composition of that space contributes to the overall form.

Until this point I was stuck designing at the megascale, thinking how the whole design relates to one another. It was impossible to think this way without the rest of the design available for reference, as it always is in digital.

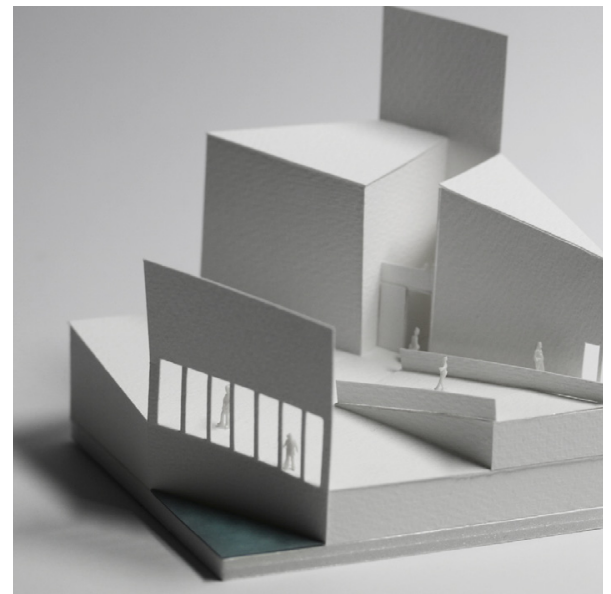

MM05

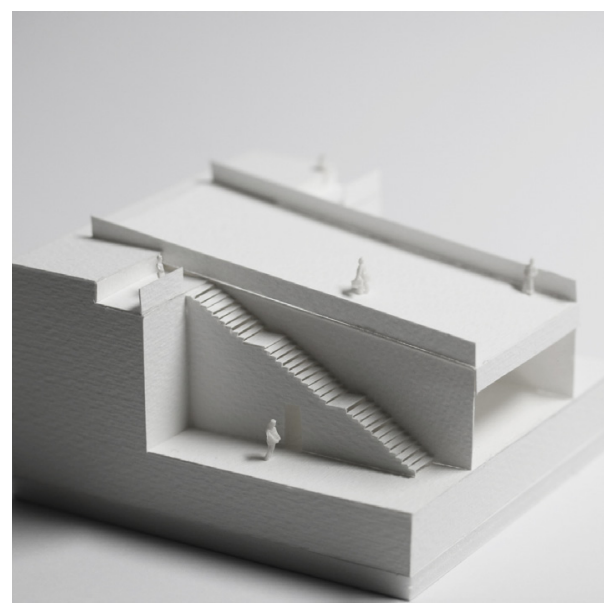

MM0 4

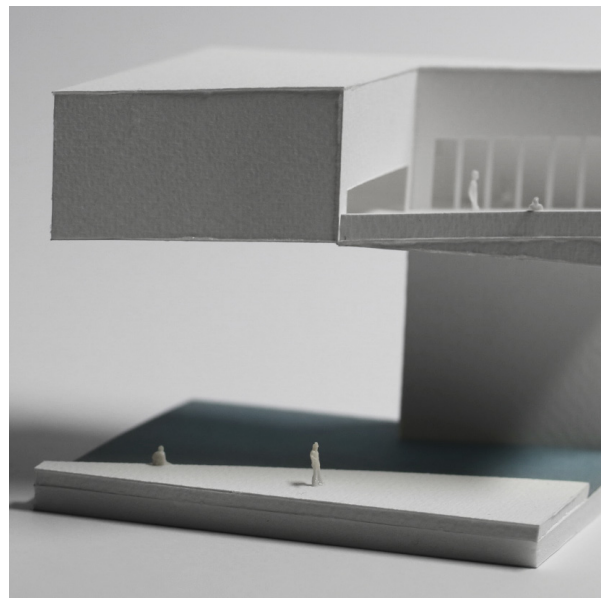

MM06 


\section{Critique 02 - reflection}

In the August critique it was bought to my attention the extent to which I was stuck viewing the project at the megascale. This was a defining moment. I realised that this idea of megascale planning versus human-scale moments was an underlying current in my entire thesis that I had not anticipated in the beginning.

The critiquers agreed that the scale of the project was justified. However, they strongly encouraged me to refocus the last stage of the project, creating the final render views on the day-to-day experience of the individual people. It was the suffering of these people which had originally inspired the project.

Although there are large parts of this project that fell beyond the scope of the thesis and were not highly resolved, the final months spent creating the rendered views were the key and final design exploration to cement the overall purpose and vision of the design.

Each render aims to capture a key transitional space within the project which was identified as representing a focused area of design. Due to the scope of this thesis, the renders are the key tool in representing the spaces which were most developed. Each view is summarised in a small caption of how I imagined the inhabitants experience the space.

The style of the renders is significant. The minimal palette and removed landscaping let the architectural moves speak clearly, bringing the focus to the surface treatments, shadows and reflections which have been key design drivers throughout each exploration. It also adds to the dystopian narrative that this landscape has been tarnished and no longer offers any amenity to the people of Namie.

The renders are sequenced to experience the journey through the two structures, beginning inland and venturing out to the floating structure.

The final exhibition was designed to reflect the same minimalist, Japanese design language that is central to the entire architectural thesis. Clear, reflective acrylic was used, and images were hung to create a sense of light and delicacy. The squares mirror the use of "pure" geometry, like the circle which inspired both of my final forms. Finally, a 'less is more' mentality was applied when curating the final images. 

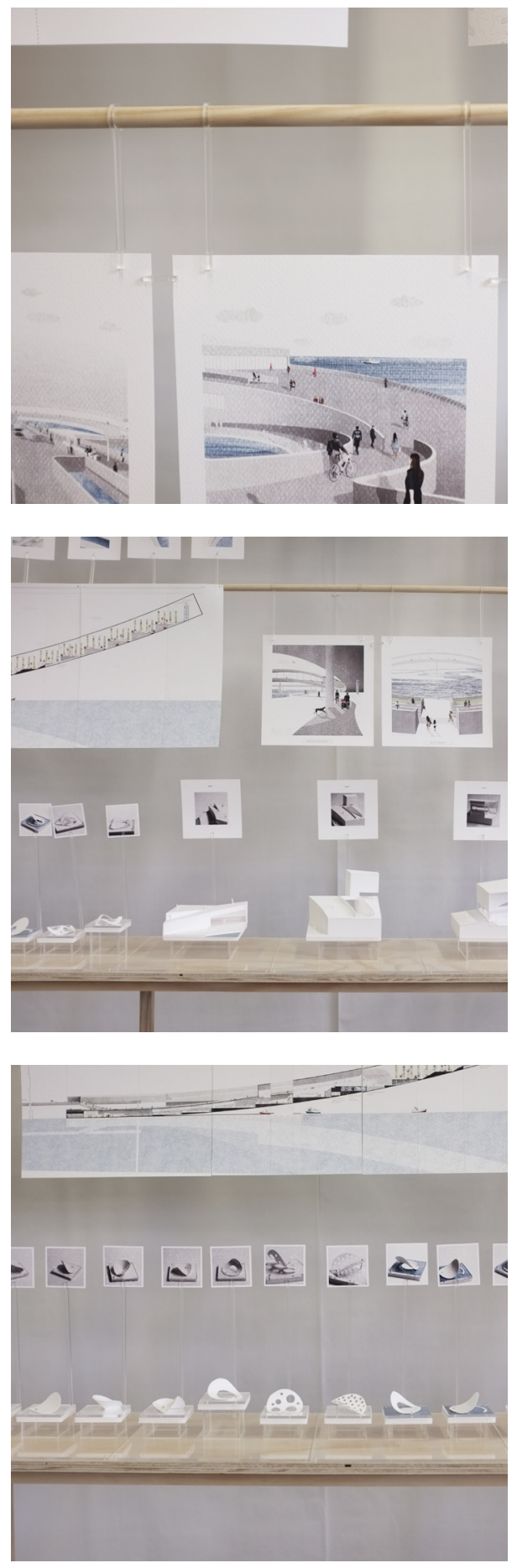


\subsection{Market renders}

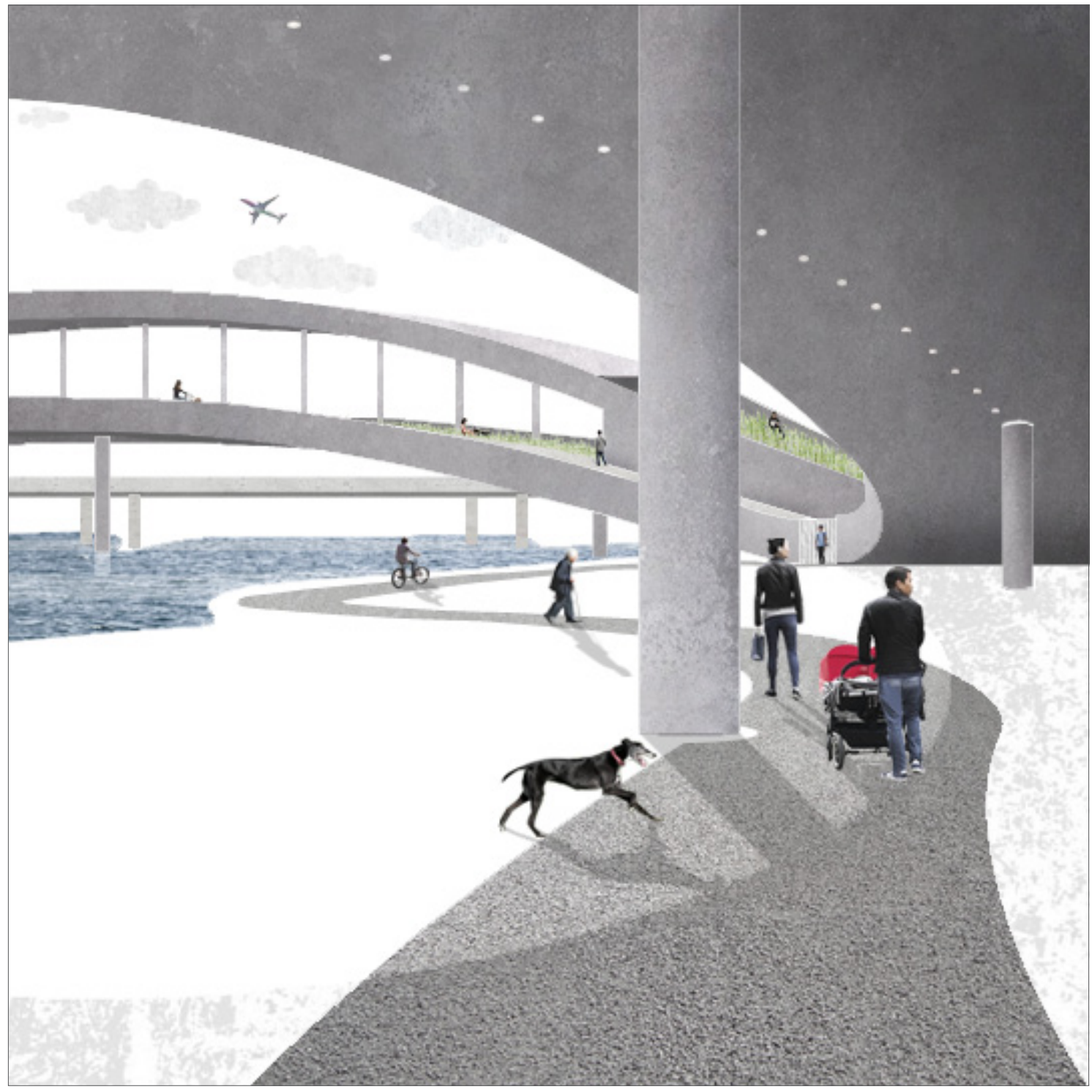

Walkway under market

On a laid-back Saturday a young family strolls along the existing river walkway in the cool shadow of the market. 


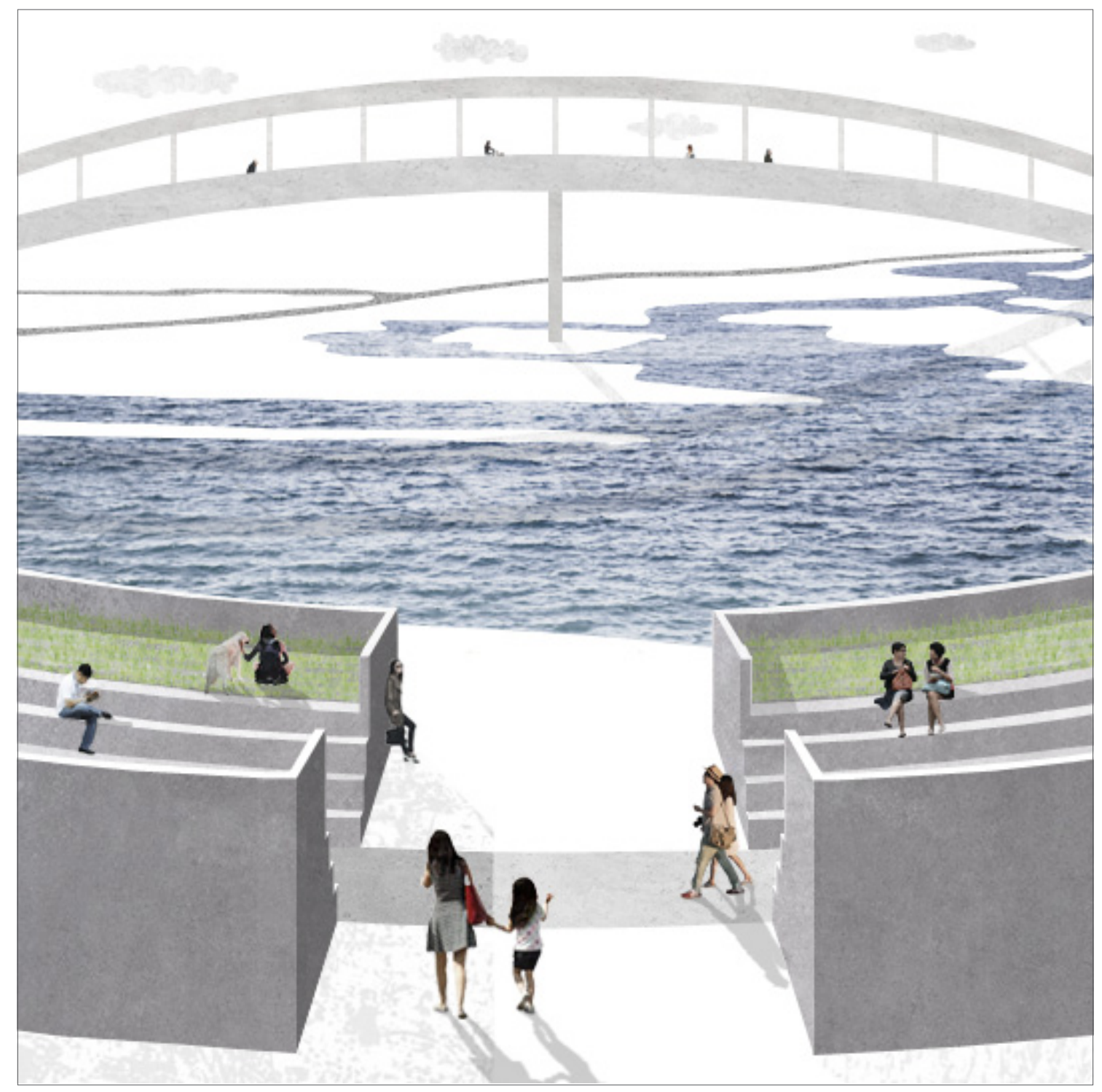

Entry to market

Late Sunday afternoon, the residents of Namie head to the market to catch the last bit of weekend sun. 


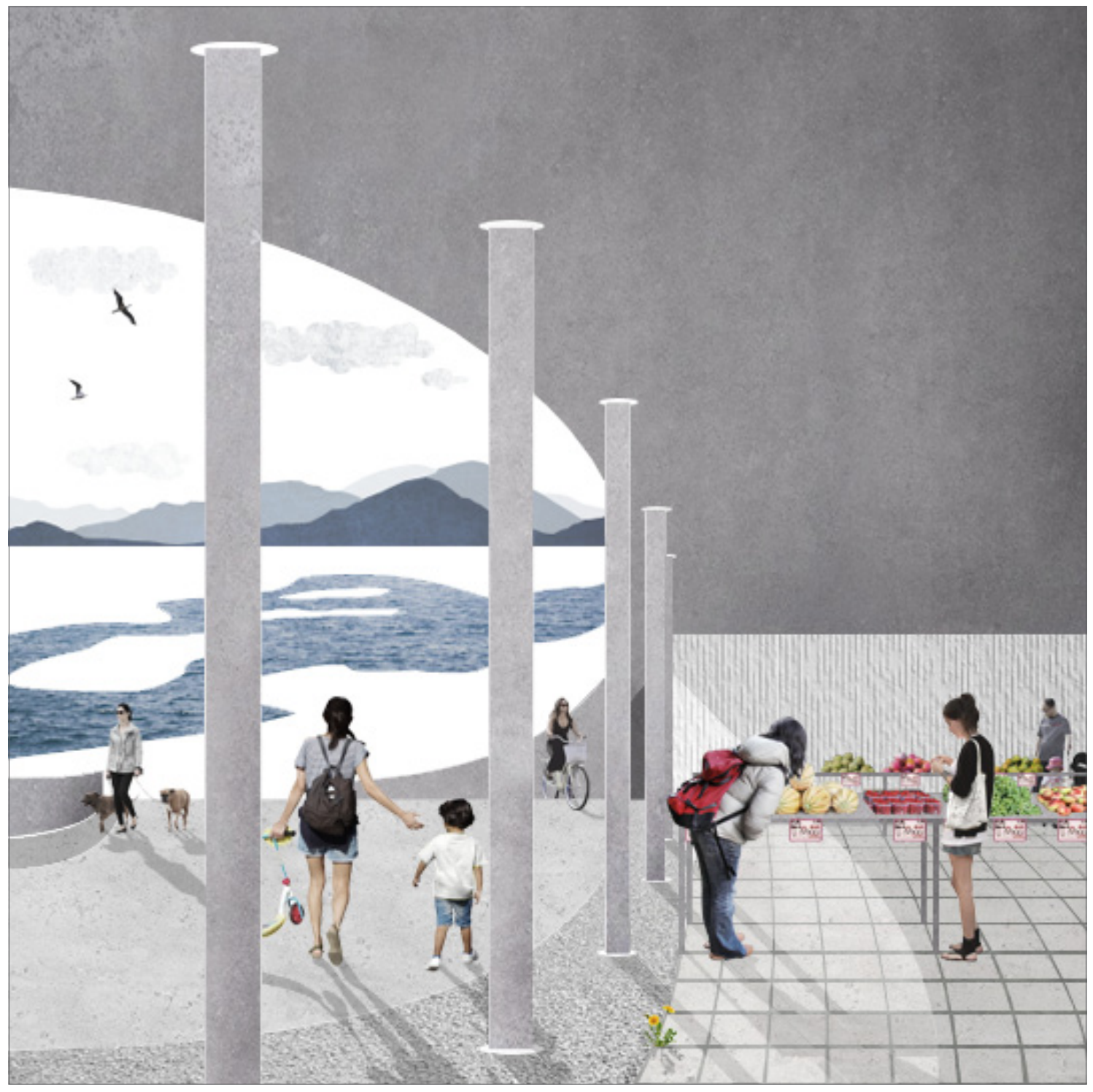

Fresh produce market

As the sun comes up residents head to the Monday morning markets to stock up on fresh fruit and vegetables. 


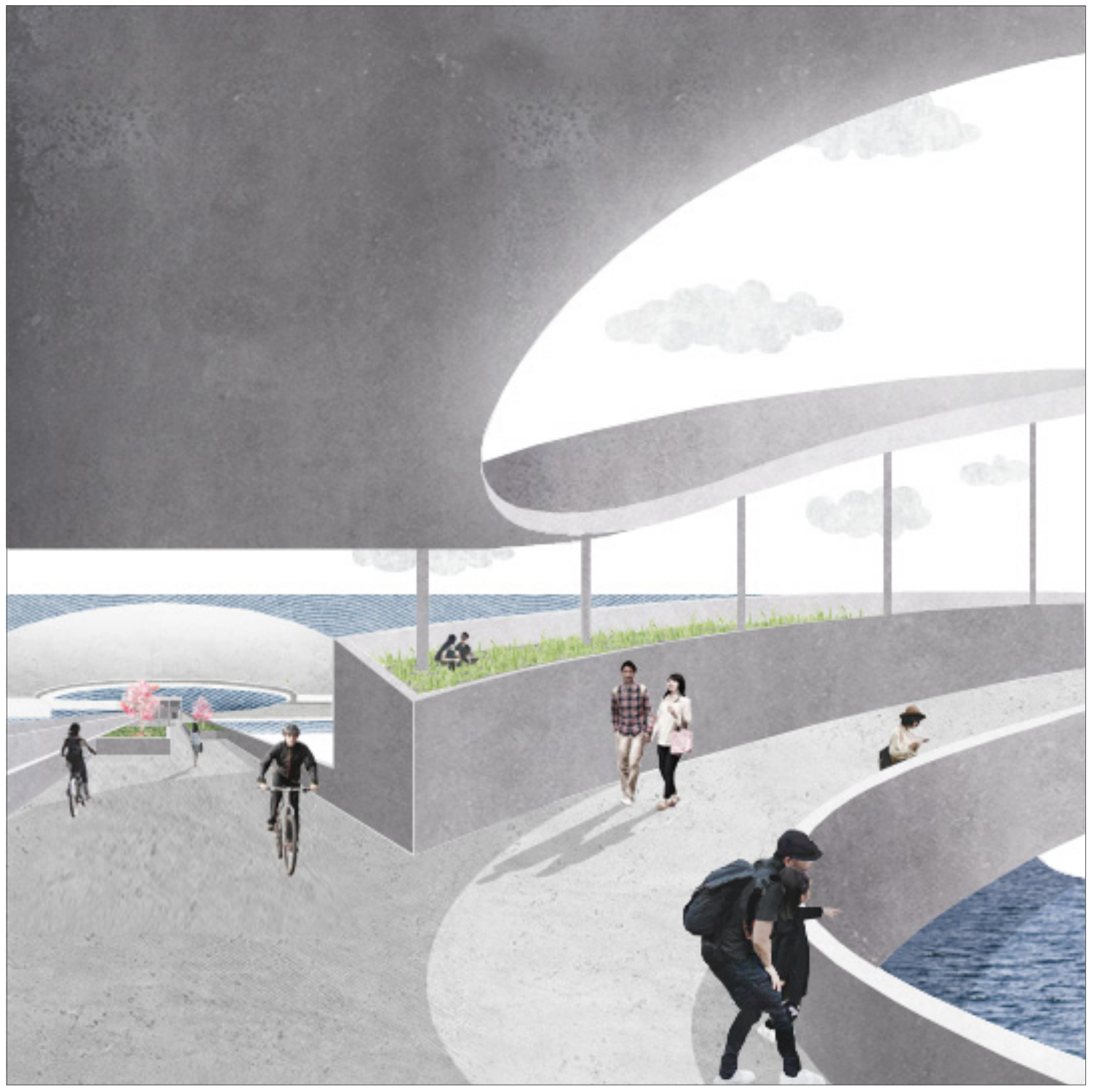

Market to promenade

Making the most of the beautiful spring weather some

residents bike along the promenade to work at the farm. 


\subsection{Farm renders}

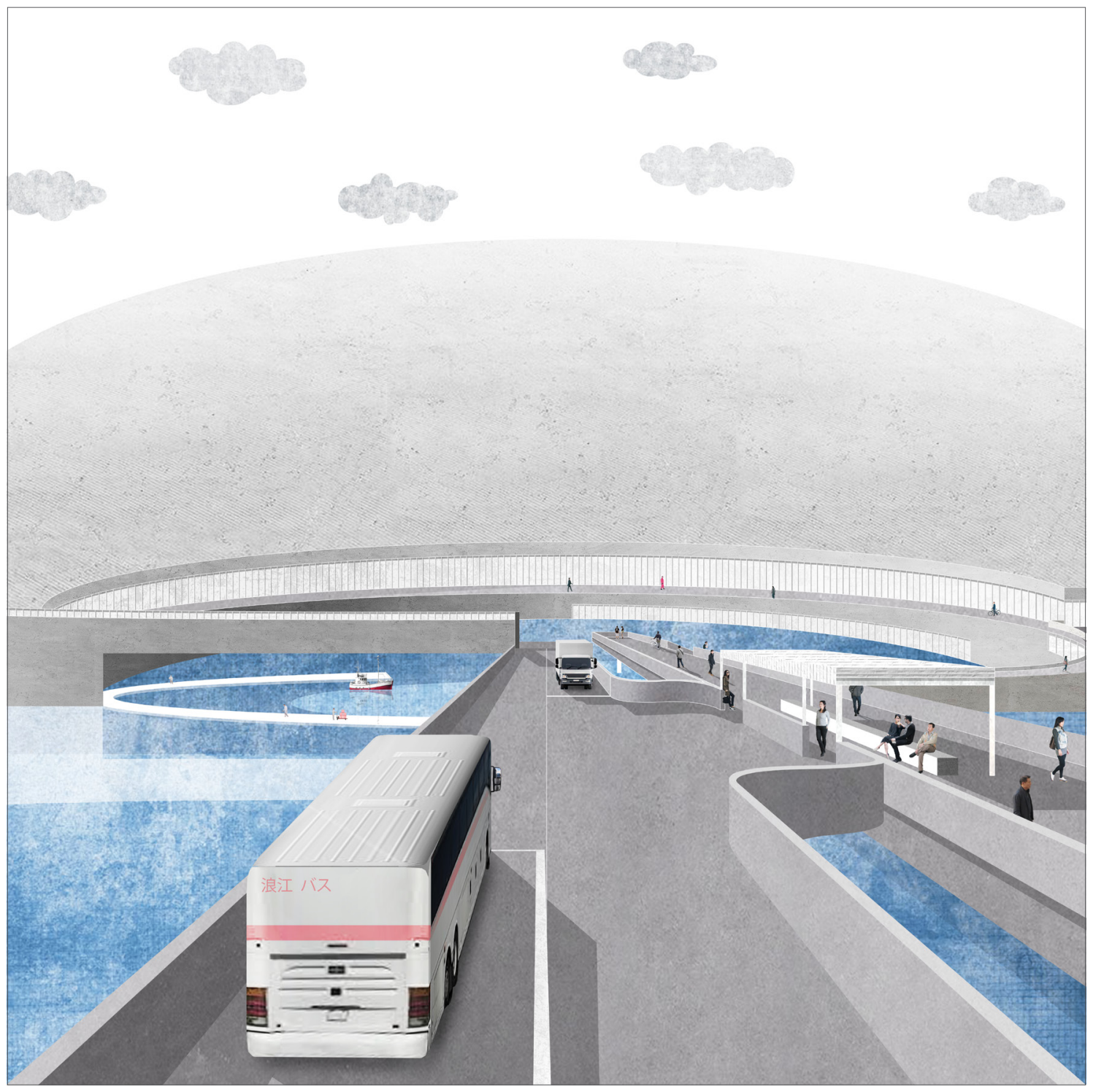

Approach to urban farm

The complementary company bus pulls up to the ocean farming structure dropping off workers for the day. 


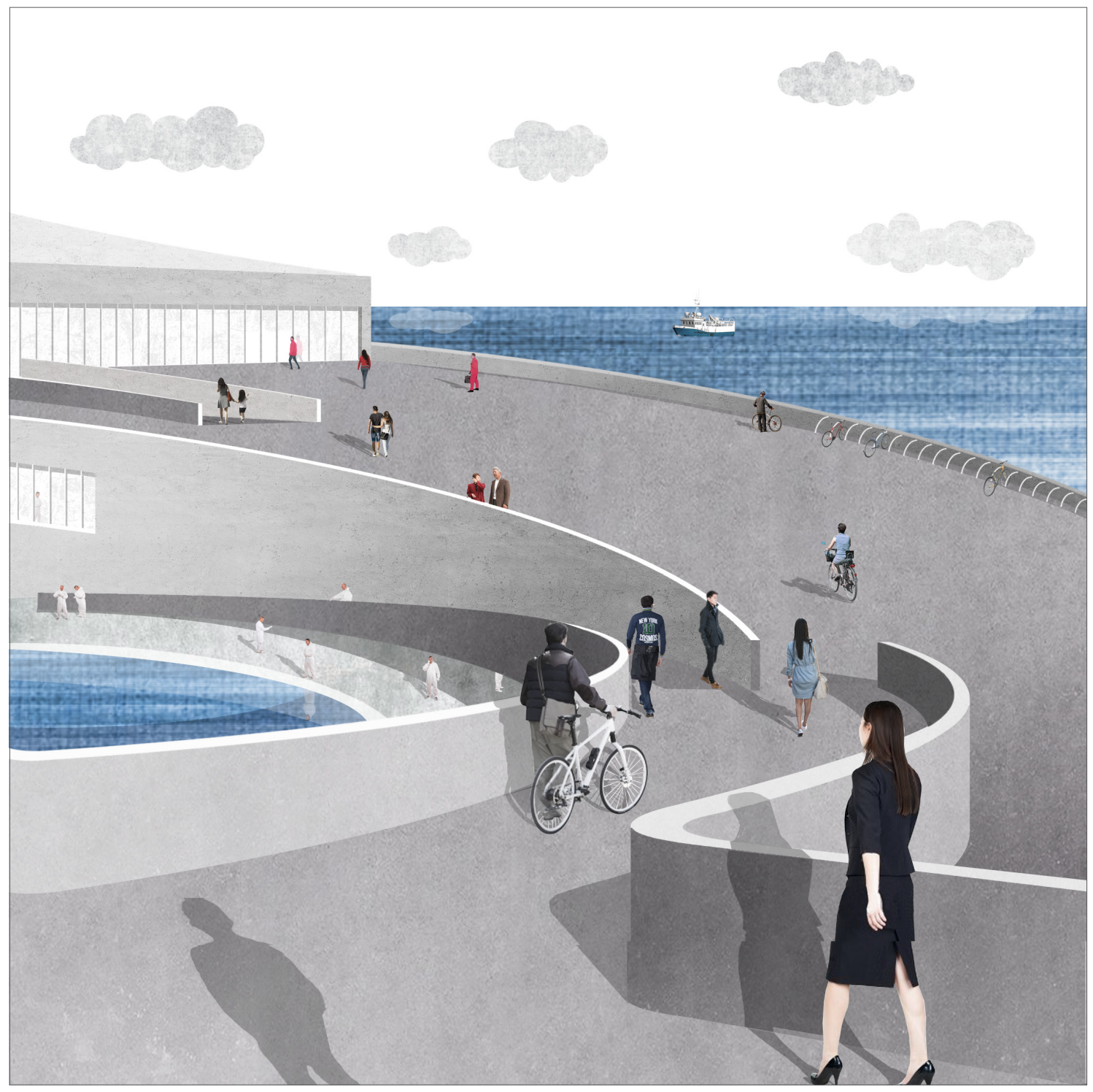

Access to farm and fishing

Workers make their way down to the cycle parks leading to the urban farm entrance, overlooking the bustling fishing docks. 


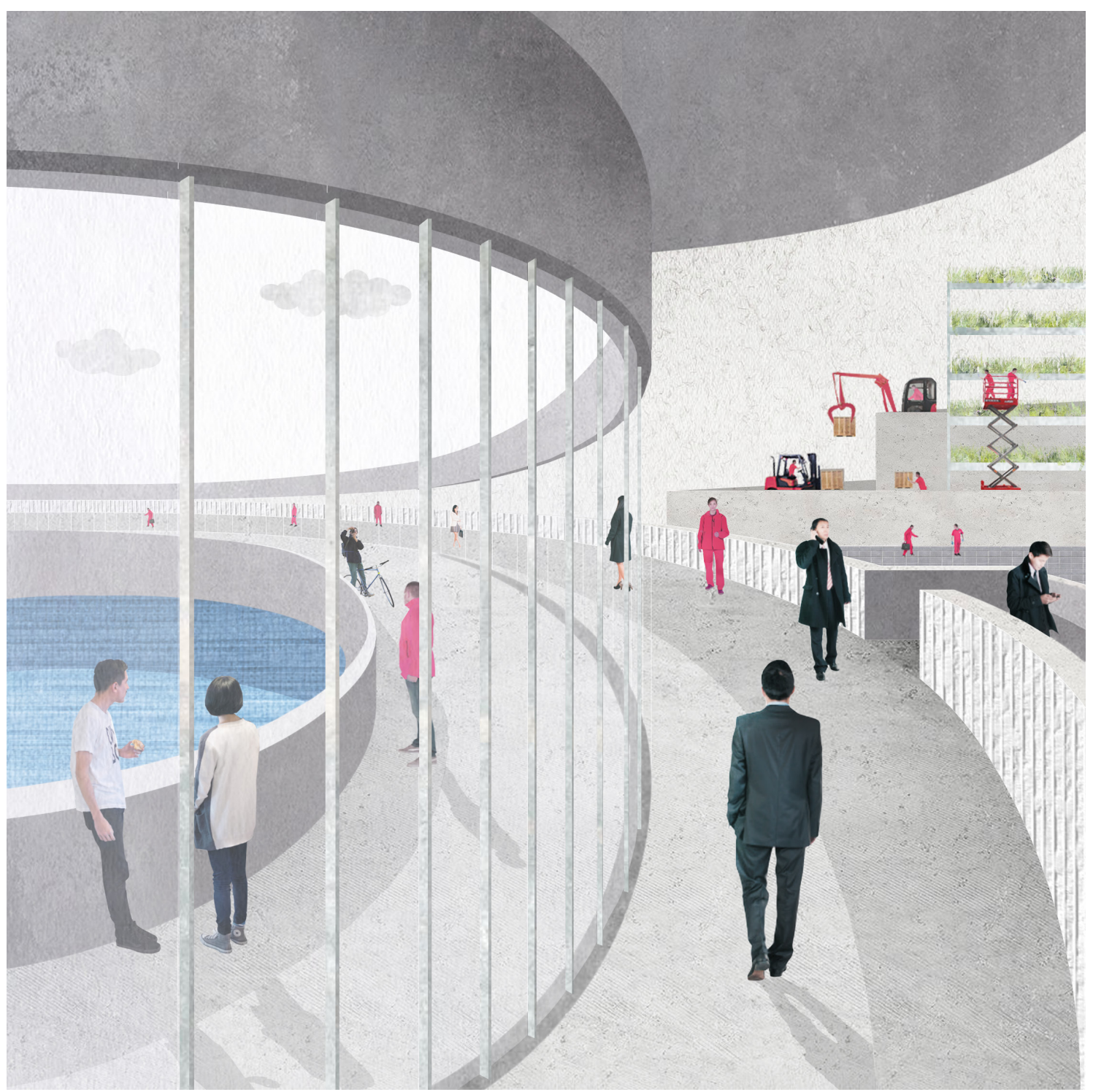

Urban farm circulation ring

Workers stroll leisurely around the circulation ring to their work stations overlooking the farming floors out over to the docks. 


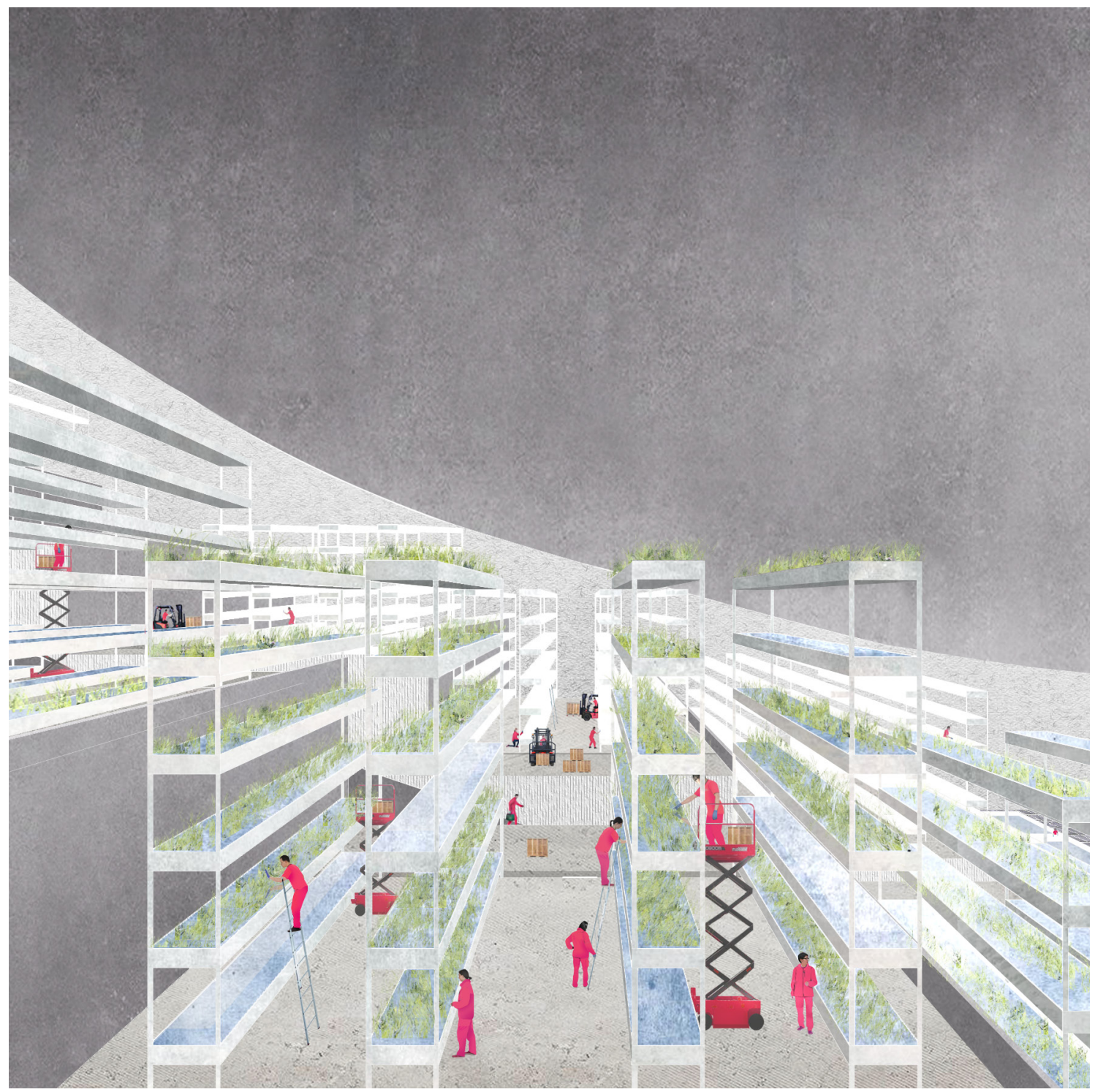

Urban farming floors

The workers at Namie urban farm humming away cultivating fresh greens for the people of the town and region. 


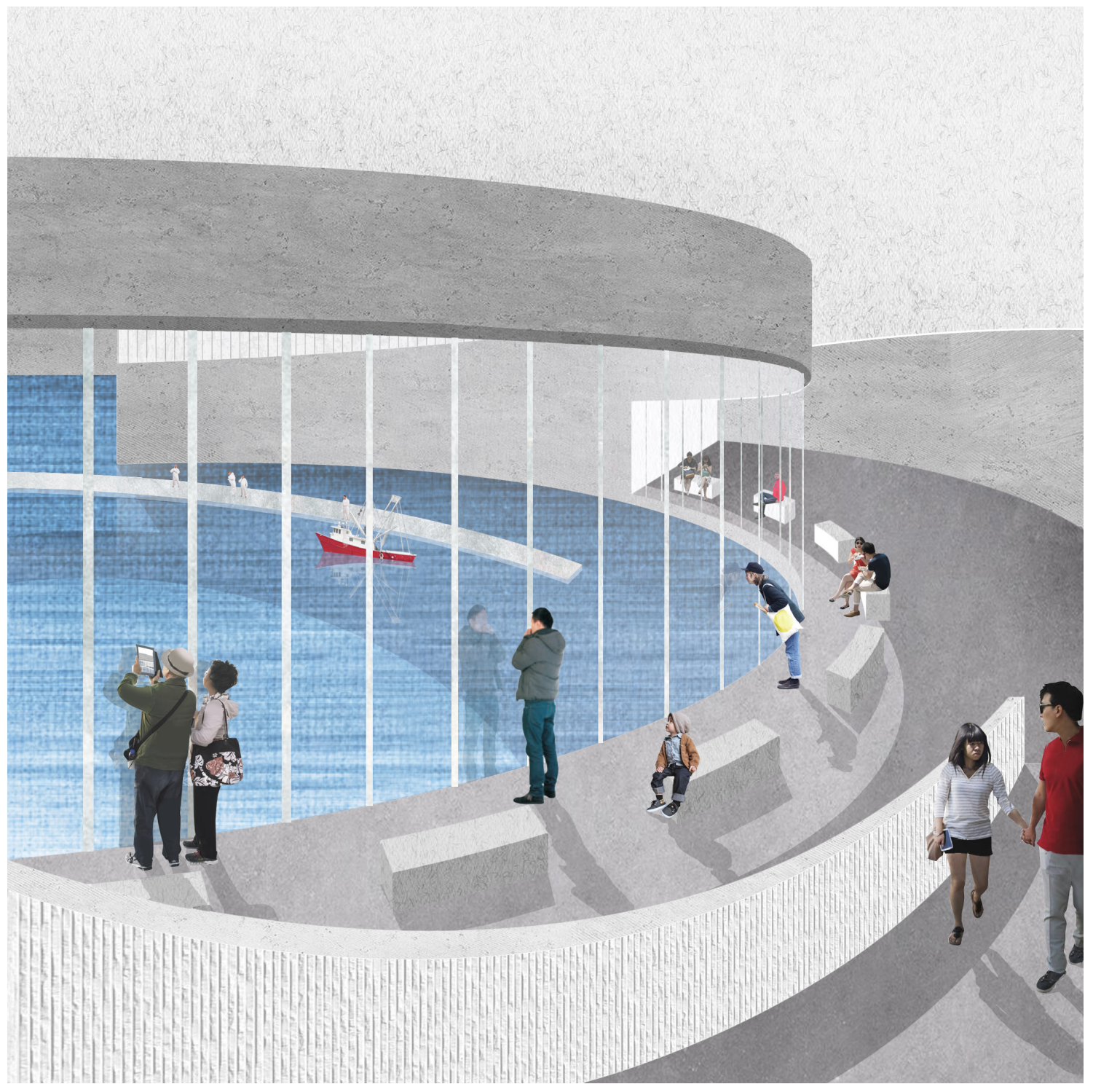

Public ocean viewing deck

Workers and public mingle in the publicly accessible viewing deck with adjoining cafe to enjoy a weekday lunch with a view. 


\subsection{Conclusion pt.1}

This thesis aimed to demonstrate the positive contribution architecture can make to conditions during post-nuclear disaster recovery. This research stream, Architecture and Dystopia, uses speculative architectural projects to comment on global issues. The nuclear industry is powerful. In the case of Japan, it often has influence over the government that has allowed it to grow, unchecked, and at the expense of investors in safer renewable energy sources. The full risk of this power source came to light six years ago when the Fukushima region of Japan was devastated by a triple meltdown at the TepCo plant. This thesis addressed the issues surrounding Namie, a town in the Fukushima Exclusion Zone that was reopened at the beginning of this year.

In my mind there were three defining features of this thesis upon which to critically reflect:

1. The scale of the project scope, a combination of six programmes across $2.5 \mathrm{~km}$. This was a response to the extensive, lasting devastation a nuclear disaster inflicts.

2. The framework, which separated the practical research and the design exploration into two streams of work. This resulted in practical texts being preferred over architectural theory, and a heavier influence on precedents as visual representational studies.

3. Megascale vs human scale. The project's key aim was to challenge the larger issues of the corrupt and fraught nuclear industry while simultaneously addressing the needs of the people of Namie at an intimate human scale. 


\subsection{Critical reflection}

\section{The scale of the project scope}

The immensity of the problem that this thesis has attempted to respond to has had a clear effect on the linear nature of the design experimentations that resulted. The initial idea was so large, with so much to uncover, that I was constantly under pressure not to stray too far from the path. The design experiments built upon one another as a way of layering information at differing scales.

This linear design experimentation limited the extent the design could evolve, as the goal was to solidify ideas so the design could be resolved in time for the final critique. The lack of comparative explorations reduced the opportunity to critique the chosen design path along the way, instead building on decisions that had already been made.

The limitation of this huge initial scope was that it required consistent monitoring. As each month went by it was important to reflect on the progression of the work and constantly make decisions to more closely focus on particular areas at the expense of other aspects of the design. Large portions of the design were not progressed beyond concept level and, without a strong rationale on why some areas were selected over others, this threatened to weaken the thesis as a whole.

The scale of the design challenged me to come up with explorations (like the six hand-crafted moment models) that served as a tool to simplify the project and allow me to continue design without being overwhelmed by the entirety of the project. These exercises were where I feel I made the clearest and most valuable design decisions.

\section{The framework}

Separating the practical research and the design explorations has had positive and negative effects on the thesis development.

The pragmatic research phase allowed for a clear, critical understanding of the nuclear industry to be formed early. This was invaluable as the scope of the project was challenged during the critique. I felt well justified by the fact that extensive and unalterable damage caused by the nuclear radiation to the towns of Fukushima demanded a response of this magnitude.

The practical knowledge was prioritised over architectural theory. This largely came down to the objective to respond directly to a real life issue. Understanding all aspects (scientific, environmental, political) as key drivers to the architectural response took precedence over theoretical concepts. While this did limit the strength of my project as a whole, it was a decision I consciously made early on.

The main challenge came when the two streams of information converged as a final design. I feel the final documentation of work feels slightly fragmented and disconnected in places, as this method required many loose ends to be reconnected.

The strength of having an unhindered stream of design exploration was that it allowed me to freely experiment with the forms, which resulted in a very strong overall architectural language. The beauty of the design was very important architecturally, as well as a tool to inspire hope in the people of Namie. 


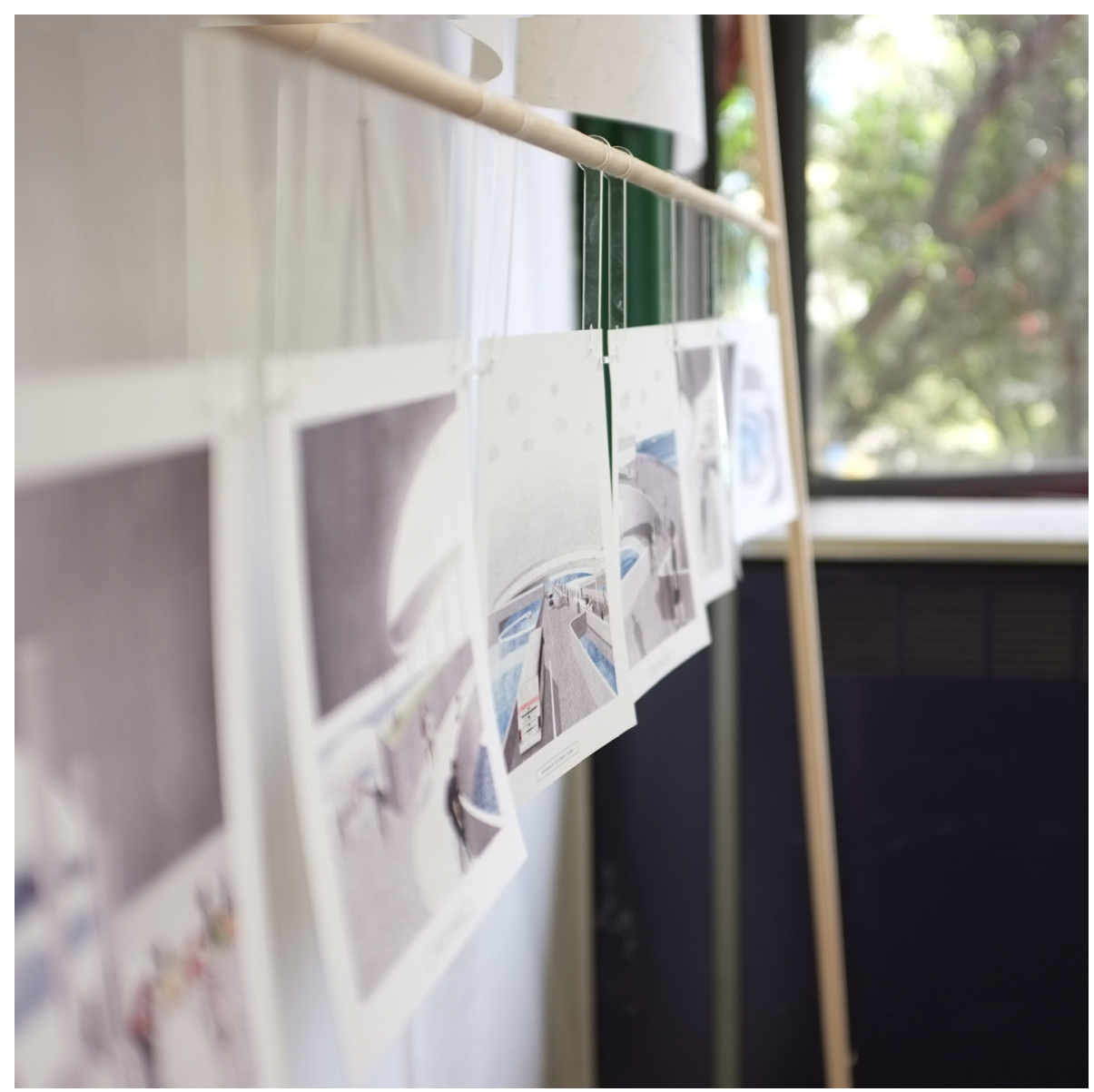




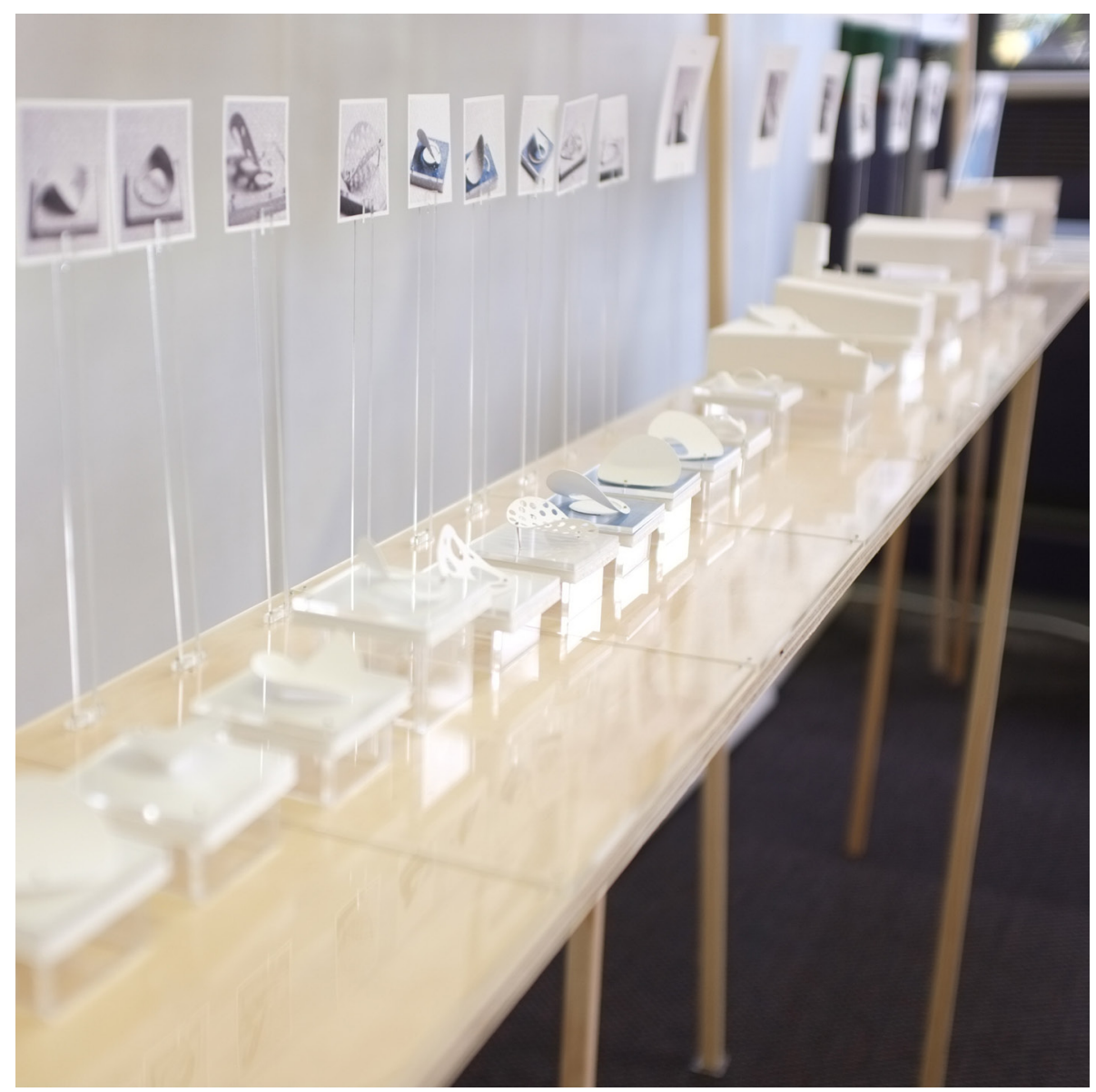




\subsection{Conclusion pt.2}

\subsection{Critical reflection cont.}

\section{Megascale vs human scale}

I believe the duality and compromise between exploring the megascale and the human-scale within one thesis, although a challenge, strengthened the project overall. The biggest constraint was the question of whether I should narrow the scope on one or the other to achieve a successfully resolved design. However, my aim and objectives clearly demanded consideration of both.

Having to compromise some aspects of the design to allow time spent developing others created opportunities to critically examine the scope of my thesis. The clarifying decision to have a scheme that spoke at the megascale but was detailed at the human-scale also helped focus my final design explorations on the experience of the people, who have been impacted by these disasters.

The areas where I was forced to compromise the design were where the most interesting solutions resulted. They were a catalyst for the true development and influential changes to the design. The tension set up between designing something that is magnificent at the mega scale and also intimate at the human scale resulted in something that was pure and simple but filled with multiple elaborate programmes. I believe that having to meet in the middle grounded my design between being fantastical and thoughtful reality.
I set out to explore architectural responses to a dystopian issue of global concern, and I did it by focusing on a scattered former community of people from a single village in Japan. What was needed to empower those families to circle back, to re-fashion themselves once more as a sustainable community in the place where they feel they belong?

Unconsciously, or as a result of necessity through the time constraint, the thesis set up two sets of interrelated contradictions: megascale versus human-scale and the scope of programmes required to effectively respond to the impact of nuclear disaster versus the need to adequately investigate at least some of these elements. With the latter, once the entirety of the project was mapped, I had to leave a number of programmes fallow, areas I was satisfied have a role in the overall project but which I simply had to leave because of time constraints. With the former, there was a point where I considered focusing on either the mega or human scale, but ultimately realised that the most satisfying explorations and conclusions came from the tension set up between the two. This seemed fitting, despite my concern that the thesis is not conventional and may be considered lacking in some areas. From the beginning, there was a sense that I needed to continue considering all elements to achieve a fitting outcome. In all my underpinnings, there is this binary, circular sense of black and white, yin and yang, light and shade, land and sea, the circular form, things coming around to where they began - the global issue and the individual impact and response.

The exercise of this thesis has taught me what I think is an important lesson about my chosen profession: that it can have impacts at many levels of human experience - personal, society wide and worldwide and that each of these touch-points interrelates and can be connected within a thoughtful architectural narrative. 


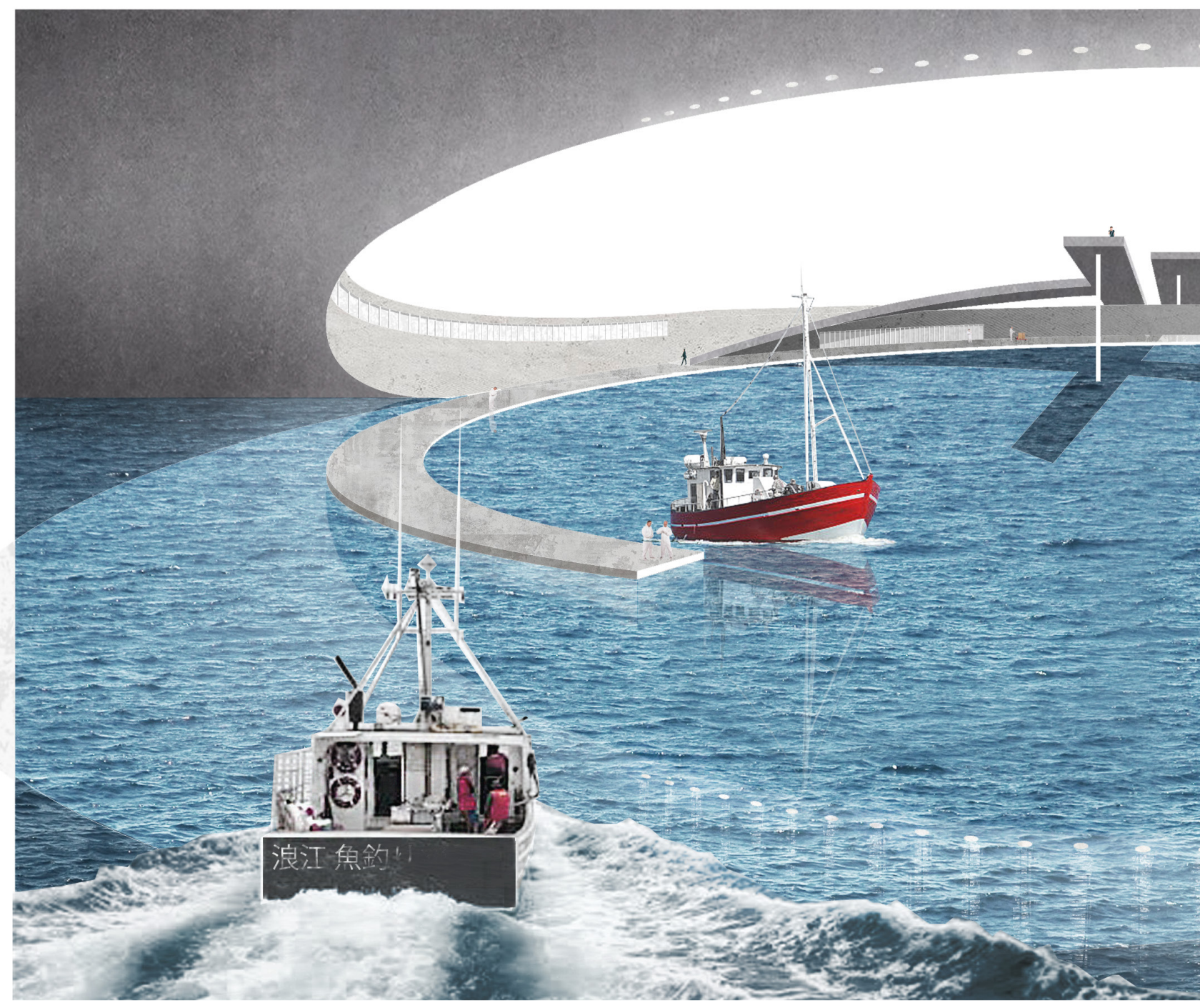

Fishing docks ocean approach

After a few days at sea fishermen pull into the light-bathed Namie fishing hub, looking forward to a hot shower on arrival. 


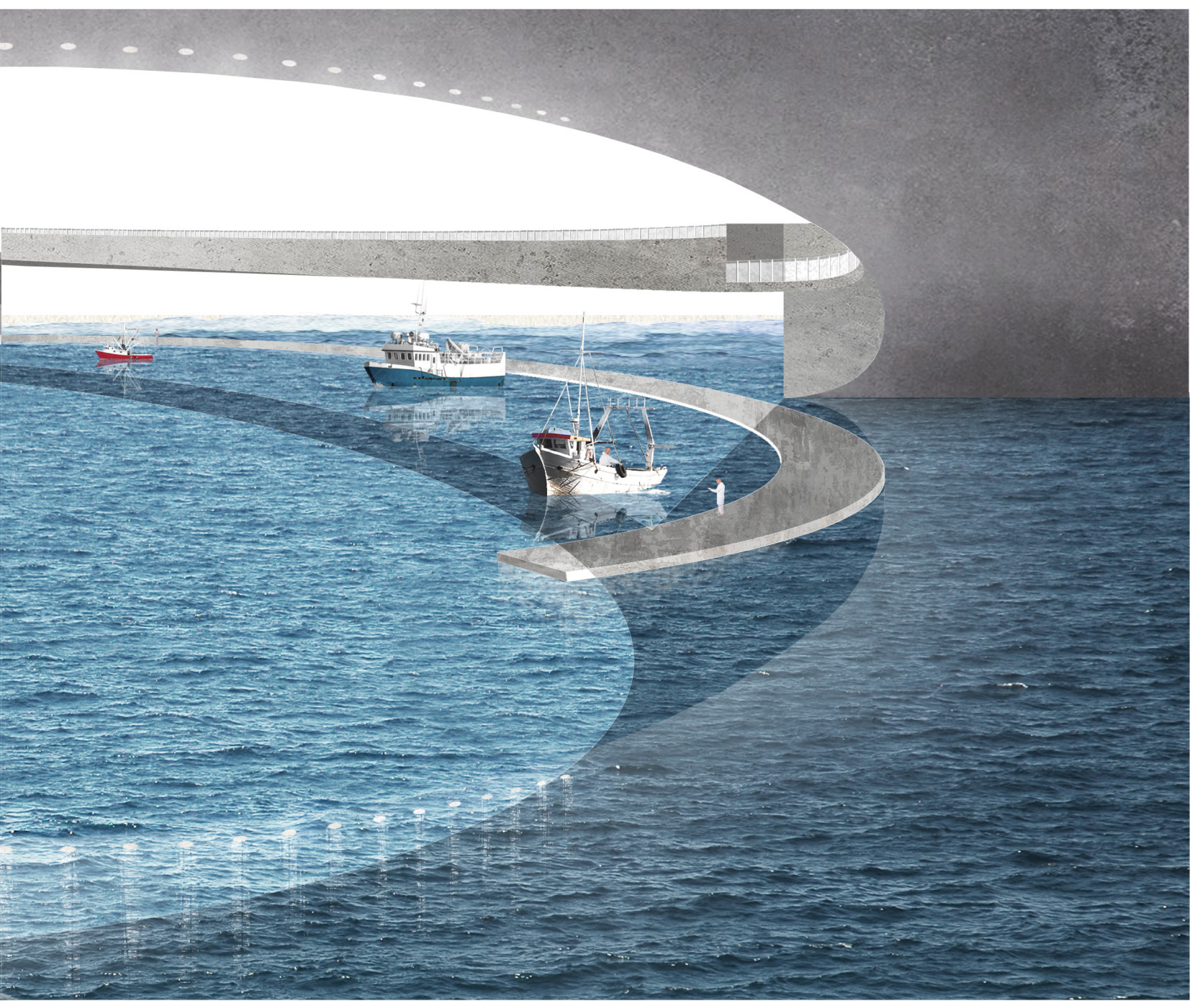




\section{List of references}

Fukushima Daiichi Nuclear Disaster

- Broinowski, R. (2013). Fallout From Fukushima. Brunswick, Vic: Scribe Publications Pty Ltd.

- Caldicott, H. (2014). Crisis Without End: The Medical and Ecological Consequenses of the Fukushima Nuclear Catastrophe. New York: The New York Press.

- Funahashi, A. (Director). (2013). Nuclear Nation [Motion Picture].

- Kadota, R., \& Tokuhiro, A. (2014). On the Brink: The Inside Story of Fukushima Daiichi. (S. Varnam, Trans.) Fukuoka: Kurodahan Press.

- Lochbaum, D., Lyman, E., \& Stranahan, S. Q. (2015). Fukushima: The Story of a Nuclear Disaster. New York: The New Press.

- O'Brien, M. (Director). (2015). PBS Nova - Nuclear Meltdown Disaster [Motion Picture].

- Study: Radioactive Cesium-137 Released From Fukushima 1.5 Times TepCo Estimates. (2014, May 10). The Japan Times Online, Web article.

Japanese Living, Rural Lifestyles and Culture

- Black, A., \& Murata, N. (2012). The Japanese House: Architecture and Interiors. Clarendon, VT: Tuttle Publishing.

- Elmer, L., \& Karashima, D. (Eds.). (2012). March Was Made of Yarn: Writers Respond to Japan's Earthquake and Tsunami. London: Harvill Secker.

- Hall, S., \& Eckhouse, B. (2017). Japan's Renewable Energy Revolution. Bloomberg - Asia Edition, Web article.

- Inaba, K., \& Nakayama, S. (2000). Japanese Homes and Lifestyles: An Illustrated Journey Through History. Tokyo: Kodansha International.

- Lin, Z. (2010). Kenzo Tange and the Metabolist Movement: Urban Utopias of Modern Japan. New York: Routeledge.

- Pollock, N. (2015). Jutaku - Japanese Houses. London: Phaidon Press.

- Sato, S. (2014). Shodo: The Quiet Art of Japanese Zen Calligraphy. Boston: Tuttle Publishing.

- Sorenson, A. (2004). The Making of Urban Japan: Cities and Planning from Edo to the 21st Century. London: Routeledge.

Namie, Fukushima

- Grossman, D. (2017, March 13). Six Years Later, People Are Moving Back to Fukushima. Popular Mechanics, Web article.

- Hirano, K., \& Yuichi, S. (2017). Reconstruction Disaster: The Human Implications of Japan's Forced Return Policy in Fukushima. Asia-Pacific Research, web journal.

- Namie Town at a Glance. (2017, April 18). Retrieved from Namie-Machi Website: http://www.town.namie. fukushima.jp/

- Pearce, F. (2017, March 27). A Nuclear Ghost Town in Japan Welcomes Back Residents This Week. Newscientist, Web article.

- Takenaka, K., \& Kasai, T. (2017, March 08). Six Years After Fukushima Nuclear Disaster, Residents Trickle Back to Deserted Towns. Reuters, Web article.

- TANI Kenji Lab - Saitama University. (2017, May 10). Maps and GIS Data Relating to the Great East Japan Earthquake. Retrieved from KTGIS: http://ktgis.net/tohoku_data/index_e.html

- Tran, J. L. (2017, March 11). Namie: One Step Forward, a Few Steps Back. The Japan Times Online, Web article.

Nuclear Radiation

- Acquista, D. A. (2003). The Survival Guide: What to do in a Biological, Chemical or Nuclear Emergency. New York: Random House.

- Gale, R. P., \& Lax, E. (2013). Radiation: What It Is, What You Need to Know. New York: Vintage International.

- Madsen, M. (Director). (2010). Into Eternity [Motion Picture]. 
- NEl. (2017, March 11). World Statistics: Nuclear Energy Around the World. Retrieved from Nuclear Energy Institute.org: https://www.nei.org/Knowledge-Center/Nuclear-Statistics/World-Statistics

\section{Precedent Studies}

- Auping, M., \& Tadao, A. (2002). Seven Interviews with Tadao Ando. Fort Worth, Tex: Modern Art Museum.

- Frick, M. (Director). (2013). Tadao Ando: From Emptiness to Infinity [Motion Picture].

- Jodidio, P., \& Ando, T. (2009). Tadao Ando at Naoshima: Art, Architecture, Nature. New York: Universe.

- Shima Kitchen / Atelier Ryo Abe Works. (2011, March 02). Retrieved from Arch Daily: https://www.archdaily. com/113903/shima-kitchen-atelier-ryo-abe-works

- Teshima Art Museum / Ryue Nishizawa. (2011, July 19). Retrieved from Arch Daily: https://www.archdaily. com/151535/teshima-art-museum

\section{Self-sustainable Communities}

- Breacher, W. P. (2013). Sustainability as Community: Healing in a Japanese Ecovillage. Electronic Journal of Contemporary Japanese Study, Web article.

- Marcus, A. (2013). Must Utopia Be An Island? Positioning An Ecovillage Within Its Region. Social Sciences Directory; Ripon, Web journal.

- Miles, M. (2008). Urban Utopias: The Built and Social Architecture of Alternative Settlements. London: Routledge.

- Wang, G., Huang, Q., \& Yuan, J. (2011). Chinese Ecovillage Practice with Cradle to Cradle Design. Applied Mechanics and Materials; Zurich, 121-126.

- Yoneda, Y. (2012, September 14). Transition Towns in Japan and a Try for Local Energy Independence. JFS Japan for Sustainability, Web article.

Urban Farming, Solar Power, Factory, Desalination and Market Research

- ACE Water. (2017, May 08). Seawater Desalination Plant. Retrieved from Ace Water Treatment Co. Ltd: http:// www.acewater.co.jp/en

- Bosworth, R. (2016, August 30). High Rise Agriculture, Farewell Field Farmers? Pure Advantage, Web article.

- Dickie, G. (2014, July 19). Q\&A: Inside the World's Largest Indoor Urban Farm. National Geographic, Web article.

- FAO. (2017, June 14). FAO Corporate Document Repository - Fruit and Vegetable processing. Retrieved from Food and Agriculture Organization of the United Nations: http://www.fao.org/

- Greene, N. (2014, November 17). Toshiba Hydroponic Systems Introduces the Urban Farms of the Future. Retrieved from The Coolist: http://www.thecoolist.com/toshiba-hydroponic-systems-indoor-farm-urban-farming/

- Jacobsen, R. (2016). Israel Proves the Desalination Era is Here. Scientific American, Web journal.

- Kloosterman,K. (2014, May 08). Floating Desalination Plants for Japan. Isreal 21c, Web article.

- Lee, K. (2016, October 10). Seoul Pushes for More Urban Rice Farms. Korea Bizwire, p. Web Article.

- Marel Fish Corp. (2016). Tilapia Processing at Terrapez - Standard Flowline [Motion Picture].

- Matsutani, M. (2014, May 13). Toshiba Harvests Lettuce Grown in Semiconductor Plant. The Japan Times, Web Article.

- Nagata, K. (2014, August 11). Future Appears Bright For Indoor Veggie Farms. The Japan Times, Web Article.

- Pentland, W. (2017, January 23). Japan's Solar Boom is Accerlerating. Forbes, Web article.

- Walsh, N. (2017, April 02). Sasaki Unveils Design for Sunquio, a 100-hectare Urban Farming District in Shanghai. Retrieved from Arch Daily: http://archdaily.com/868129/

\section{Visionary Architecture}

- Brayer, M.-A., Alison, J., Migayrou, F., \& Spiller, N. (2007). Future City: Experiment and Utopia in Architecture. New York: Thames \& Hudson.

- Forster, E. (2013). The Machine Stops. New York: A Forster Book.

- Hodge, O. (Director). (2007). Garbage Warrior [Motion Picture].

- Kikutake, K. (1998). Kiyonori Kikutake: From Tradition to Utopia. Milano: Art Stock Books Ltd.

- Koolhass, R. (2011). Project Japan: Metabolism Talks. London: Taschen.

- Sturm, P., \& Schmal, P. C. (2016). Yesterday's Future Visionary Designs by Future Systems and Archigram. Munich: Prestel. 


\section{Source of figures}

fig 01. Kambayashi, S. (Photographer). (2014). A married couple wearing protective gear and masks walk beneath the cherry trees in the town of Tomioka. [digital image]. Tokyo: Reuters.

fig 02. The Asahi Shimbun. (2015). Removal of the cover on Fukushima Daiichi Reactor 3. [digital image]. Retrieved from http://www.gettyimages.it/license/482829624

fig 03. Fukudome, Y. (Photographer). (2015). Removal work starts on a pro-nuclear sign in the evacuated Fukushima town, Futaba. [digital image]. Retrieved from https://www.japantimes.co.jp/

fig 04. Lunes, D. (Photographer). (2013). Yuzo Mihara and his wife Yuko pose on a deserted street in the town of Namie. [digital image]. Retrieved from http://strangesounds.org/2013/03/picture-of-the-day-

fig 05. Site analysis map SA01, Tohoku Earthquake intensity and radiation plume. Author's own image, 2017.

fig 06. Site analysis map SA02, Fukushima prefecture evacuation zones. Author's own image, 2017.

fig 07. Site analysis map SA03, Namie 2017 government zoning announcement. Author's own image, 2017.

fig 08. Site analysis map SA04, Namie overall town analysis. Author's own image, 2017.

fig 09. Yoh, K. (Photographer). (2009). Namie High School before the nuclear disaster. [digital image]. Retrieved from http://apjjf.org/2017/07/Hirano.html

fig 10. The Asahi Shimbun. (2017). Local residents wave "Welcome Home" sign for the first train service pulls into Namie Station for the first time in 6 years. [digital image]. Retrieved from http://www.gettyimages.it/license/482829624

fig 11. Issei, K. (Photographer). (2012). A worker is given a radiation screening as he enters the emergency operations centre at TepCo Fukushima Daiichi. [digital image]. Tokyo: Reuters.

fig 12. Guttenfelder, D. (Photographer). (2011). In a gym in Hirono, residents in protective suits are briefed before being escorted to their homes to retrieve a few small items. [digital image]. Retrieved from http://ngm. nationalgeographic.com/

fig 13. Graphic mapping of key bodies of water contaminated by radiation in the Namie town area. Author's own image, 2017.

fig 14. Koriyama, S. (Photographer). (2016) Japanese persimmons photographed on an abandoned farm in Namie town area. [digital image]. Retrieved from http://soichirokoriyama1.sites.livebooks.com/

fig 15. Issei, K. (Photographer). (2012). TepCo workers don protective gear and survey the damage following the disaster. [digital image]. Tokyo: Reuters.

fig 16. Stillings, J. (Photographer). (2017). A photovoltaic project and adjacent rice fields in Ibaraki Prefecture, Japan. [digital image]. Retrieved from https://www.bloomberg.com/

fig 17. Hokusai, K. (1832). The Great Wave off Kanagawa. [woodblock print\}.

fig 18. Kikutake, K. (Architect). (1963). Marine City.

fig 19. Jazeera, A. (2015). A look inside Fujitsu's Aizu-Wakamatsu factory. [video still]. Retrieved from https://www.japantimes.co.jp/

fig 20. Miura, Y. (Photographer). (2014). Leafy vegetables that were grown in Mirai Co.'s factory in Kashiwanoha, Chiba Prefecture. [digital image]. Retrieved from https://www.japantimes.co.jp/

fig 21. Anonymous post. (2011). Fruit and vegetables for sale at the Tsukiji Markets, Tokyo. [digital image]. Retrieved from https://www.tripadvisor.com/

fig 22. Sample of calligraphy. Author's collage, unknown sources, 2017.

fig 23. Hiroshigi, U. (1840). Snow Falling on a Town. [woodblock print].

fig 24. Unknown author. Drawing of Seashells. [paint on paper]. Retrieved from http://www.krogen.co/

fig 25. Lines as waves. Author's own image, 2017.

fig 26. Kusama, Y. (1994). Waves. [etching on paper].

fig 27. Lines as wall. Author's own image, 2017.

fig 28. Precedent matrix 01. Author's collage, multiple sources, 2017.

fig 29. Precedent matrix 02. Author's collage, multiple sources, 2017.

fig 30. Baan, I. (Photographer). (2011). Teshima Art Museum entryway. [digital image]. Retrieved from https://www.archdaily.com/

fig 31. Ohsawa, S. (Photographer). (2016). Chichu Art Museum courtyard. [digital image]. Retrieved from http:// benesse-artsite.jp/en/ 
fig 32. Ano, D. (Photographer). (2011). Shima Kitchen. [digital image]. Retrieved from https://www.archdaily.com/

fig 33. Sample of early concept sketches. Author's own images, 2017.

fig 34. Urban farm exterior sketch samples. Author's own images, 2017.

fig 35. Urban farm interior sketch samples. Author's own images, 2017.

fig 36. Market sketch samples. Author's own images, 2017.

fig 37. Promenade sketch samples. Author's own images, 2017.

fig 38. Form-finding 01 exploration iterations 1-9. Author's own images, 2017.

fig 39. Form-finding 01 exploration iterations 10-12. Author's own images, 2017.

fig 40. Form-finding 01 exploration FFC3, chosen form. Author's own image, 2017.

fig 41. Form-finding 01 exploration items 13-15. Author's own images, 2017.

fig 42. Form-finding 01 exploration, as final form in site. Author's own image, 2017.

fig 43. Ohsawa, S. (Photographer). (2016). Chichu Art Museum aerial image. [digital image]. Retrieved from http:// benesse-artsite.jp/en/

fig 44. Vieira, T. (Photographer). (2012). Brazilian National Congress. [digital image]. Retrieved from https://www.domusweb.it/

fig 45. Form-finding 02 exploration iterations 1 \& 3. Author's own images, 2017.

fig 46. Form-finding 02 exploration FFF2, chosen form. Author's own image, 2017.

fig 47. Final site plan. Author's own image, 2017.

fig 48. Urban farm final plan. Author's own image, 2017.

fig 49. Axonometric programme diagram 02 - Access. Author's own image, 2017.

fig 50. Axonometric programme diagram 02 - Entry. Author's own image, 2017.

fig 51. Axonometric programme diagram 03 - Farming. Author's own image, 2017.

fig 52. Axonometric programme diagram 04 - Factory. Author's own image, 2017.

fig 53. Market plan. Author's own image, 2017.

fig 54. Promenade plan. Author's own image, 2017.

fig 55. Urban farm section 01. Author's own image, 2017.

fig 56. Urban farm section 02. Author's own image, 2017.

fig 57. Digital moments exploration iterations 1-9. Author's own images, 2017.

fig 58. Moment precedent image matrix. Author's collage, multiple sources, 2017.

fig 59. Moment model 01. Author's own image, 2017.

fig 60. Moment models, photographic compositions. Author's own images, 2017.

fig 61. Moment models 04, 05, 06. Author's own images, 2017.

fig 62. Photos 01, 02, 03 of final critique display. Author's own images, 2017.

fig 63. Walkway under market. Author's own image, 2017.

fig 64. Entry to market. Author's own image, 2017.

fig 65. Fresh produce market. Author's own image, 2017.

fig 66. Market to promenade. Author's own image, 2017.

fig 67. Approach to urban farm. Author's own image, 2017.

fig 68. Access to farm and fishing. Author's own image, 2017.

fig 69. Urban farm circulation ring. Author's own image, 2017.

fig 70. Urban farming floors. Author's own imags, 2017.

fig 71. Public ocean viewing deck. Author's own image, 2017.

fig 72. Photo 04 of final critique display. Author's own image, 2017.

fig 73. Photo 05 of final critique display. Author's own image, 2017.

fig 74. Fishing docks ocean approach. Author's own image, 2017.

dia 01. Thesis framework. Author's own image, 2017.

dia 02. Universe of study. Author's own image, 2017.

dia 03. Project progression. Author's own image, 2017. 
